\title{
WestVirginiaUniversity
}

THE RESEARCH REPOSITORY @ WVU

Graduate Theses, Dissertations, and Problem Reports

2010

\section{Feasibility and Implementation of Self - Consolidating Concrete}

Kyle B. Baranowski

West Virginia University

Follow this and additional works at: https://researchrepository.wvu.edu/etd

\section{Recommended Citation}

Baranowski, Kyle B., "Feasibility and Implementation of Self - Consolidating Concrete" (2010). Graduate Theses, Dissertations, and Problem Reports. 2278.

https://researchrepository.wvu.edu/etd/2278

This Thesis is protected by copyright and/or related rights. It has been brought to you by the The Research Repository @ WVU with permission from the rights-holder(s). You are free to use this Thesis in any way that is permitted by the copyright and related rights legislation that applies to your use. For other uses you must obtain permission from the rights-holder(s) directly, unless additional rights are indicated by a Creative Commons license in the record and/ or on the work itself. This Thesis has been accepted for inclusion in WVU Graduate Theses, Dissertations, and Problem Reports collection by an authorized administrator of The Research Repository @ WVU. For more information, please contact researchrepository@mail.wvu.edu. 


\title{
Feasibility and Implementation of Self - Consolidating
} Concrete

\author{
Kyle B. Baranowski, E.I.T
}

Thesis submitted to the College of Engineering and Mineral Resources

at West Virginia University

in partial fulfillment of the requirements

for the degree of

Master of Science

in

Civil Engineering

Roger H. L. Chen, Ph.D., Chair

Udaya B. Halabe, Ph.D., P.E.

Caulton L. Irwin, Ph.D.

John D. Quaranta, Ph.D., P.E.

Department of Civil and Environmental Engineering

Morgantown, West Virginia

2010

Keywords: Self-Consolidating Concrete; Robustness; Stability;

Formwork Pressure 


\title{
ABSTRACT
}

\section{Feasibility and Implementation of Self-Consolidating Concrete}

\author{
Kyle B. Baranowski, E.I.T
}

This study focused on the construction and placement issues that are common among the production and utilization of self-consolidating concrete (SCC). Six distinct areas were looked at. Robustness and loss of passing ability were related to the change in water and high range water content. Mixes were batched and altered in such a way to determine the point when lack of robustness becomes unacceptable. The compaction, by vibration, of an SCC mix is not normally necessary, however may be needed under certain scenarios. A standard test for determining the static segregation resistance of SCC was altered to determine the effects of vibration duration. A foam layer was sometimes observed on the top of freshly cast SCC. It was found that this layer could be from certain material constituents, high fineness modulus of sand, High Range Water Reducer, or mix instabilities which are detrimental. A guideline for conducting trial batches in the laboratory was established. Field trips to ready-mix and precast plants producing SCC were conducted. SCC mixes can be replicated, in a production environment, although environmental and human factors can cause variability in the mix. SCC is more fluid than that of traditional vibrated concrete; it is believed to have a higher influence on the developed formwork pressure. Short and tall columns were erected and traditional vibrated concrete (TVC) as well as SCC mixes were cast in them. The lateral formwork pressure was recorded using sensors.

The results from this study show that a robust SCC mix can tolerate up to about a five percent increase in water content. A robust SCC mix can also be vibrated in short duration if need be. The generation of air and its migration of air with a fluid body of SCC were explored in order to determine how properties of the mix such as fineness modulus of the sand, mix instabilities, and HRWR (High Range Water Reducer) could cause this phenomenon. Guidelines for making and reproducing small batches of SCC in the laboratory were made and took into account the aggregates, chemical admixtures, the mixer, and batch sequence. The formwork pressures measured in short columns (47 in. head height) reached full hydrostatic pressure using TVC and SCC. The tall TVC and SCC columns (105 in. head height) tested did not reach hydrostatic pressure, but the pressure measured in the tall TVC column was significantly lower. 


\section{ACKNOWLEDGEMENTS}

There are many to thank for their support during this study. My advisor and chairperson of my advisory committee, Dr. Roger Chen has helped me tremendously since being his advisee during my undergraduate career. I am thankful that he has given me an opportunity to conduct graduate research to fulfill my goals of obtaining a Master’s degree. Thanks are also extended to the members of my academic committee, Dr. Udaya Halabe, Dr. Carl Irwin, and Dr. John Quaranta, for reviewing my work and providing constructive criticisms.

This research was entirely funded by the West Virginia Department of Transportation (RP221B). The assistance and constructive comments provided by the WVDOT project monitors Mr. Mike Mance and Mr. Donald Williams was greatly appreciated. I would also like to thank Armstrong Cement, Sidley Pre-Cast, WVU Physical Plant, Hoy Redi-Mix Co., Greer Limestone, and Central Supply Company as well as the Sika, BASF, and Grace Admixture Companies for their donations of various materials and services used for this research. The Concrete producers Alcon and Eastern Vault were of assistance as well.

Special thanks are extended to my colleague, Joseph Sweet, whom helped me during this study. His help through both the planning and execution of the numerous laboratory tests as well as review of my work was an invaluable resource. Mention of my other co-workers and officemates, Alper Yikici, Susana Rojas, and Binwei Zhang, is in order for their help throughout

my research. Lastly, I would like to thank my family, Carl, Pam, Kayla, and Parker Baranowski, and friends for their support during my academic career.

The work within this paper will also be used for a final report for WVDOT project RP221B. Authors will include Kyle Baranowski, Joseph Sweet, and Dr. Roger Chen. 


\section{TABLE OF CONTENTS}

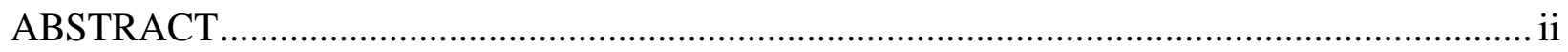

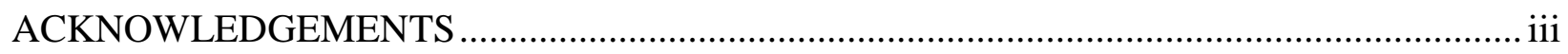

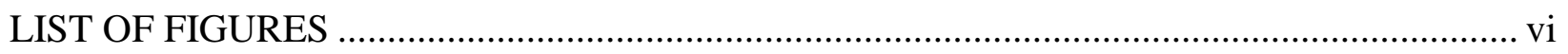

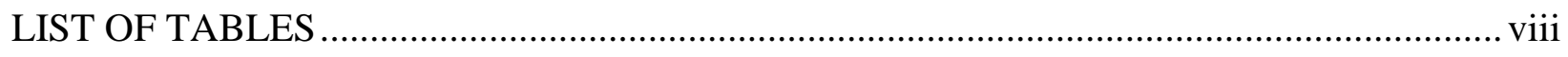

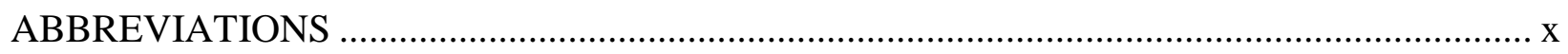

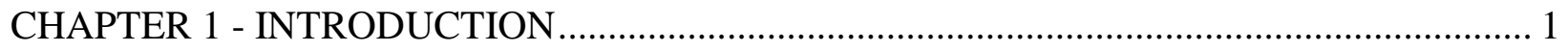

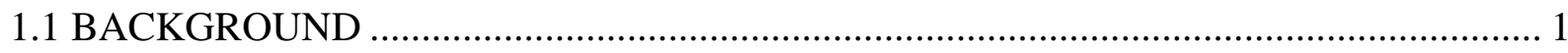

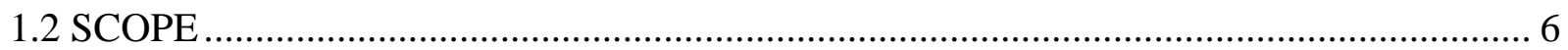

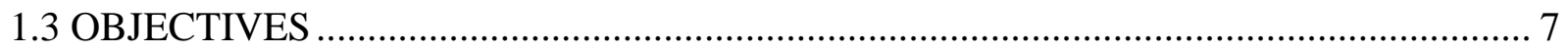

CHAPTER 2 - ROBUSTNESS AND LOSS OF PASSING ABILITY OF SCC MIXES ........... 10

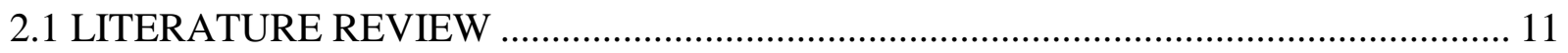

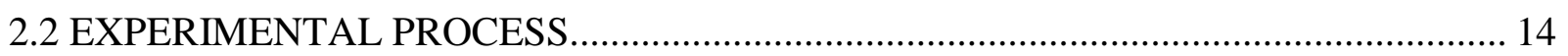

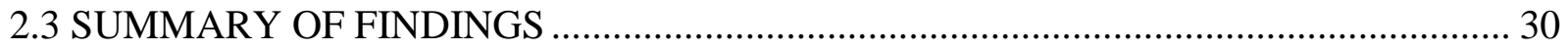

CHAPTER 3 - STABILITY UNDER VIBRATION OF SCC MIXES ........................................ 34

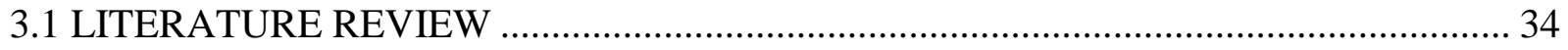

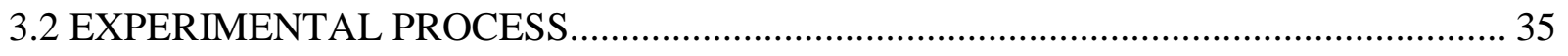

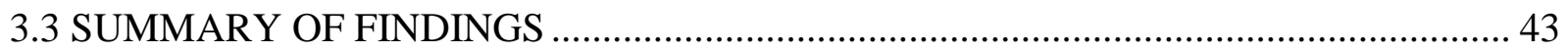

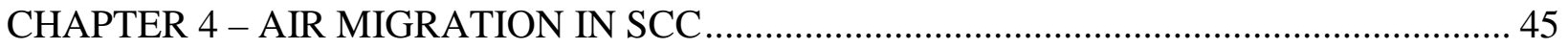

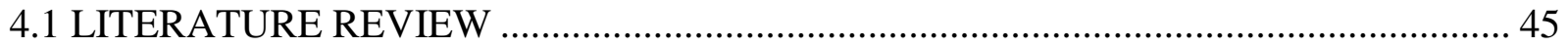

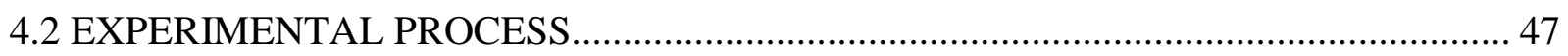

4.3 SUMMARY OF FINDINGS ……………………….............................................. 52

CHAPTER 5 - EFFECTS OF HANDLING ON SMALL BATCH PERFORMANCE ................ 54

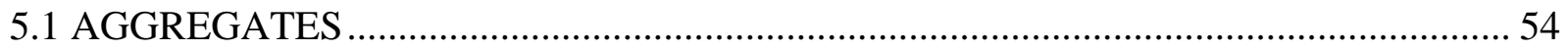

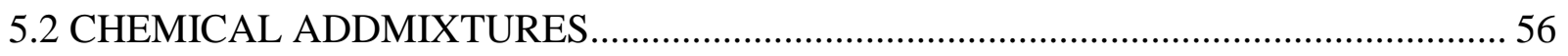

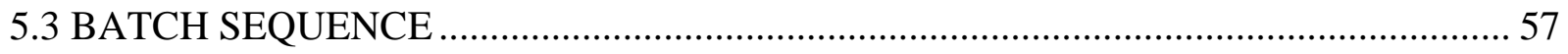

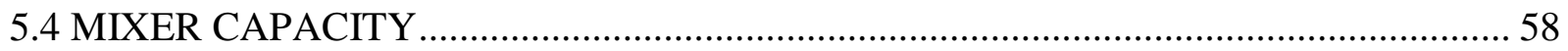

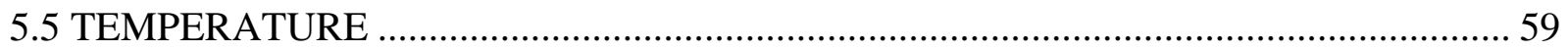

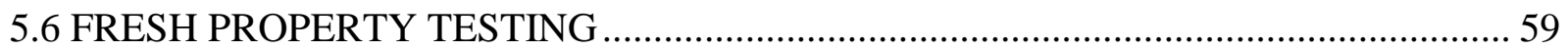

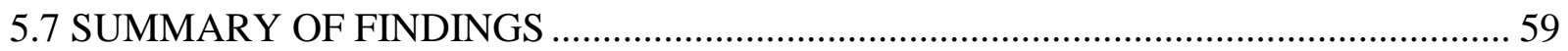

CHAPTER 6 - VARIABILITY OF SCC AS BATCHED IN A BATCH PLANT …………........ 62

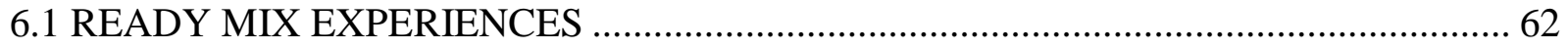

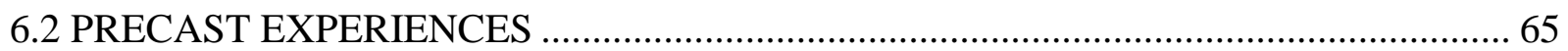




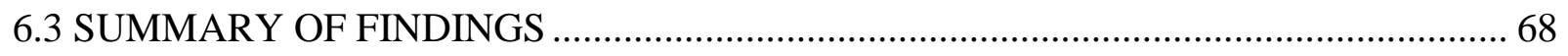

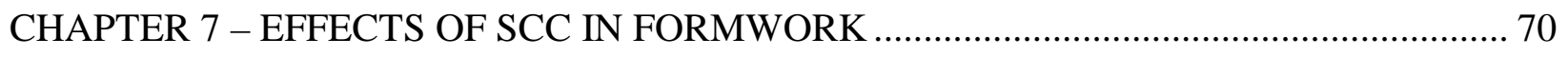

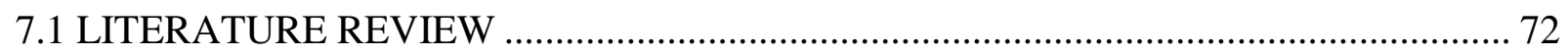

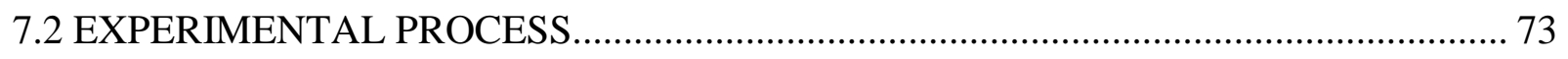

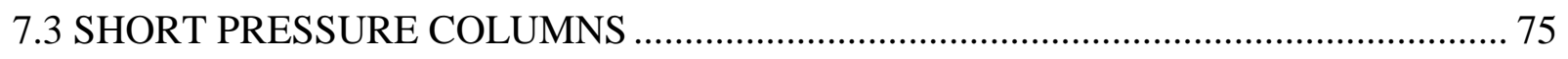

7.3.1 SHORT PRESSURE COLUMN CALIBRATION ……............................................ 75

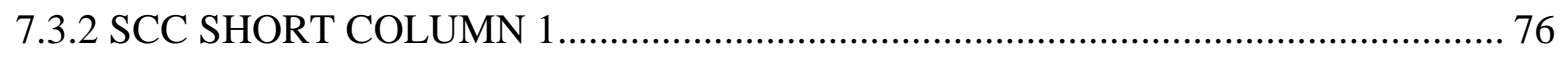

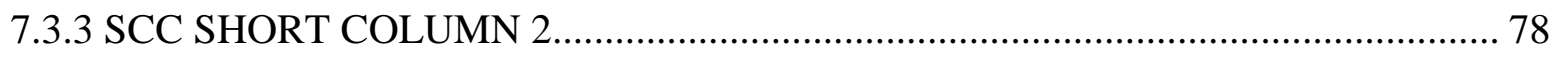

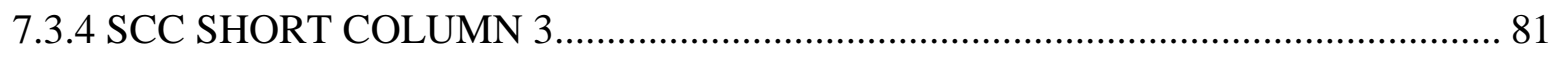

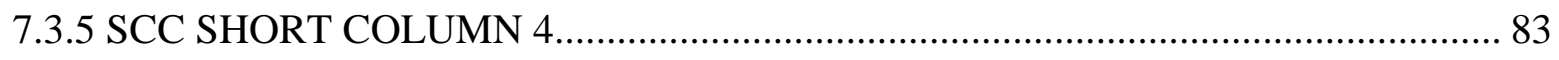

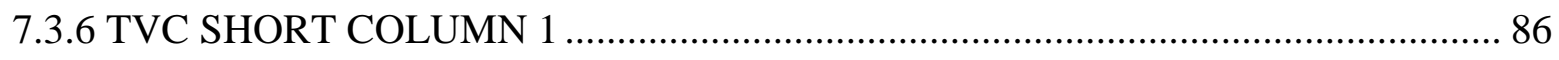

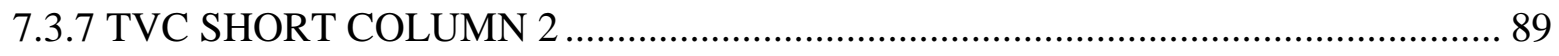

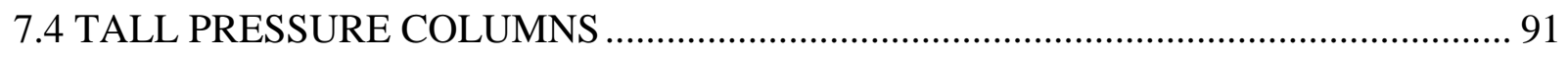

7.4.1 TALL PRESSURE COLUMN CALIBRATION ......................................................... 91

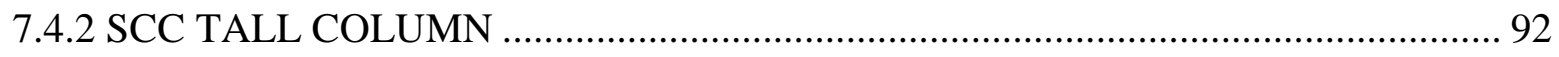

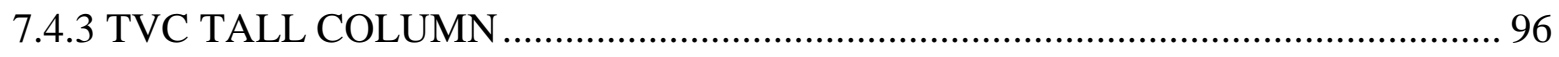

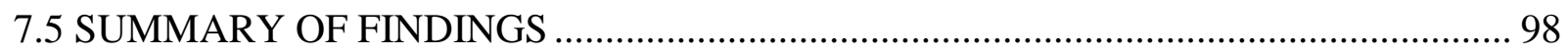

CHAPTER 8 - CONCLUSIONS AND RECCOMENDATIONS............................................. 104

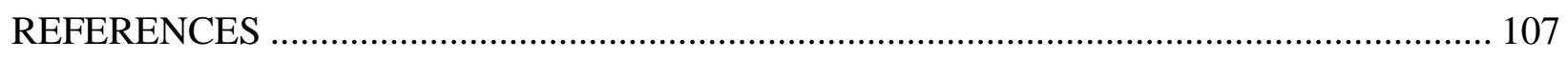

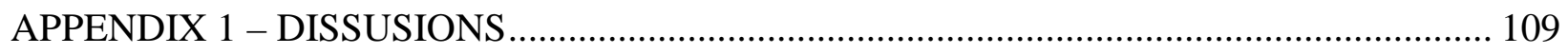

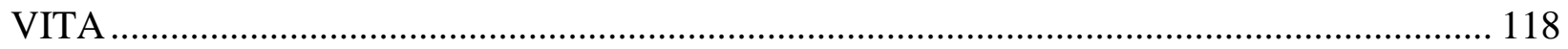




\section{LIST OF FIGURES}

Figure 1.01: (a) Picture of the Fresh Concrete Patty after the Slump Flow Test for SCC.

(b) Picture of the Fresh Concrete Patty after the J-Ring Test for SCC.

Figure 1.02: Air Content Test using Type B Pressure Meter.

Figure 1.03: Prepared Sample for the Hardened VSI Test.

Figure 2.01: Speedy Moisture Meter Setup.

Figure 2.02: Picture of Performing the Segregation Probe Test on an SCC Mix.

Figure 2.03: Picture of Performing the Measurement of Probe Depth.

Figure 2.04: (a) Dimensions of the Penetration Apparatus used during this Study (Bui et. al., 2002).

Figure 2.04: (b) Dimensions of the Penetration Apparatus per ASTM C1712.

Figure 3.01: Experimental Setup for the Vibration Testing of SCC.

Figure 3.02: Schematic Drawing of Modified Segregation Column with Extra Top Section.

Figure 4.01: Foam Layer Observed during the RP221 Project.

Figure 4.02: Air Bubbles Escaping from a Freshly Batched SCC During a Trial Mix.

Figure 4.03: Batching of SCC Mix for the Observation of Air Migration.

Figure 4.04: Few Air Bubbles Rising to the Surface upon First Batch.

Figure 4.05: Observation of Air Bubbles coming to the Surface of Static Mix.

Figure 7.01: Schematic of the Short and Tall Pressure Column Setups.

Figure 7.02: (a) Diaphragm Pressure Transducer. (b) Typical Short Pressure Column Setup.

Figure 7.03: Testing of the Short Pressure Column with Water.

Figure 7.04: First Hour Pressure Recordings for SCC Short 1.

Figure 7.05: First Hour Pressure Recordings for SCC Short 2.

Figure 7.06: Recorded Pressures for SCC Short 2.

Figure 7.07: First hour Pressure Recordings for SCC Short 3.

Figure 7.08: Recorded Pressures for SCC Short 3.

Figure 7.09: First Hour Pressure Recordings for SCC Short 4.

Figure 7.10: Recorded Pressures for SCC Short 4.

Figure 7.11: Temperatures Recorded During SCC Short Column 4.

Figure 7.12: First Hour Pressure Recordings for TVC Short 1. 
Figure 7.13: Recorded Pressures for TVC Short 1.

Figure 7.14: First Hour Pressure Recordings for TVC Short 2.

Figure 7.15: Tall Column Water Calibration.

Figure 7.16: First Hour Pressure Recordings for SCC Tall.

Figure 7.17: Recorded Pressures for SCC Tall.

Figure 7.18: Temperatures Recorded During SCC Tall Column.

Figure 7.19: First Hour Pressure Recordings for SCC Tall.

Figure 7.20: Recorded Pressures for TVC Tall.

Figure 7.21: Comparison of Tall SCC Column Recorded Pressures and Modeling Equations.

Figure 7.22: Comparison of Tall SCC Column Recorded Pressures and Modeling Equations. 


\section{LIST OF TABLES}

Table 1.01: Rating Criteria for the VSI Test for Fresh SCC.

Table 2.01: One Cubic Yard Mix Design for Mix 1.

Table 2.02: Measured Fresh Properties of Mix 1.

Table 2.03: One Cubic Yard Mix Design for Mix 2.

Table 2.04: Measured Fresh Properties of Mix 2.

Table 2.05: One Cubic Yard Mix Design for Mix 3 and the Addition of Water Mix 3A.

Table 2.06: Measured Fresh Properties of Mix 3 and Mix 3A.

Table 2.07: Performance criteria for ASTM C 1712.

Table 2.08: One Cubic Yard Mix Design for Mix 4 and the Addition of Water Mix 4A.

Table 2.09: Measured Fresh Properties of Mix 4 and Mix 4A.

Table 2.10: One Cubic Yard Mix Design for Mix 5 and the Addition of Water Mix 5A.

Table 2.11: Measured Fresh Properties of Mix 5 and Mix 5A.

Table 2.12: One Cubic Yard Mix Design for Mix 6 and the Addition of Water Mix 6A.

Table 2.13: Measured Fresh Properties of Mix 6 and Mix 6A.

Table 2.14: Measured Compressive Strength of Mix 6.

Table 2.15: Measured Compressive Strength of Mix 6A.

Table 2.16: One Cubic Yard Mix Design for Mix 7 and Mix 7A with Added HRWR.

Table 2.17: Measured Fresh Properties of Mix 7 and Mix 7A.

Table 2.18: One Cubic Yard Mix Design for Mix 8.

Table 2.19: Measured Fresh Properties of Mix 8.

Table 2.20: Comparison of all of the Mix Designs of this Study.

Table 2.21: Comparison for all of the Mix Fresh Properties of this Study.

Table 3.01: Vibration Tests Results for Mix 1.

Table 3.02: Vibration Test Results for Mix 2.

Table 3.03: Vibration Test Results from Mix 3.

Table 3.04: Vibration Test Results from Mix 5A.

Table 3.05: Vibration Test Results of Mix 8.

Table 4.01: Sieve Analysis of the Natural Sand used during this Study with ASTM Limits.

Table 4.02: One Cubic Yard Mix design for the Observation of Air Migration. 
Table 4.03: Fresh Properties of the Mix for the Observation of Air Migration.

Table 4.04: One Cubic Yard Mix design of $2^{\text {nd }}$ Mix for the Observation of Air Migration.

Table 6.01: Fresh Properties of the Trucks during the Caisson Casting at Stalnaker Run.

Table 6.02: Fresh Properties of SCC Produced at a Precast Plant During Trial Batches.

Table 7.01: One Cubic Yard Mix Design for SCC Short Column 1.

Table 7.02: Fresh Properties of SCC Short Column 1.

Table 7.03: One Cubic Yard Mix Design for SCC Short Column 2.

Table 7.04: Fresh Properties of SCC Short Column 2.

Table 7.05: One Cubic Yard Mix Design for SCC Short Column 3.

Table 7.06: Fresh Properties of SCC Short Column 3.

Table 7.07: One Cubic Yard Mix Design for SCC Short Column 4.

Table 7.08: Fresh Properties of SCC Short Column 4.

Table 7.09: One Cubic Yard Mix Design for TVC Short Column 1.

Table 7.10: Fresh Properties of TVC Short Column 1.

Table 7.11: One Cubic Yard Mix Design for TVC Short Column 2.

Table 7.12: Fresh Properties of TVC Short Column 2.

Table 7.13: One Cubic Yard Mix Design for SCC Tall Column.

Table 7.14: Fresh Properties of SCC Tall Column.

Table 7.15: Comparison of all of the Short Columns Tested.

Table 7.16: Comparison of the SCC and TVC Tall Columns Tested.

Table 7.17: Chemistry Coefficients for Equation 5 (Hurd, 2007).

Table A.01: Mix Design of the Batch Tested with River Gravel.

Table A.02: Fresh Properties of the Batch with River Gravel Compared to Mix 4. 


\section{ABBREVIATIONS}

West Virginia Department of Transportation (WVDOT)

West Virginia Department of Highways (WVDOH)

Self-Consolidating Concrete (SCC)

Traditional Vibrated Concrete (TVC)

High Range Water Reducer (HRWR)

Viscosity Modifying Admixture (VMA)

Visual Stability Index (VSI)

Saturated Surface Dry (SSD)

Standard Temperature and Pressure (STP) 


\section{CHAPTER 1 - INTRODUCTION}

Self-Consolidating Concrete (SCC) was originally developed as a special concrete mix for underwater use in Japan. However, because of the fluidity and ability for this type of concrete to fill formwork without additional compaction, it was soon adapted to several areas of concrete casting. The widespread use of this type of concrete is becoming more popular in the United States; however some state agencies, such as the West Virginia Department of Transportation, do not have a standard specification to allow the use of SCC on their construction projects.

This project aided in the understanding of self-consolidating concrete (SCC) material requirements, producing a satisfactory SCC mix design, and how to perform new fresh property tests. This study looked at specific topics which characterize SCC such as passing ability, slump retention, filling ability, and workable period. The main area of interest of this study was the differences between traditional vibrated concrete (TVC) and SCC, such as special construction acceptance tests and requirements, field placement techniques and limitations, and material constituents. Additionally, the results from this study will help in the development of an SCC specification for the use on WVDOT projects.

\subsection{BACKGROUND}

When developing an SCC mix design, many of the materials used are the same as for making TVC: cement, large and small aggregates, and water. However, the ratios and properties of these materials may need to be altered in order to achieve desired fresh properties of an SCC mix. SCC can also have similar water to cementitious material ratios $(\mathrm{w} / \mathrm{cm})$ as high performance TVC, around 0.4 or below, but the total binder content is usually higher to achieve flowability. The fine aggregate to total aggregate ratio (FA/TA) is normally higher as well for 
SCC. The coarse aggregates for SCC are generally smaller, with a maximum coarse aggregate size of 3/4" commonly being specified, and using a blend of sizes, \#67 and \#8 coarse aggregate together for example, are often used to achieve desired flowability, stability, and performance. The combination of higher binder content, a higher fine aggregate to total aggregate ratio, and smaller sized blended coarse aggregates gives an SCC mix its required fine particle amount to be considerably more workable than TVC. However, in order to achieve high flowability commonly attributed to SCC, above 18 inches in slump flow diameter, SCC mixes do rely heavily on chemical admixtures as well.

The chemical admixture that is most instrumental in making SCC is the high range water reducing admixture (HRWR). A HRWR is able to achieve a highly flowable SCC mix without the detrimental effects that would result from using extra water to loosen up a mix. One other admixture which is relatively new to the concrete industry and is often used to improve stability of an SCC is a viscosity modifying admixture (VMA). VMAs are designed to increase the viscosity of a SCC mix without greatly hindering flowability in order to reduce stability problems, thus enhancing robustness. Some SCC mixes, if appropriately proportioned, may not require the addition of a VMA. Other chemical admixtures normally associated with the making of TVC, such as air entrainers, retarders, accelerators, and corrosion inhibiters will generally work in SCC. However, admixture compatibility should always be checked prior to the implementation in a mix that requires multiple types of chemical admixtures. It has been noted in the literature, that some polycarboxylate-based HRWRs may induce air within an SCC mix (Szwabowski and Lanzniewska-Piekarcyz, 2009). However, the resulting air void size and spacing due to the addition of HRWR may not be uniform or stable, so the addition of an air entraining admixture may be desirable, even for elements cast without the need for freezing and 
thawing resistance, as this will allow for a more even distribution of smaller air voids within the concrete matrix.

Supplementary cementitious materials or mineral admixtures are becoming more popular in the concrete industry. Not only can the use of mineral admixtures such as slag, fly ash, or microsilica make concrete more sustainable, but they also can improve the overall properties of concrete. SCC, which generally has a higher binder contents than TVC, can benefit from the use of slag or fly ash which can reduce the overall heat of hydration present during setting and reduce the amount of cement. Also, it has been shown that the addition of such mineral admixtures play an important role in improving the durability and long term properties of the mix (Mindess, Young, and Darwin, 2003). Slag and fly ash have been used to replace cement content of a concrete mixture without sacrificing 28-day compressive strength (SCA, 2002).

The test methods for quantifying the properties of SCC were also explored during this project. Due to SCC having high flowability, fresh property tests generally required for TVC, such as the slump test (ASTM C 143), are not applicable. As an alternative, the slump flow of SCC is determined using ASTM C 1611. During the slump flow test, a procedure similar to the slump test is conducted on an impervious surface, but the diameter of the fresh concrete patty, shown in Figure 1.01a, is measured along with the $\mathrm{T}_{50}$ time (time at which the flow reaches the boundary of a circle with diameter of $50 \mathrm{~cm}$ (20 in)) and visual stability index (VSI) is rated. The VSI is the rating of the fresh patty to determine if instability can be visual detected. The rating system is from 0 to 3 and is described in Table 1.01. The J-ring test (ASTM C 1621), shown in Figure 1.01b, is often used in conjunction with the slump flow test in order to determine passing ability of SCC. Another test, the column static segregation test (ASTM C 1610) helps determine the amount of segregation plastic SCC can have by determining the movement of coarse 
aggregates within a vertical section. Tests for air content, unit weight, and yield are performed in the same manner as TVC. The test for air content using the pressure method, type B, was used during this study. Figure 1.02 shows the type B pressure apparatus. Hardened properties such compressive strength, durability, and long term effects are tested in the same manner as TVC as well. A test for hardened VSI, shown in Figure 1.03, which involves the casting of a standard cylinder, leaving it stationary, and saw cutting the hardened specimen longitudinally, can also be conducted on SCC. The filling procedure for items such as sample cylinders, slump cone, and air bowl when using SCC is filled in one lift and generally no rodding is required. Slight tapping can release entrapped air that is induced during the filling process.

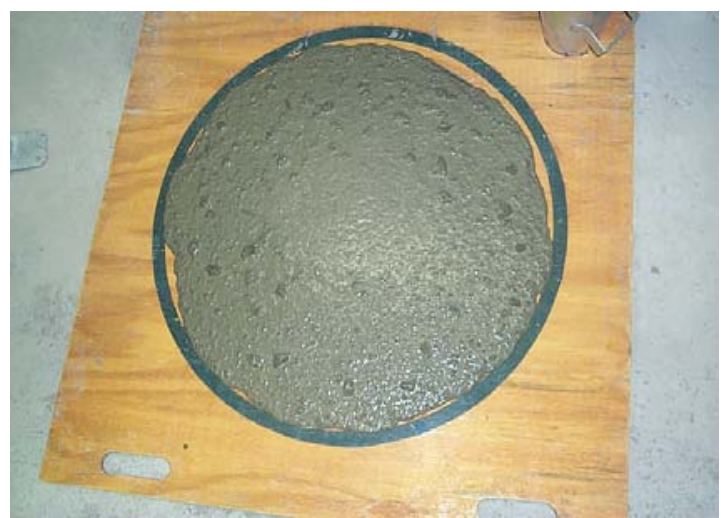

(a)

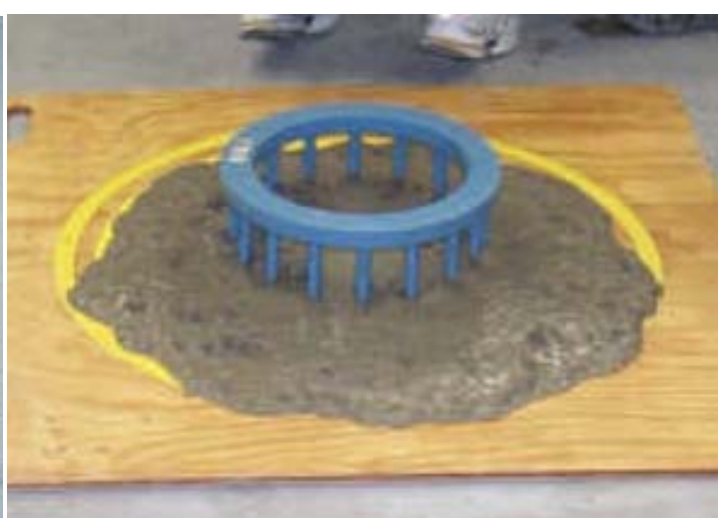

(b)

Figure 1.01: (a) Picture of the Fresh Concrete Patty after the Slump Flow Test for SCC. (b) Picture of the Fresh Concrete Patty after the J-Ring Test for SCC. 
Table 1.01: Rating Criteria for the VSI Test for Fresh SCC.

\begin{tabular}{|c|l|}
\hline Rating & \multicolumn{1}{c|}{ Criteria } \\
\hline 0 & No evidence of segregation in slump flow patty or in the wheelbarrow. \\
\hline 1 & $\begin{array}{l}\text { No mortar halo or aggregate pile in the slump flow patty but some slight } \\
\text { bleed or air popping on the surface of the concrete in the wheelbarrow. }\end{array}$ \\
\hline 2 & $\begin{array}{l}\text { A slight mortar halo ( }<3 / 8 \text { inch) and/or aggregate pile in the slump flow } \\
\text { patty and highly noticeable bleeding in the wheelbarrow. }\end{array}$ \\
\hline 3 & $\begin{array}{l}\text { Clearly segregating by evidence of a large mortar halo ( }>3 / 8 \text { inch) and/or } \\
\text { large aggregate pile in the center of the concrete patty and a thick } \\
\text { layer or paste on the surface of the resting concrete in the } \\
\text { wheelbarrow. }\end{array}$ \\
\hline
\end{tabular}

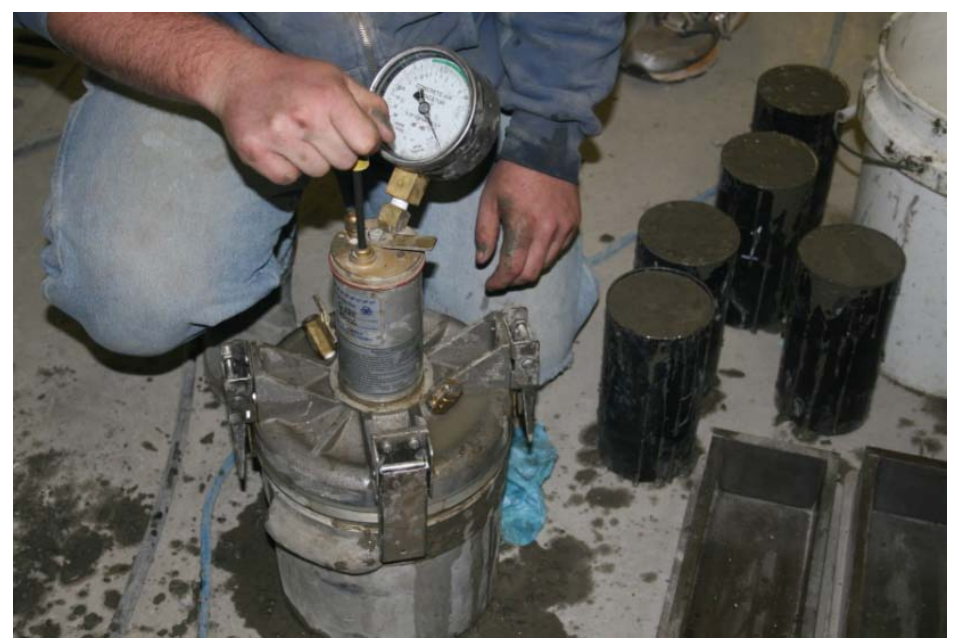

Figure 1.02: Air Content Test using Type B Pressure Meter.

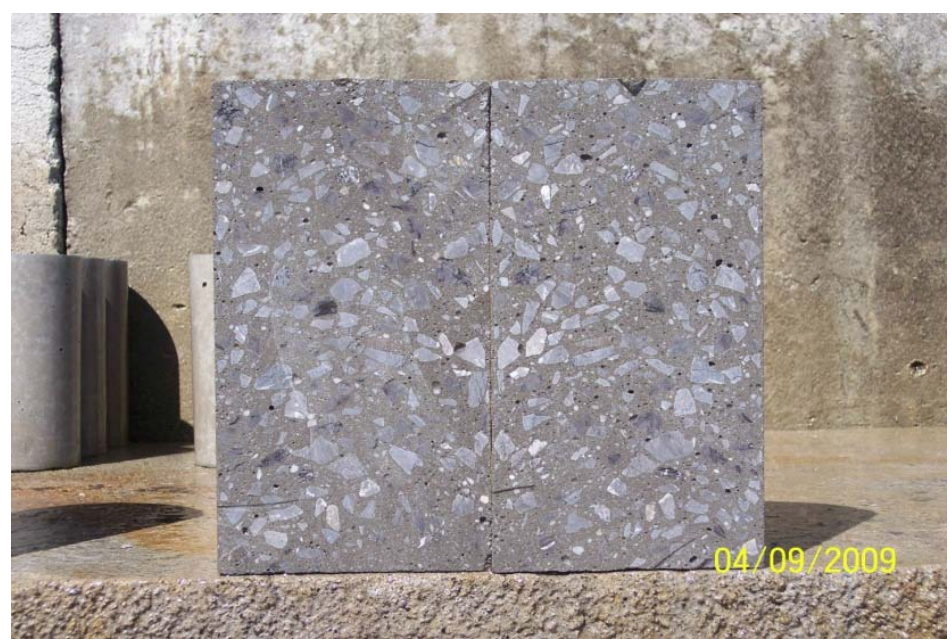

Figure 1.03: Prepared Sample for the Hardened VSI Test. 
In all, seven mix designs were developed during the first study (Sweet and Chen, 2008). The fresh and hardened properties were evaluated for each mix. Mixes were varied by the amounts of cementitious materials, sizes and amounts of aggregates, as well as different combinations and amounts of admixtures. The HRWR that makes SCC flowable begins to lose its effectiveness over time; therefore the slump flow was taken at various times to determine a workable period for these mixes. Also, the passing ability vs. time was determined using the Jring test. A few of the mixes were tested on their ability to fill moderately- and heavilyreinforced mock structural members. Members that resembled a floor, column, and wall section were tested. The results and conclusions of the study by Sweet and Chen helped gain practical knowledge in the areas of making an SCC mix design using local aggregates for the West Virginia Department of Transportation.

\subsection{SCOPE}

West Virginia Department of Transportation (WVDOT) research project \#RP221B, Supplemental Tasks for "Feasibility and Implementation of Self-Consolidating Concrete," was a continuation of the agency-funded research project \#RP221. Research project \#RP221 did a substantial job in accomplishing the objectives related to the discovery of producing a satisfactory SCC mix design when using West Virginia aggregates. Research project, \#RP221B, was conducted in order to learn more about field implementation and construction issues, handling and laboratory qualification, and robustness and stability properties of SCC. Upon the conclusion of the first phase of the RP221 project, the WVDOT had the following areas which they would like to know more about SCC. 
1. Which tests (slump flow, j-ring, column segregation, etc.) to perform at what frequencies (in mix design development and in the field) and what ranges of results are acceptable?

2. Materials limitations - what types, what amounts, and what combinations should be permitted?

3. Time constraints on SCC mixes and any special batching or mixing requirements?

4. Variability and repeatability in SCC mixes (variability would play a large part in the required testing frequencies) due to the sensitivity of SCC and due to the use of different materials?

5. Concerns with air content and the air void spacing system (we often see a layer of foam form at the top of an SCC placement)

6. Any field placement limitations?

\subsection{OBJECTIVES}

Research project RP221B was conceived in order to properly answer the above questions for the WVDOT. Six tasks were developed and investigated through not only an extensive literature review process, but also through laboratory experimentation and field visits to concrete producers. The six tasks developed are stated below.

Task 1: Robustness and Loss of Passing Ability of SCC Mixes - This task explored how deviations from theoretical mix designs with respect to changes in quantities of the mix materials of water and HRWR affect the observed fresh properties. By finding out how an SCC mix's properties are influenced by changes in these material quantities, tolerances on these materials can be established. 
Task 2: Stability under Vibration of SCC Mixes - An SCC mix due to its high fluidity and self compacting properties does not require additional energy, in the form of vibration, for compaction. However, some instances may require compaction efforts to help alleviate entrapped air voids or cold joints. This task will explore the vitality of using vibration during the casting of an SCC element.

Task 3: Air Migration in SCC - The generation of a foam layer is sometimes observed on the top of an element freshly cast with SCC. This task will explore possible areas of origin of the foam, different types of foam, and whether or not particular types of foam have a negative effect on the fresh and hardened properties of the resulting element.

Task 4: Effects of Handling on Small Batch (Test Batch) Performance - Prior to the production of SCC and during laboratory batching for the experimental testing of SCC, small batches are produced. These small batches usually are below one cubic yard and for the case of the laboratory batches for this project are only a few cubic feet in volume. This task will explore the proper guidelines that must be handled to make a successful and repeatable batch of SCC.

Task 5: Variability of SCC as Batched in a Batch Plant - During the course of this study, field trips were made to precast and ready-mix plants producing SCC. The plants visited were both experienced and not experienced in the field of producing SCC. This task will show the differences in the variability of common practices of the visited plants and will note any observations that are relevant to this project. 
Task 6: Effect of SCC in Formwork - This task will explore the differences in formwork pressure between SCC and traditionally vibrated concrete. SCC is thought to produce higher lateral formwork pressure because it is more fluid than TVC. However, there are several material constituents and casting conditions that effect formwork pressure. In exploring different conditions of casting and material constituents of SCC and relating them to a TVC mix design often used by the WVDOT conclusions can be made concerning this topic. 


\section{CHAPTER 2 - ROBUSTNESS AND LOSS OF PASSING ABILITY OF SCC MIXES}

Task \#1 was developed to find the acceptable levels of tolerance for SCC mix components, water and HRWR. An incorrect dosage of either of these materials could very easily produce an unstable and unusable batch of SCC. The amount of water that is contained within a certain concrete mix comes from not only the amount added to the mix, but also may come from free water on the aggregates and water within certain chemical admixtures. In practice, water contained within an admixture is normally ignored due to its small effect on the fresh properties and compressive strength of the concrete. Normally, the water contained in the admixtures will affect the w/cm by less than one percent; however it is good practice to determine admixture water contents during SCC mix design development. In order for SCC to exhibit adequate performance in the fresh state, the amount of water in the mix needs to be within a tighter tolerance than TVC. The WVDOT requires that water added to the mix be measured by weight or volume and be measured within one percent of the value needed when batching concrete. It is often the difference from the theoretical moisture content of the aggregates that contributes negatively to the water content of an SCC mix, if not adjusted for.

A plus or minus one percent change in the free moisture content of the total aggregate content can add or subtract around three gallons of water per cubic yard of concrete, or around eight percent of the total volume of water. This would change the water to cementitious ratio from 0.4 to 0.43 , which might only slightly affect the fresh properties of a traditional vibrated concrete mix. However, this same change in water content could lead to instability for an SCC mix.

The amount of water contained within aggregates, which are normally stored outside, can vary significantly within the stockpile. Theoretical concrete mix designs call for aggregates to 
be in its SSD (Saturated Surface Dried) state, which means the amount of water contained in the aggregates' pores is equal to the amount they are able to absorb. Depending on ambient conditions, the aggregates on the top part of the pile may be dryer due to exposure to the atmosphere. Stockpile aggregates will normally not be in SSD condition and can be dryer or wetter than SSD. Proper measures should be taken in order to fully understand the moisture content of the aggregate stockpile and the moisture gradient of the stockpile before attempting to batch SCC.

Adjustments to the concrete mix design, particularly water content, will have to be made prior to mixing to ensure proper performance. It has been experienced that some concrete producers use a moisture meter with a relatively high degree of accuracy (such as the Speedy moisture meter), but only take the aggregate moisture content in the morning prior to batching. The changes of temperature and humidity levels throughout the day can easily influence stockpile moisture content. While other producers, common among the ready-mix industry, continually monitor moisture, but with a less accurate microwave probe. Since these methods seem to be common practices that were witnessed, this phase of the study was implemented to determine the potentially detrimental effects from varying material properties when dealing with SCC, and whether refinements to existing quality control measures are necessary to ensure adequate performance of SCC.

\subsection{LITERATURE REVIEW}

The robustness of an SCC mix is its capacity to retain its fresh properties when small variations in the properties or quantities of the constituent materials occur (ACBM, 2007). Agencies also consider robustness not only among a single batch being produced, but for all SCC 
batches being produced during a casting run (ACBM, 2007). Small changes in the moisture content of aggregates or the decision of how to proportion chemical admixtures often can change the fresh properties of SCC. A one percent change in water content within an SCC mix can change the diameter of the slump flow by 4in. (ACBM, 2007). The European Guidelines for Self-Compacting Concrete explains that a robust SCC mix may only be able to accept change in water content of 8.5 to $17.5 \mathrm{lb} / \mathrm{yd}^{3}$ (1 to $2 \mathrm{gal} / \mathrm{yd}^{3}$ ). The tighter tolerances on material proportioning are often attributed to a SCC mix design's detailed requirements, more complex mix design, and low yield and viscosity. The batch sequence may also attribute to the lack of robustness for an SCC (Eurocode, 2005). The order that materials are charged into the mixer is known as the batch sequence. The batch sequence used during this project is fully outlined in Chapter 5. If this order is not kept constant than the mix could show signs of losing robustness; for example if the HRWR is added earlier in the batch sequence than previous batches it may have time to begin to lose its effect and the resulting batch will not show the same fresh properties as previous batches.

Measurement of the robustness of an SCC mix often involves tests that are related to the stability of plastic SCC. Terms such as the dynamic and static segregation resistance are often associated when characterizing the robustness of a plastic mix. Dynamic segregation refers to the settling and separation of coarse aggregates as well as the escaping of bleed water and air from the mix during transport and casting, while static segregation refers to these occurrences when the mix is at rest. The standard method for checking the static segregation resistance, in the laboratory, of an SCC mix requires the use of the column segregation test according to ASTM 1610. The VSI test performed by observing the fresh SCC patty after the procedure for the slump flow and $\mathrm{T}_{50}$ tests are conducted gives an indication of dynamic segregation. 
However, dynamic segregation resistance should not be based solely upon the VSI/ $\mathrm{T}_{50}$ result (ACBM, 2007).

Recently, ASTM has published a test method for the rapid assessment of the static segregation of SCC using the penetration test (ASTM C 1712). This test uses a special probe that is placed on the top of the leveled slump cone prior to conducting the slump flow test and allowed to settle for a specific amount of time. The measurement of the probe's penetration into the fresh SCC gives a rapid assessment of its static segregation. This method was employed during some of the mixes during this study, but this test was not observed by ASTM during the laboratory testing of this study. So, the penetration apparatus used during this study varied from that of ASTM C 1712.

This test became a standard test method because of its ease of performing the test, especially in the field. The test can be performed by one operator and only takes about two minutes to complete. The other method of measuring the static segregation resistance of SCC, ASTM C1610, is very labor intensive and time consuming. It was originally designed as a laboratory test and not suited for the field. The column segregation test is hard to perform with one operator and has a minimum wait time of 15 minutes after the column is filled. The test itself can take over twice that long to perform the required steps to gather the data.

Agencies often release steps to follow to help produce more robust SCC mixes (ACBM, 2007). General steps such as keeping the w/cm low and including a dosage of VMA should be considered when making an SCC mix design. The addition of mineral admixtures to a mix design can often modify particular aspects. If the viscosity of the mix is in need of modification then a small dosage of VMA or silica fume could be used. However, if the density is in need of improvement than the addition of slag or a limestone filler may be needed (ACBM, 2007). 


\subsection{EXPERIMENTAL PROCESS}

An experimental process for determining the water tolerance and change in properties due to varying the dosage of HRWR of a particular SCC mix design was used in order to gain firsthand experience. The mix chosen for testing was a variation of Mix-G from the original \#RP221 project. The theoretical materials and quantities for this mix, Mix 1, are given in Table 2.01. The chemical admixtures for this part of this study were produced by SIKA. The air entrainer was model AEA-15, the HRWR was model V2100, the VMA was model 300SCC, and the set retarder was called Plastiment. The Type 1 cement was Armstrong brand, while the slag as well as the coarse and fine aggregates came from the Central Supply Company.

Table 2.01: One Cubic Yard Mix Design for Mix 1.

\begin{tabular}{|l|c|r|}
\hline \multicolumn{1}{|c|}{ MATERIAL } & UNIT & MIX 1 \\
\hline Cement Type 1 & lb & 600 \\
\hline Slag & lb & 150 \\
\hline \#8 Crushed Limestone & lb & 553 \\
\hline \#67 Crushed Limestone & lb & 830 \\
\hline Natural Sand & lb & 1384 \\
\hline Water & lb & 300 \\
\hline w/cm & & 0.4 \\
\hline Air Entrainer & Oz/cwt & 0.1 \\
\hline VMA & Oz/cwt & 2.5 \\
\hline HRWR & Oz/cwt & 5 \\
\hline
\end{tabular}

After establishing Mix 1, the deviation of this mix was done in two different ways. One way was to change the amount of water that was contained within the mix by either adding or subtracting the amount of required water for the mix. The required water for the mix is the amount of water after adjusting to include the water added or subtracted to satisfy the SSD condition for the coarse and fine aggregates. The testing of the aggregates for total moisture content was accomplished with a Speedy Moisture Meter prior to batching. The Speedy Moisture 
Meter uses a small aggregate sample size and a reagent to measure the moisture to $0.1 \%$. Figure 2.01 shows the typical setup of the Speedy Moisture Meter as used in the laboratory.

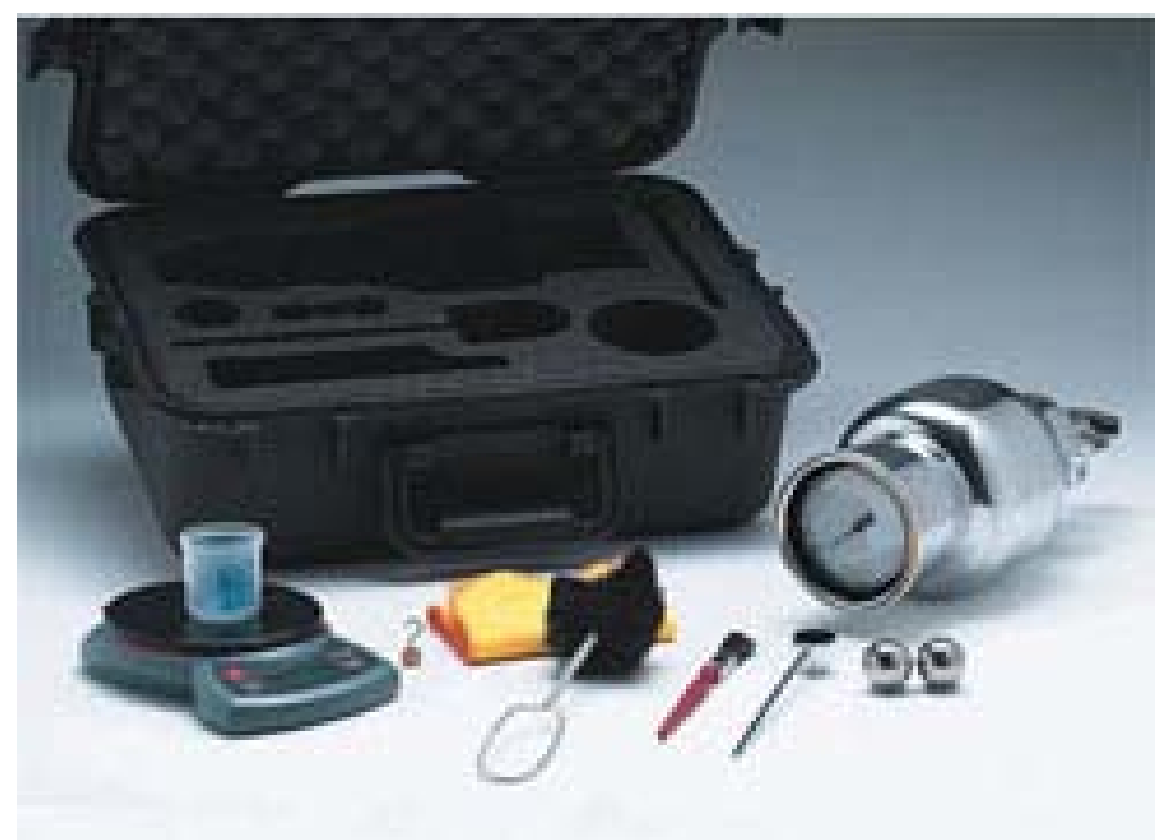

Figure 2.01: Speedy Moisture Meter Setup.

The production of an SCC mix must rely on a set of acceptance/performance criteria in order to properly judge its quality before placement. A set of performance criteria were placed in order to experimentally identify mix robustness. The target slump flow for the SCC mix design was selected to be 24 inches with a tolerance of 2 inches. This is considered a medium flowing SCC mix. SCC mixes can be classified as low, medium, and high flowing mixes (Khayat \& Mitchell, 2009). The difference between the slump flow and J-ring should be below 2 inches and the $\mathrm{T}_{50}$ time within a 2 to 7 second range. The air content for the control mix was designed to be within the 4 to 7 percent range. The VSI ratings should also be from 0 to 1 for a stable mix. These criteria were used as a guideline to produce laboratory batches and have a way to relate them back to the performance criteria. 
During the making of Mix 1, the ambient temperature in the concrete lab was 54 degrees Fahrenheit. The water temperature was 56 degrees Fahrenheit. The fresh properties are given in Table 2.02.

Table 2.02: Measured Fresh Properties of Mix 1 .

\begin{tabular}{|l|c|}
\hline \multicolumn{1}{|c|}{ PROPERTY } & MIX 1 \\
\hline Slump Flow (in) & 24.0 \\
\hline T50 (sec) & 1.3 \\
\hline J-ring (in) & 3.0 \\
\hline T50 (sec) & 5.2 \\
\hline Air Content (\%) & 5.8 \\
\hline Unit Weight (lb/ft ${ }^{3}$ ) & 143.9 \\
\hline Ambient Air Temperature ( ${ }^{\mathbf{0}}$ F) & 54 \\
\hline Mix Water Temperature $\mathbf{(}^{\mathbf{0}} \mathbf{~ F )}$ & 56 \\
\hline
\end{tabular}

The static segregation, by the column technique, was also measured, but the value was unusually high, at 22.5\%. The problem was later discovered as a poor handling procedure of the fresh concrete, inducing dynamic segregation into the mix before testing. This problem and its solution are referenced in the Chapter 3 -Stability under Vibration of SCC Mixes.

In order to replicate the fresh properties of Mix 1 with the ambient temperature at 71 degrees Fahrenheit, which was considerably warmer than the previous attempt, Mix 2 was created to induce slight alterations to the admixture contents. The amount of HRWR was increased during this warmer casting day to achieve the fresh properties set forth by this study. The amount of HRWR was increased from $5 \mathrm{fl} \mathrm{oz/cwt} \mathrm{to} 6 \mathrm{fl} \mathrm{oz/cwt.} \mathrm{The} \mathrm{slump} \mathrm{flow} \mathrm{measured}$ at $5 \mathrm{fl} \mathrm{oz/cwt} \mathrm{of} \mathrm{HRWR}$ was 18 inches when using the same material proportions as Mix 1 (Table 2.02), but with a different temperature (Air- $71^{\circ} \mathrm{F}$, Water- $74^{\circ} \mathrm{F}$ ). The slump flow was increased to 24 inches at the HRWR dosage of $6 \mathrm{fl} \mathrm{oz/cwt,} \mathrm{as} \mathrm{shown} \mathrm{in} \mathrm{Table} \mathrm{2.04.} \mathrm{The} \mathrm{water}$ 
temperature of 74 degrees Fahrenheit for this batch made a big influence on the slump flow. The mix design for this batch is shown in Table 2.03 and the fresh properties for Mix 2 are shown in Table 2.04. This experience illustrates that the mix design and batching of SCC can be dependent on the ambient temperature; a mix design that is used or established when temperatures are in the 50's may not be reproducible without minor adjustment when the temperatures are in the 80 's.

Table 2.03: One Cubic Yard Mix Design for Mix 2.

\begin{tabular}{|l|c|r|}
\hline \multicolumn{1}{|c|}{ MATERIAL } & UNIT & MIX 2 \\
\hline Cement Type 1 & $\mathrm{lb}$ & 600 \\
\hline Slag & $\mathrm{lb}$ & 150 \\
\hline \#8 Crushed Limestone & $\mathrm{lb}$ & 553 \\
\hline \#67 Crushed Limestone & $\mathrm{lb}$ & 830 \\
\hline Natural Sand & $\mathrm{lb}$ & 1384 \\
\hline Water & $\mathrm{lb}$ & 300 \\
\hline w/cm & & 0.4 \\
\hline Air Entrainer & Oz/cwt & 0.1 \\
\hline VMA & Oz/cwt & 2.5 \\
\hline HRWR & Oz/cwt & 6 \\
\hline
\end{tabular}

Table 2.04: Measured Fresh Properties of Mix 2.

\begin{tabular}{|c|c|}
\hline PROPERTY & MIX 2 \\
\hline Slump Flow (in) & 24.0 \\
\hline T50 (sec) & 1.5 \\
\hline J-ring Value (in) & 2.0 \\
\hline T50 (sec) & $\sim 2$ \\
\hline Air Content (\%) & 3.3 \\
\hline Unit Weight $\left(\mathbf{l b} / \mathbf{f t}^{3}\right)$ & 143.2 \\
\hline Ambient Air Temperature $\left({ }^{0} \mathrm{~F}\right)$ & 71 \\
\hline Mix Water Temperature $\left({ }^{0} \mathrm{~F}\right)$ & 74 \\
\hline
\end{tabular}


The static segregation was also measured to be acceptable at $4.9 \%$. However, the handling procedure issue when filling the segregation columns was not yet resolved at the time of this batch, so the values for the vibrated columns (Chapter 3, Mix 2) did not complement this value. This handling problem and its solution are outlined in Chapter 3 - Stability under Vibration of SCC Mixes.

To see effects from deviations of water content, Mix 2 (with 6fl oz/cwt of HRWR) was reproduced and denoted as Mix 3, then the w/cm was increased from 0.4 to 0.45 and is denoted as Mix 3A; the mix designs for these mixes can be seen in Table 2.05. This increase in w/cm would be equivalent to adding 4 gallons of extra water to every cubic yard of concrete produced, which is about a $10 \%$ increase. As can be seen in Table 2.06, this increase in water resulted in a slump flow increase from 24.5 inches to 30 inches. The air content decreased from $3.3 \%$ to 2.3\% and the J-ring flow was 25.5 inches. The unit weight measured was $145 \mathrm{lb}$, which was comparable to the other mixes produced. The ambient temperature for this casting day was 77 degrees Fahrenheit with a mix water temperature of 74 degrees Fahrenheit.

Table 2.05: One Cubic Yard Mix Design for Mix 3 and the Addition of Water Mix 3A.

\begin{tabular}{|l|c|c|c|}
\hline \multicolumn{1}{|c|}{ MATERIAL } & UNIT & MIX 3 & MIX 3A \\
\hline Cement Type 1 & lb & 600 & 600 \\
\hline Slag & lb & 150 & 150 \\
\hline \#8 Crushed Limestone & lb & 553 & 553 \\
\hline \#67 Crushed Limestone & lb & 830 & 830 \\
\hline Natural Sand & lb & 1384 & 1384 \\
\hline Water & lb & 300 & 334 \\
\hline w/cm & & 0.4 & 0.45 \\
\hline Air Entrainer & Oz/cwt & 0.1 & 0.1 \\
\hline VMA & Oz/cwt & 2.5 & 2.5 \\
\hline HRWR & Oz/cwt & 6 & 6 \\
\hline
\end{tabular}


Table 2.06: Measured Fresh Properties of Mix 3 and Mix 3A.

\begin{tabular}{|c|c|c|}
\hline PROPERTY & MIX 3 & MIX 3A \\
\hline Slump Flow (in) & 24.5 & 30.0 \\
\hline T50 (sec) & $\sim 1.5$ & 1.1 \\
\hline J-ring (in) & - & 4.5 \\
\hline T50 (sec) & - & - \\
\hline Air Content (\%) & 3.3 & 2.3 \\
\hline Unit Weight (lb/ft $^{\mathbf{3}}$ ) & 144.3 & 145.0 \\
\hline Ambient Air Temperature ( & $\mathbf{0}$ \\
\hline F) & \multicolumn{2}{|c|}{77} \\
\hline Mix Water Temperature $\left.\mathbf{(}^{\mathbf{0}} \mathbf{F}\right)$ & \multicolumn{2}{|c|}{74} \\
\hline
\end{tabular}

At this time, a test apparatus that could quickly assess the static segregation resistance of an SCC mix design in a manner that would be feasible for high quantity and quick in-situ acceptance of SCC mixes. The test apparatus and method was developed and extensively tested by Van Bui. (Bui, Montgomery, Hinczak, \& Turner, 2002) The test can be associated with a performance criterion in order to accept or reject the concrete. The test was not an ASTM test method during this study, as stated previously. However, it has recently been adopted and is ASTM C 1712. Figures 2.02 and 2.03 show this tested being performed.

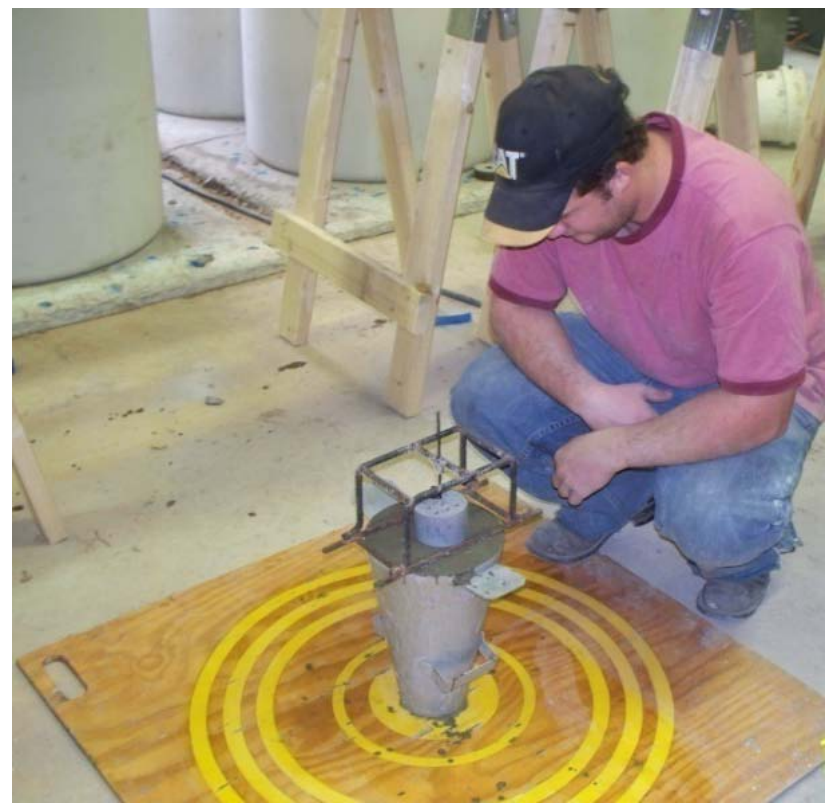

Figure 2.02: Picture of Performing the Segregation Probe Test on an SCC Mix. 


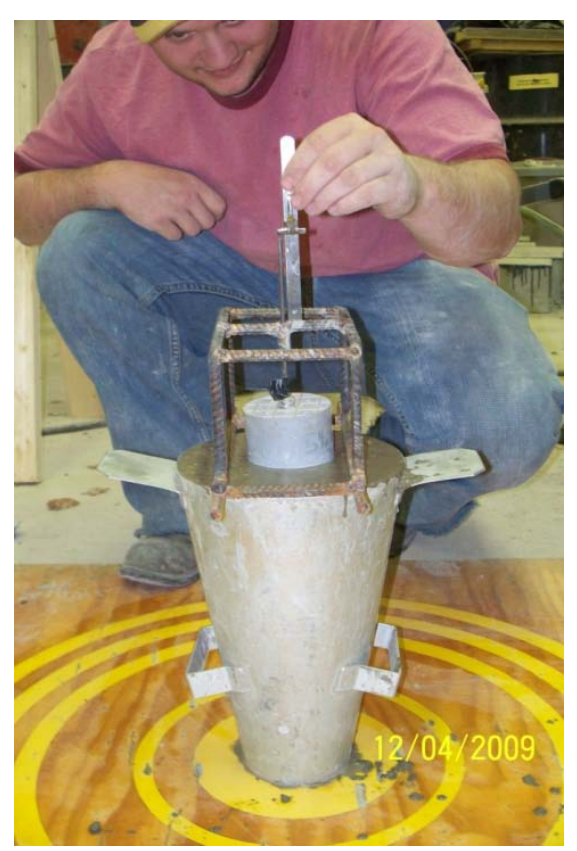

Figure 2.03: Picture of Performing the Measurement of Probe Depth.

Since the penetration apparatus used during the laboratory experimentation was not an ASTM standard, the one fabricated and used does not conform to the newly made standard. Noticeable difference in the one used was the penetration head mass. The mass of the standard penetration apparatus calls for the head to weigh 45 grams, while the one used during testing of this study weighed 54 grams. The standard also gives exact times in which portions of the test should be performed and the acceptance criteria for the penetration depth (Pd) measurement. Table 2.07 shows the performance criteria of this test. Lastly, the difference in the dimensions of the supporting frame of the penetration apparatus, Figure 2.04a shows the dimensions of the penetration apparatus used during this study, was different from that of the current ASTM C 1712 (Figure 2.04b). The difference in supporting frame dimensions, however, does not significantly alter the test results like the weight of the penetration head and the times of testing. 
Table 2.07: Performance criteria for ASTM C 1712.

\begin{tabular}{ll}
\hline Penetration depth $(P d)$ & Degree of static segregation resistance \\
$P d \leq 10 \mathrm{~mm}$ & Resistant \\
$10 \mathrm{~mm}<P d<25 \mathrm{~mm}$ & Moderately resistant \\
$P d \geq 25 \mathrm{~mm}$ & Not resistant \\
\hline AT &
\end{tabular}

AThese criteria were developed based on use of the penetration apparatus with an inverted slump mold and are valid for SCC mixtures with a total aggregate volume fraction of less than $65 \%$. The criteria may be different if a sample container other than the inverted slump mold is used.

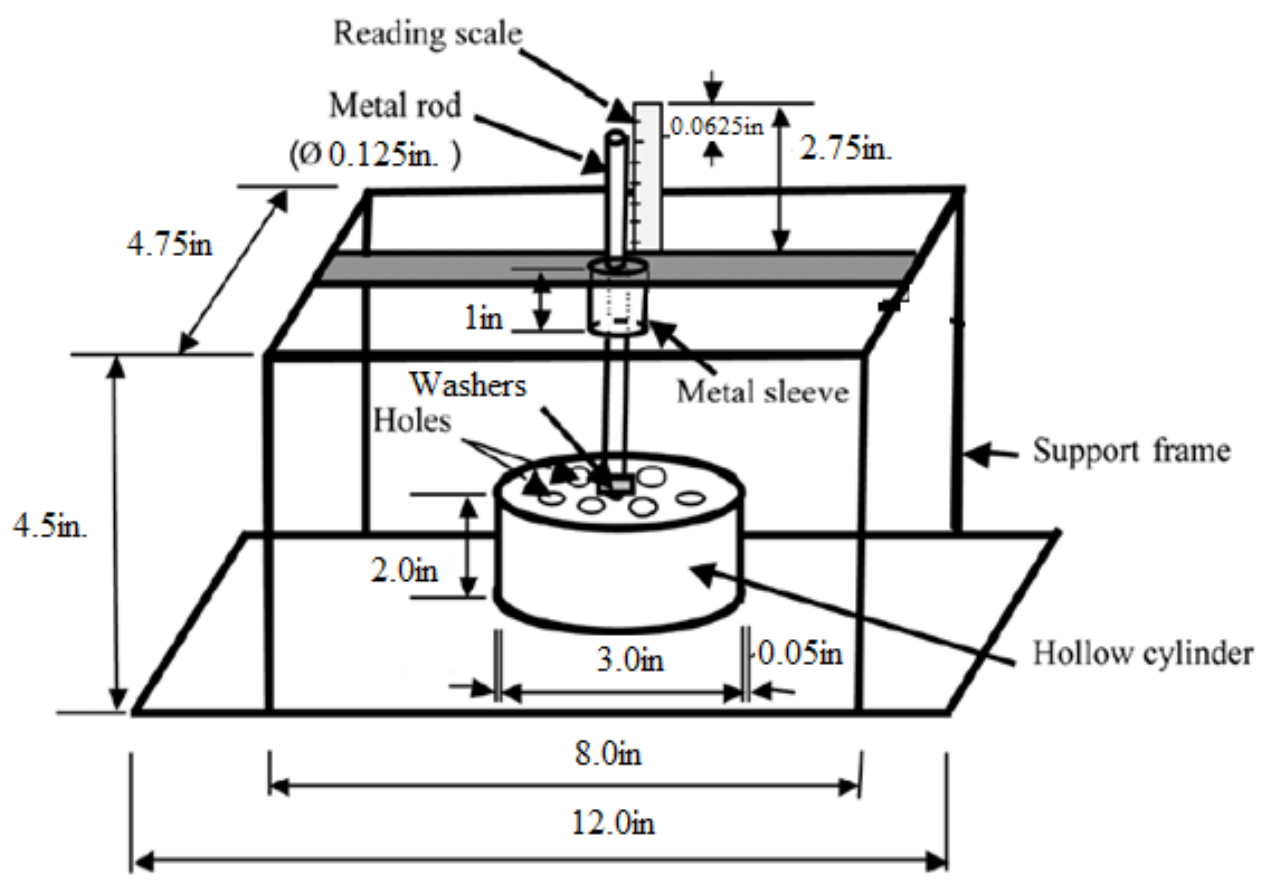

Figure 2.04: (a) Dimensions of the Penetration Apparatus used during this Study (Bui et. al., 2002). 


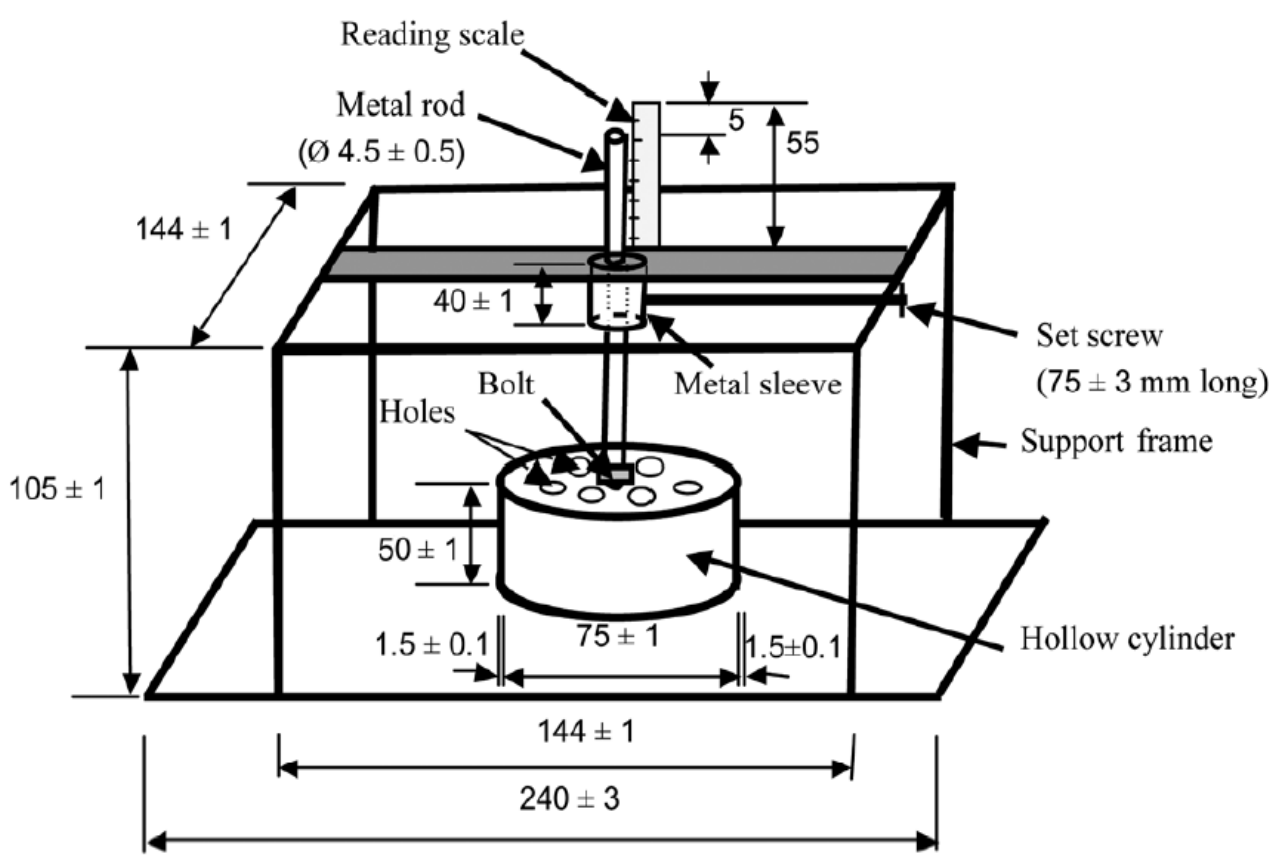

All dimensions in mm

Figure 2.04: (b) Dimensions of the Penetration Apparatus per ASTM C1712.

The production of Mix 3 would be the last time that the current mix design was able to be replicated in the lab with the desired fresh properties. It was determined that the environment of the concrete lab was changing due to the change in seasons from winter at the beginning of this study to summer. With higher ambient temperatures reaching the eighties along with elevated aggregate and mix water temperatures, a consistent mix with a slump flow of 24 inches plus or minus 2 inches could not be obtained using the quantities of Mix 2. The mix when produced at higher temperatures was only able to produce a slump flow of 21.5 inches. The higher temperature made working conditions more difficult especially performing the required barrage of tests in order to satisfactorily quantify the current mix before excessive loss of slump flow occurred.

To combat the problems associated with higher temperature of the batching environment, it was decided to alter the batch in such a manner to include a set retarder. Set retarding admixtures increase the workable period of a concrete mix by prolonging the hydration of the 
cement within the concrete. The addition of a compatible set retarder is beneficial to the production of SCC because it helps to extend its workable period in hot weather casting. As SCC is nearing its maximum allowable working period, the HRWR begins to lose its affect and slump flow can be quickly lost especially in hot weather. The workable period of an SCC mix can also be altered by selecting lower heat of hydration materials during the development of the mix design. However, proper trial batches must be conducted in order to understand the retarders affect on an SCC mix. Set retarders may contain water which will be added to the mix and some set retarders may also have water reducing characteristics. The addition of a set retarder to an SCC mix can be beneficial, but needs to be thoroughly assessed by trial batches.

Mix 4 was produced in order to follow the same performance criteria as the other mixes in lieu of the altered environmental conditions. Table 2.08, Mix 4 column, shows how the original mix design was altered to include the addition of a retarding admixture. The amount of air entrainer was also increased because of the low air content reading from the previous mixes.

Mix 4 was then altered by adding water to the mix in stages in order to see the water tolerance. It was observed that the mix could tolerate about a 5\% increase in the amount of added water to the mix, such that the fresh properties were still acceptable. This is about 2 gallons of water per yard batched. However, when the water was increased to about $7 \%$ of the original amount of mix water, or approximately 2.5 gallons per yard, the fresh properties changed dramatically, and are denoted by Mix 4A. The slump flow went from 23.5 inches to 25.5 inches to 29 inches when increasing the mix water by $0 \%, 5 \%$, and $7 \%$, respectively. The mix design after the 7\% increase in water (Mix 4A) is given in Table 2.08, and the fresh properties are seen in Table 2.09. The water temperature during this batching was 79 degrees Fahrenheit and the ambient temperature was the same. 
Table 2.08: One Cubic Yard Mix Design for Mix 4 and the Addition of Water Mix 4A.

\begin{tabular}{|l|c|r|r|}
\hline \multicolumn{1}{|c|}{ MATERIAL } & UNIT & MIX 4 & MIX 4A \\
\hline Cement Type 1 & lb & 600 & 600 \\
\hline Slag & lb & 150 & 150 \\
\hline \#8 Crushed Limestone & lb & 553 & 553 \\
\hline \#67 Crushed Limestone & lb & 830 & 830 \\
\hline Natural Sand & lb & 1384 & 1384 \\
\hline Water & lb & 300 & 325 \\
\hline w/cm & & 0.4 & 0.43 \\
\hline Air Entrainer & Oz/cwt & 0.15 & 0.15 \\
\hline VMA & Oz/cwt & 2.5 & 2.5 \\
\hline HRWR & Oz/cwt & 6 & 6 \\
\hline Retarder & Oz/cwt & 2.5 & 2.5 \\
\hline
\end{tabular}

Table 2.09: Measured Fresh Properties of Mix 4 and Mix 4A.

\begin{tabular}{|l|c|c|}
\hline \multicolumn{1}{|c|}{ PROPERTY } & MIX 4 & MIX 4A \\
\hline Slump Flow (in) & 23.5 & 29.0 \\
\hline T50 (sec) & 1.4 & 0.7 \\
\hline J-ring Difference(in) & 0 & 2.5 \\
\hline T50 (sec) & 1.9 & 1.3 \\
\hline Air Content (\%) & 2.5 & $\sim 3$ \\
\hline Unit Weight (lb/ft ${ }^{3}$ ) & 146.0 & 141.4 \\
\hline Segregation Probe (in) & 0.125 & 0.5 \\
\hline Ambient Air Temperature ( $\left.{ }^{\mathbf{0}} \mathbf{F}\right)$ & \multicolumn{2}{|c|}{79} \\
\hline Mix Water Temperature $\left.\mathbf{(}^{\mathbf{0}} \mathbf{F}\right)$ & \multicolumn{2}{|c|}{79} \\
\hline
\end{tabular}

Mix 5 was a reproduction of the previous mix with the set retarder. The supplementary water that was added was incorporated in two steps in the same manner as with Mix 4/Mix 4A. The water was added to increase the additional water by $4 \%$ in the first step, and the second step was to increase the water content by $7 \%$ in the same way as the previous mix production. The main difference between the Mix 4/Mix 4A and Mix 5/Mix 5A was the difference in temperature. The ambient temperature during this casting day was 82 degrees Fahrenheit. The concrete temperature during batching was 85 degrees Fahrenheit. Before the addition of water, 
the slump flow was 23.25 inches, the unit weight was $144 \mathrm{lb} / \mathrm{cu} \mathrm{ft}$, and the air content was 4.7 percent. The additional water of $4 \%$ was only able to increase the slump flow by 0.5 inches during this batching and with all of the additional water (7\%) the slump flow reached 26 inches. The static segregation resistance was $0 \%$ after all of the water was added (7\%). The handling procedure for conducting the static segregation test was improved at this point in the testing regimen. The mix design and fresh properties for Mix 5 and after the additional water was added, Mix 5A, and are given in Table 2.10 and Table 2.11, respectively.

Table 2.10: One Cubic Yard Mix Design for Mix 5 and the Addition of Water Mix 5A.

\begin{tabular}{|l|c|r|r|}
\hline \multicolumn{1}{|c|}{ MATERIAL } & UNIT & MIX 5 & MIX 5 A \\
\hline Cement Type 1 & lb & 600 & 600 \\
\hline Slag & lb & 150 & 150 \\
\hline \#8 Crushed Limestone & $\mathrm{lb}$ & 553 & 553 \\
\hline \#67 Crushed Limestone & $\mathrm{lb}$ & 830 & 830 \\
\hline Natural Sand & $\mathrm{lb}$ & 1384 & 1384 \\
\hline Water & $\mathrm{lb}$ & 300 & 325 \\
\hline w/cm & & 0.4 & 0.43 \\
\hline Air Entrainer & $\mathrm{Oz} / \mathrm{cwt}$ & 0.15 & 0.15 \\
\hline VMA & $\mathrm{Oz} / \mathrm{cwt}$ & 2.5 & 2.5 \\
\hline HRWR & $\mathrm{Oz} / \mathrm{cwt}$ & 6 & 6 \\
\hline Retarder & $\mathrm{Oz} / \mathrm{cwt}$ & 2.5 & 2.5 \\
\hline
\end{tabular}


Table 2.11: Measured Fresh Properties of Mix 5 and Mix 5A.

\begin{tabular}{|l|c|c|}
\hline \multicolumn{1}{|c|}{ PROPERTY } & MIX 5 & MIX 5A \\
\hline Slump Flow (in) & 23.25 & 26.0 \\
\hline T50 (sec) & - & - \\
\hline J-ring (in) & - & 0 \\
\hline T50 (sec) & - & - \\
\hline Air Content (\%) & 4.7 & 7.0 \\
\hline Unit Weight (lb/ft ${ }^{3}$ ) & 144.0 & 137.8 \\
\hline Ambient Air Temperature ( $\left.{ }^{\mathbf{0}} \mathbf{F}\right)$ & \multicolumn{2}{|c|}{82} \\
\hline Mix Water Temperature $\left.\mathbf{(}^{\mathbf{0}} \mathbf{F}\right)$ & \multicolumn{2}{|c|}{85} \\
\hline
\end{tabular}

The mix quantities used during Mix 4 and Mix 5 were replicated a third time to batch Mix 6. This was to assure reproducibility, and therefore validity of results, when producing an SCC mix in a small-scale laboratory setting. This time only $4 \%$ of additional water was added to the mix and was denoted as Mix 6A. The mix design and fresh properties for Mix 6/Mix 6A after the additional water are given in Table 2.12 and 2.13, respectively. This amount of extra water did not seem to affect the fresh properties substantially.

Table 2.12: One Cubic Yard Mix Design for Mix 6 and the Addition of Water Mix 6 A.

\begin{tabular}{|l|c|r|r|}
\hline \multicolumn{1}{|c|}{ MATERIAL } & UNIT & MIX 6 & MIX 6A \\
\hline Cement Type 1 & $\mathrm{lb}$ & 600 & 600 \\
\hline Slag & $\mathrm{lb}$ & 150 & 150 \\
\hline \#8 Crushed Limestone & $\mathrm{lb}$ & 553 & 553 \\
\hline \#67 Crushed Limestone & $\mathrm{lb}$ & 830 & 830 \\
\hline Natural Sand & $\mathrm{lb}$ & 1384 & 1384 \\
\hline Water & $\mathrm{lb}$ & 300 & 312 \\
\hline w/cm & & 0.4 & 0.416 \\
\hline Air Entrainer & Oz/cwt & 0.15 & 0.15 \\
\hline VMA & Oz/cwt & 2.5 & 2.5 \\
\hline HRWR & Oz/cwt & 6 & 6 \\
\hline Retarder & Oz/cwt & 2.5 & 2.5 \\
\hline
\end{tabular}


Table 2.13: Measured Fresh Properties of Mix 6 and Mix 6A.

\begin{tabular}{|l|c|c|}
\hline \multicolumn{1}{|c|}{ PROPERTY } & MIX 6 & MIX 6A \\
\hline Slump Flow (in) & 22.75 & 25.5 \\
\hline T50 (sec) & 4.6 & 2.4 \\
\hline J-ring (in) & 0.25 & 1.0 \\
\hline T50 (sec) & 5.3 & 3.8 \\
\hline Air Content (\%) & 4.6 & 2.0 \\
\hline Unit Weight (lb/ft ${ }^{3}$ ) & 139.8 & 143.8 \\
\hline Segregation Probe (in) & 0.125 & 0.1875 \\
\hline VSI & 0.5 & 2 \\
\hline Ambient Air Temperature ( $\left.{ }^{\mathbf{0}} \mathbf{F}\right)$ & \multicolumn{2}{|c|}{76} \\
\hline Mix Water Temperature ( $\left.\mathbf{~}^{\mathbf{F}} \mathbf{~}\right)$ & \multicolumn{2}{|c|}{78} \\
\hline
\end{tabular}

The compressive strength of these two batches (Mix 6/Mix 6A) was also conducted at 14 and 28 days in order to see the change with increased water content. The specimens cast were 4 x 8 inch cylinders and were cured in a lime saturated bath after they were stripped from their forms on the day after casting. The compressive results for Mix 6 and Mix 6A are shown in Tables 2.14 and 2.15, respectively. The compressive strength between the two mixes at 28 days was identical.

Table 2.14: Measured Compressive Strength of Mix 6.

\begin{tabular}{|r|r|r|r|r|}
\hline \multicolumn{1}{|c|}{ Specimen } & $\begin{array}{c}\text { 14-day } \\
\text { load [lb] }\end{array}$ & $\begin{array}{c}\text { 14-day compressive } \\
\text { strength [psi] }\end{array}$ & $\begin{array}{c}\text { 28-day } \\
\text { load [lb] }\end{array}$ & $\begin{array}{c}\text { 28-day compressive } \\
\text { strength [psi] }\end{array}$ \\
\hline $\mathbf{1}$ & 83000 & 6605 & 93000 & 7401 \\
\hline $\mathbf{2}$ & 88000 & 7003 & 102000 & 8117 \\
\hline $\mathbf{3}$ & 83500 & 6645 & 103000 & 8196 \\
\hline Average & 84833 & $\mathbf{6 7 5 1}$ & 99333 & $\mathbf{7 9 0 5}$ \\
\hline Standard Deviation & 2754 & 219 & 5508 & 438 \\
\hline
\end{tabular}


Table 2.15: Measured Compressive Strength of Mix 6A.

\begin{tabular}{|r|r|r|r|r|}
\hline \multicolumn{1}{|c|}{ Specimen } & $\begin{array}{c}\text { 14-day } \\
\text { load [lb] }\end{array}$ & $\begin{array}{c}\text { 14-day compressive } \\
\text { strength [psi] }\end{array}$ & $\begin{array}{c}\text { 28-day } \\
\text { load [lb] }\end{array}$ & $\begin{array}{c}\text { 28-day compressive } \\
\text { strength [psi] }\end{array}$ \\
\hline $\mathbf{1}$ & 78500 & 6247 & 97500 & 7759 \\
\hline $\mathbf{2}$ & 68000 & 5411 & 100000 & 7958 \\
\hline $\mathbf{3}$ & 70000 & 5570 & 100500 & 7998 \\
\hline Average & 72166 & $\mathbf{5 7 4 3}$ & 99333 & $\mathbf{7 9 0 5}$ \\
\hline Standard Deviation & 5575 & 444 & 1607 & 128 \\
\hline
\end{tabular}

Mix 7 was created to determine the fresh properties of an SCC mix design that was purposely batched with not enough water. This time, $7 \%$ of the mixing water was withheld from the mix, corresponding to a $\mathrm{w} / \mathrm{cm}$ of 0.37 down from 0.4 . It is common practice during the production of SCC to not allow the addition of water after batching, such as adding water to a batch of traditional concrete at the site in order to increase consistency. Instead, the truck would have to be rejected unless a qualified person would be able to retemper the SCC with a dosage of HRWR. The qualified person would also have to know the correct dosage to use because retempering tries are often limited.

Upon batching Mix 7, with the reduced water content, the slump had to be measured in the traditional fashion, and was measured at 2.5 inches. In total, 60 percent more HRWR was necessary to achieve adequate fresh property performance under the aforementioned criteria; the dosage of HRWR was raised from $6 \mathrm{fl} \mathrm{oz} / \mathrm{cwt}$ to $9.6 \mathrm{fl} \mathrm{oz} / \mathrm{cwt}$. The mix with the added HRWR is denoted as Mix 7H. The ambient temperature for the batching was 76.5 degrees Fahrenheit and the water temperature was 74 degrees Fahrenheit. The mix design and fresh properties for Mix 7/Mix $7 \mathrm{H}$ are given in the Tables 2.16 and 2.17, respectively. After retempering, the fresh properties of Mix 7H, with the HRWR, were consistent with those of the performance criteria set for this study. 
Table 2.16: One Cubic Yard Mix Design for Mix 7 and Mix 7A with Added HRWR.

\begin{tabular}{|l|c|r|r|}
\hline \multicolumn{1}{|c|}{ MATERIAL } & UNIT & MIX 7 & MIX 7H \\
\hline Cement Type 1 & lb & 600 & 600 \\
\hline Slag & lb & 150 & 150 \\
\hline \#8 Crushed Limestone & lb & 553 & 553 \\
\hline \#67 Crushed Limestone & lb & 830 & 830 \\
\hline Natural Sand & lb & 1384 & 1384 \\
\hline Water & lb & 275 & 275 \\
\hline w/cm & & 0.367 & 0.367 \\
\hline Air Entrainer & Oz/cwt & 0.15 & 0.15 \\
\hline VMA & Oz/cwt & 2.5 & 2.5 \\
\hline HRWR & Oz/cwt & 6 & 9.7 \\
\hline Retarder & Oz/cwt & 2.5 & 2.5 \\
\hline
\end{tabular}

Table 2.17: Measured Fresh Properties of Mix 7 and Mix 7A.

\begin{tabular}{|l|c|c|}
\hline \multicolumn{1}{|c|}{ PROPERTY } & MIX 7 & MIX 7H \\
\hline Slump Flow (in) & 2.5 (SLUMP) & 23.5 \\
\hline T50 (sec) & N/A & 3.3 \\
\hline J-ring (in) & N/A & 1.5 \\
\hline T50 (sec) & N/A & 4.5 \\
\hline Air Content (\%) & - & 7.5 \\
\hline Unit Weight (lb/ft ${ }^{3}$ ) & - & 140.7 \\
\hline Ambient Air Temperature ( ${ }^{\mathbf{0}} \mathbf{~ F ) ~}$ & \multicolumn{2}{|c|}{76.5} \\
\hline Mix Water Temperature ( $\left.{ }^{\mathbf{0}} \mathbf{F}\right)$ & \multicolumn{2}{|c|}{74} \\
\hline
\end{tabular}

An additional production of Mix 4, 5, and 6, the mixes with added set retarder, was accomplished and denoted as Mix 8. The batching of this mix was mainly in order to determine the resistance to vibration that will be discussed thoroughly in the next chapter. The purpose of this mix was primarily because the mix was not properly tested for segregation resistance due to vibration during its previous batching. The ambient temperature for Mix 8 was 71 degrees Fahrenheit and the water temperature was 72 degrees Fahrenheit. The mix design and fresh properties for this mix can be seen in Tables 2.18 and 2.19, respectively. 
Table 2.18: One Cubic Yard Mix Design for Mix 8.

\begin{tabular}{|l|c|r|}
\hline \multicolumn{1}{|c|}{ MATERIAL } & UNIT & MIX 8 \\
\hline Cement Type 1 & lb & 600 \\
\hline Slag & lb & 150 \\
\hline \#8 Crushed Limestone & lb & 553 \\
\hline \#67 Crushed Limestone & lb & 830 \\
\hline Natural Sand & lb & 1384 \\
\hline Water & lb & 300 \\
\hline w/cm & & 0.4 \\
\hline Air Entrainer & Oz/cwt & 0.15 \\
\hline VMA & Oz/cwt & 2.5 \\
\hline HRWR & Oz/cwt & 6 \\
\hline Retarder & Oz/cwt & 2.5 \\
\hline
\end{tabular}

Table 2.19: Measured Fresh Properties of Mix 8.

\begin{tabular}{|l|c|}
\hline \multicolumn{1}{|c|}{ PROPERTY } & MIX 8 \\
\hline Slump Flow (in) & 23.0 \\
\hline T50 (sec) & 1.65 \\
\hline J-ring (in) & 2.0 \\
\hline T50 (sec) & - \\
\hline Air Content (\%) & 5 \\
\hline Unit Weight (lb/ft ${ }^{3}$ ) & 144.6 \\
\hline Ambient Air Temperature ( $\left.\mathbf{~}^{\mathbf{0}} \mathbf{F}\right)$ & 71 \\
\hline Mix Water Temperature $\mathbf{(}^{\mathbf{0}} \mathbf{~ F )}$ & 72 \\
\hline
\end{tabular}

\subsection{SUMMARY OF FINDINGS}

It was observed during the experimentation for this portion of the study that a change in water or HRWR content can greatly alter the fresh properties of an SCC mix. The experimentation was conducted on a robust mix design. Extra water added to the mix in the range of 0 to 5 percent seemed to be okay and the mix was stable enough to be placed in a structural member. However, if the water content is increased beyond this point the mix would display signs of instability. This also agrees with the findings in the literature review, which 
revealed that a robust mix design should be able to handle a change in water content from 3 to 5 percent depending on material selection and quantities (Eurocode, 2005).

This experimentation was conducted on essentially one control mix design even though some of the chemical admixture quantities changed slightly and the addition of a set retarder was used during the later mixes. The range for acceptable water content in the amount of 0 to 5 percent is the range for the tested control mix only. Other SCC mix designs, using other material quantities and material sources, could have different effects. It seemed that the temperature of batching had an influence on fresh properties.

The comparison of all of the mix designs of the batches used during this portion of the study are shown in Table 2.20. The measured fresh properties of those mixes are displayed in Table 2.21. The temperature did not alter the slump flow very much when comparing mixes 4 , 5, and 6. However, there was a difference in the change in slump flow between mixes $4 \mathrm{~A}$ and 5A. The retempering of an SCC mix design is possible, as shown during Mix $7 / 7 \mathrm{H}$, but needs to be handled by an experienced person that understands the amounts needed to achieve desired properties. 
Table 2.20: Comparison of all of the Mix Designs of this Study.

\begin{tabular}{|c|c|c|c|c|c|c|c|c|c|c|c|c|c|}
\hline MATERIAL & $\underset{1}{\operatorname{MIX}}$ & $\begin{array}{c}\text { MIX } \\
2\end{array}$ & $\begin{array}{c}\text { MIX } \\
3\end{array}$ & $\begin{array}{c}\text { MIX } \\
\text { 3A }\end{array}$ & $\begin{array}{c}\text { MIX } \\
4\end{array}$ & $\begin{array}{c}\text { MIX } \\
\mathbf{4 A}\end{array}$ & $\begin{array}{c}\text { MIX } \\
5\end{array}$ & $\begin{array}{c}\text { MIX } \\
5 A\end{array}$ & $\begin{array}{c}\text { MIX } \\
6\end{array}$ & $\begin{array}{c}\text { MIX } \\
6 A\end{array}$ & $\begin{array}{c}\text { MIX } \\
7\end{array}$ & $\begin{array}{c}\text { MIX } \\
7 \mathbf{H}\end{array}$ & $\begin{array}{c}\text { MIX } \\
8\end{array}$ \\
\hline Cement [lb] & 600 & 600 & 600 & 600 & 600 & 600 & 600 & 600 & 600 & 600 & 600 & 600 & 600 \\
\hline Slag [lb] & 150 & 150 & 150 & 150 & 150 & 150 & 150 & 150 & 150 & 150 & 150 & 150 & 150 \\
\hline \#8 CA [lb] & 553 & 553 & 553 & 553 & 553 & 553 & 553 & 553 & 553 & 553 & 553 & 553 & 553 \\
\hline \#67 CA [lb] & 830 & 830 & 830 & 830 & 830 & 830 & 830 & 830 & 830 & 830 & 830 & 830 & 830 \\
\hline FA [lb] & 1384 & 1384 & 1384 & 1384 & 1384 & 1384 & 1384 & 1384 & 1384 & 1384 & 1384 & 1384 & 1384 \\
\hline Water [lb] & 300 & 300 & 300 & 334 & 300 & 325 & 300 & 325 & 300 & 312 & 275 & 275 & 300 \\
\hline $\mathrm{w} / \mathbf{c m}$ & 0.4 & 0.4 & 0.4 & 0.45 & 0.4 & 0.43 & 0.4 & 0.43 & 0.4 & 0.416 & 0.367 & 0.367 & 0.4 \\
\hline $\mathrm{AE}[\mathrm{Oz} / \mathrm{cwt}]$ & 0.1 & 0.1 & 0.1 & 0.1 & 0.15 & 0.15 & 0.15 & 0.15 & 0.15 & 0.15 & 0.15 & 0.15 & 0.15 \\
\hline VMA [Oz/cwt] & 2.5 & 2.5 & 2.5 & 2.5 & 2.5 & 2.5 & 2.5 & 2.5 & 2.5 & 2.5 & 2.5 & 2.5 & 2.5 \\
\hline HRWR [Oz/cwt] & 5 & 6 & 6 & 6 & 6 & 6 & 6 & 6 & 6 & 6 & 6 & 9.7 & 6 \\
\hline Retarder [Oz/cwt] & - & - & - & - & 2.5 & 2.5 & 2.5 & 2.5 & 2.5 & 2.5 & 2.5 & 2.5 & 2.5 \\
\hline
\end{tabular}

Table 2.21: Comparison for all of the Mix Fresh Properties of this Study.

\begin{tabular}{|c|c|c|c|c|c|c|c|c|c|c|c|c|c|}
\hline PROPERTY & $\begin{array}{c}\text { MIX } \\
1\end{array}$ & $\begin{array}{c}\text { MIX } \\
2\end{array}$ & $\begin{array}{c}\text { MIX } \\
3\end{array}$ & $\begin{array}{c}\text { MIX } \\
\text { 3A }\end{array}$ & $\begin{array}{c}\text { MIX } \\
4\end{array}$ & $\begin{array}{c}\text { MIX } \\
\text { 4A }\end{array}$ & $\begin{array}{c}\text { MIX } \\
5\end{array}$ & $\begin{array}{c}\text { MIX } \\
5 A\end{array}$ & $\begin{array}{c}\text { MIX } \\
6\end{array}$ & $\begin{array}{c}\text { MIX } \\
\text { 6A }\end{array}$ & $\begin{array}{c}\text { MIX } \\
7 \\
\end{array}$ & $\begin{array}{c}\text { MIX } \\
7 \mathbf{H}\end{array}$ & $\begin{array}{c}\text { MIX } \\
8\end{array}$ \\
\hline Slump Flow (in) & 24.0 & 24.0 & 24.5 & 30.0 & 23.5 & 29.0 & 23.25 & 26.0 & 22.75 & 25.5 & 2.5 & 23.5 & 23.0 \\
\hline T50 (sec) & 1.3 & 1.5 & $\sim 1.5$ & 1.1 & 1.4 & 0.7 & - & - & 4.6 & 2.4 & N/A & 3.3 & 1.65 \\
\hline J-ring (in) & 3.0 & 2.0 & - & 4.5 & 0 & 2.5 & - & 0 & 0.25 & 1.0 & N/A & 1.5 & 2.0 \\
\hline T50 (sec) & 5.2 & $\sim 2$ & - & - & 1.9 & 1.3 & - & - & 5.3 & 3.8 & N/A & 4.5 & - \\
\hline Air Content (\%) & 5.8 & 3.3 & 3.3 & 2.3 & 2.5 & $\sim 3$ & 4.7 & 7.0 & 4.6 & 2.0 & - & 7.5 & 5 \\
\hline Segregation Probe (in) & - & - & - & - & 0.125 & 0.5 & - & - & 0.125 & 0.1875 & - & - & - \\
\hline Unit Weight (lb/ft $\left.{ }^{3}\right)$ & 143.9 & 143.2 & 144.3 & 145.0 & 146.0 & 141.4 & 144.0 & 137.8 & 139.8 & 143.8 & - & 140.7 & 144.6 \\
\hline Ambient Temp. (F) & 54 & 71 & \multicolumn{2}{|c|}{77} & \multicolumn{2}{|c|}{79} & \multicolumn{2}{|c|}{82} & \multicolumn{2}{|c|}{76} & \multicolumn{2}{|c|}{76.5} & 71 \\
\hline Concrete Temp. (F) & 56 & 74 & \multicolumn{2}{|c|}{74} & \multicolumn{2}{|c|}{79} & \multicolumn{2}{|c|}{85} & \multicolumn{2}{|c|}{78} & \multicolumn{2}{|c|}{74} & 72 \\
\hline
\end{tabular}


The researchers suggest that the one percent tolerance on measuring mix water that is in the current WVDOT specification remain intact. However, aggregate moisture measuring devices may have to be held to a tight tolerance as well. If possible, the total moisture of the coarse and fine aggregates must be measured to be within the same tolerance. This will ensure that the maximum deviation from the theoretical mix design in the amount of water be kept to 3\%. The testing for aggregate moisture content may also be specified at certain times during a production run. Batch plants would also be encouraged to test for the water content of chemical admixtures, or to obtain information from suppliers, in order to adjust for this as well, although after the mix development phase this would be more for accurate representation of the w/cm of the mix than for pragmatic purposes. During mix design development, it is important to conduct tests to determine the slump retention and loss of passing ability of the mix. This will determine the amount of time available to place the SCC mixture into the formwork. 


\section{CHAPTER 3 - STABILITY UNDER VIBRATION OF SCC MIXES}

Task \#2 of this study determined the segregation resistance of SCC when subjected to different durations of vibration. SCC, due to its high flowability and self consolidating properties, normally would not need to be vibrated when placed. However, in situations where reinforcing steel is highly congested or there has been a delay before placement it may be decided to vibrate the mix for proper consolidation. Vibration of SCC should only be carried out if completely necessary. This is because the effect of this action on SCC is believed to potentially cause high levels of segregation. This task is geared toward exploring the amount of segregation caused by vibrating different SCC mixes in order to better understand when vibration is acceptable and when it would adversely affect the final product.

\subsection{LITERATURE REVIEW}

It is evident from the literature review results that the vibration of SCC can be detrimental to its fresh and hardened properties. The act of using vibration, either internal or external, provides a means for the coarse aggregates to segregate within fresh SCC. This is due to its high fluidity over traditional low-slump concrete coupled with the larger cement content of SCC. Some literature sources claim that vibration can be used on the mix during casting, as long as the contractor demonstrated that the proposed SCC can pass all quality control parameters during the mix qualification after being subjected to vibration. (Mid-Atlantic States Prestressed Committee for Economic Fabrication QA/QC Sub-Committee, 2003)

SCC, when batched correctly, delivered, and placed without delay, does not need vibration. However, some agencies, such as the Mid-Atlantic Prestressed Concrete Committee for Economic Fabrication, specify that if vibration is required, it can only be very light and for short durations as to not produce segregation. Alternative methods such as rodding or tapping are 
suggested before the use of electric powered vibrators. One area where the use of vibration is often allowed, lightly and for short duration, is when a cold joint may interfere with the strength and bond in a critical area of a structural element.

Inducing vibrations into laboratory castings of SCC to observe its effects on segregation has been studied by other researchers (Safawi, Iwaki, \& Miura, 2003). These researchers showed that the vibration of SCC can be achieved as long as the viscosity of the mix was well known and acceptable. They produced mixes that were not harmed by vibration at different intervals. The viscosities of the mixes were measured by a common European test known as the V-funnel.

\subsection{EXPERIMENTAL PROCESS}

To determine the amount of segregation that would be introduced into SCC during vibration, a laboratory experiment was conducted. In order to measure the static segregation of SCC, ASTM C 1610 uses a column apparatus commonly referred to as a segregation column. This column is constructed out of an 8 inch diameter schedule 40 PVC pipe that is 26 inches in total height. The column is broken up into three sections (top-6.5 inches, middle-13 inches, and bottom-6.5 inches) and is stood up longitudinally. Angle brackets and spring clamps, or a similar clamping system, hold the sections together during the filling process and the bottom section is attached to a base board to allow it to free stand.

To conduct this test, fresh SCC is placed into column in one lift and left undisturbed for at least fifteen minutes. After this time, the column is separated and the concrete that is contained within the top and bottom sections are used as samples for testing. The sample is washed and wet sieved over a \#4 standard sieve. The only remaining material, after this process, is the coarse aggregate retained. The top and bottom sample is then weighed and compared. The weights of the top and bottom section of the segregation column are put into Equation 1 in order 
to determine the percent of static segregation. A low percentage means that during the static period large aggregates were not settling to the bottom of the column apparatus. Sometimes the top section sample weighs more than the bottom one, which corresponds to a segregation value of zero percent. However, if a large difference between the top and bottom section is seen, the handling procedure of filling the column should be examined. Typical values for an acceptable segregation percent are in the range of zero to 15 percent. Some agencies may apply slightly stricter or looser ranges, though.

$$
\text { Static Segregation (\%) }=2 * \frac{\left[C A_{B}-C A_{T}\right]}{\left[C A_{T}+C A_{B}\right]} * 100 \%
$$

Where:

$$
\begin{aligned}
& \mathrm{CA}_{\mathrm{T}}=\text { Coarse Aggregate Retained from the Top Portion [lb] } \\
& \mathrm{CA}_{\mathrm{B}}=\text { Coarse Aggregate Retained from the Bottom Portion [lb] }
\end{aligned}
$$

This standard test was altered in order to include the addition of vibration to the columns before they were allowed to remain undisturbed and the allocation of the top and bottom samples. For every mix that was tested, three segregation columns were filled. Two columns would undergo a predetermined amount of vibration, while the third column would remain nonvibrated in order to determine the mix's static segregation resistance. By looking at the difference between the segregation results of an SCC mix that has been subjected to two different vibration intervals and one control static column (non-vibrated column), conclusions could be drawn on the detrimental effects of vibrating SCC. Figure 3.01 shows the experimental setup. 


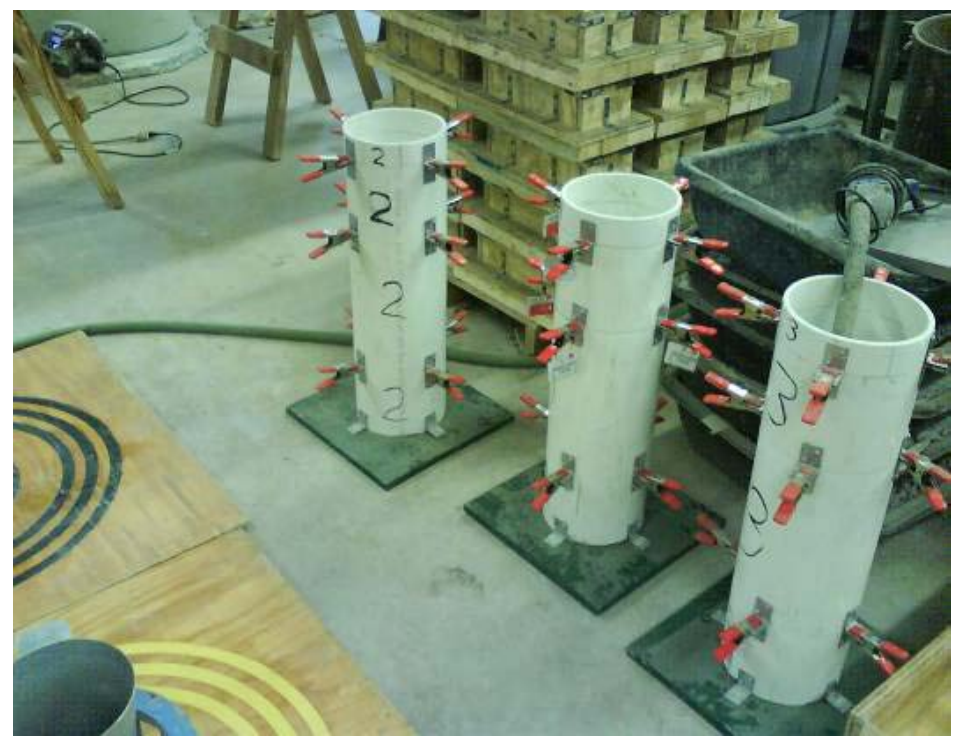

Figure 3.01: Experimental Setup for the Vibration Testing of SCC.

A common $3 / 4$ horsepower drill motor driven vibrator with a 2” diameter head was used for vibration during this testing. During the first few trials of this experimental process, the vibration was external and done by placing the vibrator up against the exterior of the segregation columns. However, to introduce a more realistic approach, the project monitors suggested the use of internal vibration. Also, volume loss of the sample within the vibrated columns was also observed during the trial testing. The action of vibrating the columns releases air within the concrete sample, and more concrete would inevitably be lost by internal vibration due to the volume of the vibrator itself, and considerable amounts of paste are lost due to splatter during vibration. This provided a problem since the amount of the concrete in the top of the column was now noticeably less than the non-vibrated column top section. To ensure that the top sections, of the three columns, would contain the same volume of concrete sample, an additional two-inch section was added to the top of the segregation columns. This additional section deviates from the current ASTM test method, but was necessary in order to retain enough 
concrete within the measured top section of the segregation column. Figure 3.02 provides a schematic of the modified segregation column with the added "Extra Section." The concrete sample in the additional top sections was not measured, but only served to provide a small volume of concrete to be lost due to internal vibration.

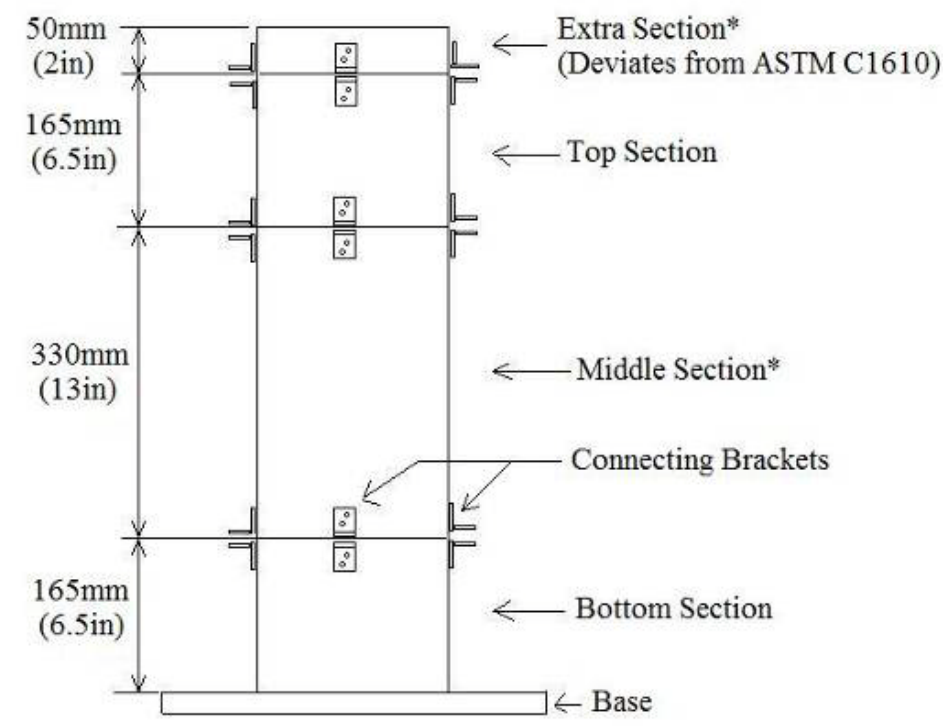

Figure 3.02: Schematic Drawing of Modified Segregation Column with Extra Top Section.

After switching to internal vibration and altering the columns to be outfitted with an additional top section, more trial batches were conducted in order to test the new experimental setup. However, the results of these tests did not show a correlation between the duration of vibration that was introduced into the mix and the amount of segregation that resulted. For instance, the static segregation column (no induced vibration) would show a higher amount of segregation than the columns that would have vibration.

Therefore, changes were made to improve the handling procedure of the fresh SCC from the mixer to the columns. Also, it was noted that the geometry of the drum mixer provokes segregation when it is idle and discharging fresh SCC, so it was undesirable to sample directly 
from the drum. Using the initial technique to fill the columns, five gallon capacity buckets were filled with fresh SCC and carried by hand over to the columns, where one third of the bucket would be dispensed into each of the three columns. The problem with the initial handling method was that when discharging the fresh SCC into a bucket from a mixer, the larger particles can become hung up on the fins of the mixer itself, so the buckets that are filled up later contain less paste and fines than the first few buckets that were discharged. The carrying of the buckets to the area where the columns were stationed also induced further segregation into the mix. This would provide for a non-uniform sample in each of the three columns prior to the start of the test, as some columns (or portions within the same column) could contain more large aggregates than other ones, having an induced segregation from the filling process. Tables 3.01 and 3.02 from Mix 1 and Mix 2, respectively, show how a poor handling procedure can result in segregation percentages that do no complement each other. The mixes displayed during this chapter have the identical mix design as in Chapter 2 (Mix 1 discussed here refers to the mix design and fresh properties of Mix 1 displayed in Chapter 2). Mix 1 shows that the non-vibrated column contains 10 and 4 percent less segregation than the ones vibrated for a duration of 5 and 20 seconds, respectively. The vibration results of Mix 2 shows a similar trend; however the nonvibrated column contained over 500 grams less of coarse aggregates in the top and bottom sections. 
Table 3.01: Vibration Tests Results for Mix 1.

\begin{tabular}{|l|r|r|r|}
\hline \multirow{2}{*}{ Segregation Column \# } & \multicolumn{3}{|c|}{ MIX 1 } \\
\cline { 2 - 4 } Duration of Vibration (s) & \multicolumn{1}{|c|}{$\mathbf{1}$} & \multicolumn{1}{c|}{$\mathbf{3}$} \\
\hline Top (g) & 0 & 5 & 20 \\
\hline Bottom (g) & 3945 & 4240 & 4095 \\
\hline Total (g) & 4944 & 4803 & 4930 \\
\hline Percent Segregation (\%) & $\mathbf{2 2 . 5}$ & $\mathbf{1 2 . 5}$ & $\mathbf{1 8 . 5}$ \\
\hline
\end{tabular}

Table 3.02: Vibration Test Results for Mix 2.

\begin{tabular}{|l|r|r|r|}
\hline \multirow{2}{*}{ Segregation Column \# } & \multicolumn{3}{|c|}{ MIX 2 } \\
\cline { 2 - 4 } Duration of Vibration (s) & \multicolumn{1}{|c|}{$\mathbf{2}$} & \multicolumn{1}{c|}{ 3 } \\
\hline Top (g) & 4217 & 4558 & 4439 \\
\hline Bottom (g) & 4431 & 4720 & 4751 \\
\hline Total (g) & 8648 & 9278 & 9190 \\
\hline Percent Segregation (\%) & $\mathbf{4 . 9}$ & $\mathbf{3 . 5}$ & $\mathbf{6 . 8}$ \\
\hline
\end{tabular}

The vibration results of Mix 3A, shown in Table 3.03, shows unusual test results. The percent of segregation for all three segregation columns seem to be very good, but when looking at the differences in the amounts of aggregates in the tops and bottoms of the segregation columns, a starling discover is made. Most likely due to poor handling procedures, there is over 600 grams more of coarse aggregates in the tops of the segregation columns, after the undisturbed period, than the bottom. This illustrates that with the initial filling technique, a nonuniform initial aggregate distribution was created, so improvements were necessary to adequately portray the amount of segregation present in an SCC mix and to determine the segregation induced by vibration. 
Table 3.03: Vibration Test Results from Mix 3.

\begin{tabular}{|l|r|r|c|}
\hline \multirow{2}{*}{ Segregation Column \# } & \multicolumn{3}{|c|}{ MIX 3 } \\
\cline { 2 - 4 } Duration of Vibration (s) & $\mathbf{1}$ & \multicolumn{1}{c|}{$\mathbf{2}$} & \multicolumn{1}{c|}{$\mathbf{3}$} \\
\hline Top (g) & 4816 & 4974 & 15.9 \\
\hline Bottom (g) & 4188 & 4356 & 4730 \\
\hline Total (g) & 9004 & 9330 & 9414 \\
\hline Percent Segregation (\%) & $\mathbf{0}$ & $\mathbf{0}$ & $\mathbf{1 . 0}$ \\
\hline
\end{tabular}

In order to minimize the problems associated with the non-uniform aggregate distribution during initial column filling, a new handling procedure was established. After the appropriate batching and mixing procedures, the fresh SCC was discharged into a large bin next to the columns. A small scoop was used, instead of a large bucket, to minimize the settling in the transport container. The scoop was also used to stir the SCC in the bin to keep the sample homogenous. A scoops worth of SCC, about 5 lbs, would then be extracted from the bin and deposited into one of the columns. This method was rotated between the columns, so that all three columns were being filled simultaneously. In between SCC extraction from the bin via the scoop, the scoop was used to thoroughly stir the remaining SCC in the bin to homogenize it. By filling the columns by this method, no noticeable segregation is introduced. All of the segregation, to be accurately measured, took place in the segregation columns and not before. The results for the experiments conducted after these changes were much more in line with anticipated behaviors.

The first batch tested with the new handling procedure was accomplished on Mix 5A that was used during Task 1. Mix 5A was a mix that had additional water added to it, and the slump flow was 26 inches. The results seem more typical, with the columns that contain more vibration having a larger amount of segregation. However, Column 1 with no induced vibration seemed to 
contain a smaller total quantity of coarse aggregates than the other two. The results from Columns 2 and 3 seem to show good results in the sense that the columns that receive more vibration will have more segregation. The values of 21.9 and 38.9 percent segregation would be unacceptable by most standards when casting a structural element.

Table 3.04: Vibration Test Results from Mix 5A.

\begin{tabular}{|l|r|r|c|}
\hline \multirow{2}{*}{ Segregation Column \# } & \multicolumn{3}{|c|}{ MIX 5A } \\
\cline { 2 - 4 } Duration of Vibration (s) & \multicolumn{1}{|c|}{$\mathbf{1}$} & \multicolumn{1}{c|}{$\mathbf{2}$} \\
\hline Top (g) & 0 & 10 & 16.5 \\
\hline Bottom (g) & 4524 & 4358 & 3937 \\
\hline Total (g) & 4335 & 5431 & 5835 \\
\hline Percent Segregation (\%) & 8858 & 9789 & 9771 \\
\hline
\end{tabular}

Mix 8 was produced in the laboratory so that the vibration test could be run on a mix design with no added water and using the handling procedure to ensure that no induced segregation would occur within the mix during the filling of the columns. The results from this mix were as expected. All three of the columns contained approximately the same amount of coarse aggregates and the added vibration increased the amount of measured segregation. It is seen from the results in Table 3.05 that the amount of segregation in each of the columns would pass the static segregation criteria. The column that was introduced to the longest vibration duration only showed 11.3 percent segregation. 
Table 3.05: Vibration Test Results of Mix 8.

\begin{tabular}{|l|r|r|r|}
\hline \multirow{2}{*}{ Segregation Column \# } & \multicolumn{3}{|c|}{ MIX 8 } \\
\cline { 2 - 4 } & \multicolumn{1}{|c|}{$\mathbf{1}$} & \multicolumn{1}{c|}{$\mathbf{2}$} \\
\hline Duration of Vibration (s) & 0 & 10 & 16 \\
\hline Top (g) & 4582 & 4700 & 4612 \\
\hline Bottom (g) & 4780 & 4929 & 5162 \\
\hline Total (g) & 9362 & 9629 & 9774 \\
\hline Percent Segregation (\%) & $\mathbf{4 . 2}$ & $\mathbf{4 . 8}$ & $\mathbf{1 1 . 3}$ \\
\hline
\end{tabular}

\subsection{SUMMARY OF FINDINGS}

From the literature review result and the laboratory experimentation, several conclusions can be made about the vibration of SCC. The experimental setup showed that the handling procedure of an SCC mix needs special caution so that it would not induce segregation before placement. It seemed that an SCC mix that was batched well and fairly robust could handle moderate amounts of vibration if deemed necessary. However, a less stable SCC mix may not be able to endure vibration.

SCC mix acceptance criteria are usually held within a tight tolerance. The slump flow is usually only allowed to deviate within a few inches of the proposed target flow. Other tests such as the J-ring and VSI must have defined performance criteria that must be adhered to as well. Often the need to vibrate an SCC mix comes at a time during construction when it is completely vital. For instance, when the SCC mix is near the end of its workable period or when there is the possibility of a formed cold joint due to a major delay. Both of these instances would contain an SCC mix that was losing its thixotropy. So by vibrating the SCC mix at this point, the workability is most likely low enough to be considered as traditional vibrated concrete. The batch that is placed on top of a potential cold joint area would be of the most concern because of that concrete being highly fluid while that underneath being very stiff. Inspectors from the 
WVDOT or other agencies should be trained to properly identify if the SCC is not consolidating on its own. The allowance of vibration would have to come from an experienced inspector. 


\section{CHAPTER 4 - AIR MIGRATION IN SCC}

One effect of mix instability is called air migration, in which air bubbles relocate within the mix to form concentrated areas of higher and lower air contents. This has been observed in some laboratory mixes with the generation of a foam layer forming at the top of the SCC. Since the migration of air bubbles will affect the air void structure of the concrete, and consequently will potentially affect its durability, this phenomenon must be investigated to determine what causes it and if there should be any restrictions on material usage to prevent air migration from occurring.

Mix instability, where air bubbles are observed escaping from the surface of a freshly cast SCC is often in conjunction with the segregation of aggregates. As air is moving towards the top of the cast element, coarse aggregates are sinking to the bottom simultaneously. This type of mix instability, lack of robustness, was observed in two different occasions during the production of SCC by both a precaster and a ready-mix producer. This task was created in order to find information about the migration of air within a fluid body of SCC and to determine the particular mix constituents or settings where this phenomenon would occur.

\subsection{LITERATURE REVIEW}

Air bubbles are formed within concrete for multiple different reasons, particularly during mixing. Some water reducing admixture can also be the catalyst of air within the mix. However, it has been forewarned that the air void structure produced by a polycarboxylate high range water reducer is unstable, which can cause non-uniformly spaced voids of non-concentric size and shape (ACBM. 2007). Other researchers suggest that a fine aggregate with a high fineness modulus could cause air migration problems (ZTE, 2006). 
The observation of a foam layer as well as air bubbles rising to the surface of a cast SCC element have been observed in two different venues. Air foam composed of large air bubbles, similar to sea foam or blowing through a drinking straw into a glass of milk, was observed during the casting of a mock structural member during the RP221 project. A picture of this foam layer can be seen in Figure 4.01. Air migration was also observed in the form of small air bubbles rising to the surface during a trial mix at a precast plant. These air bubbles resembled the very small bubbles associated with air entrainment. A picture of the air bubbles rising to the surface and bursting is shown in Figure 4.02.

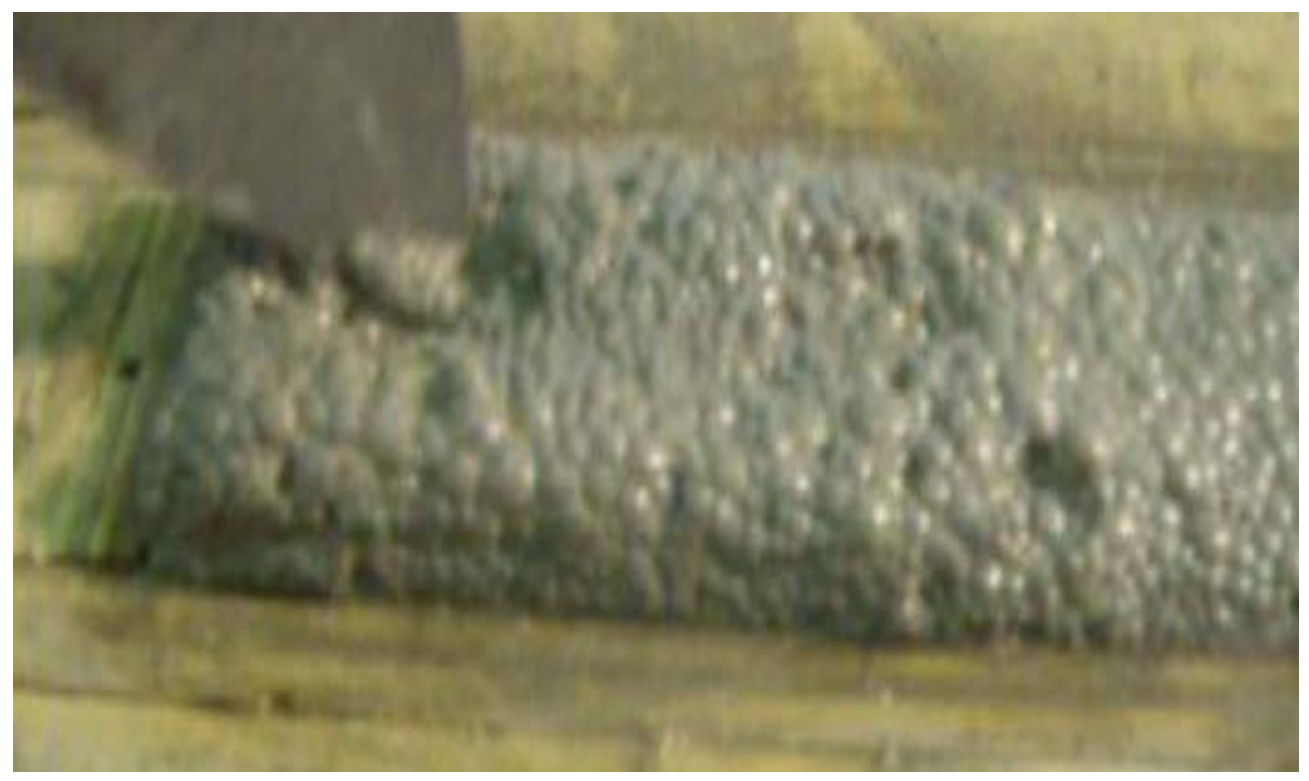

Figure 4.01: Foam Layer Observed during the RP221 Project. 


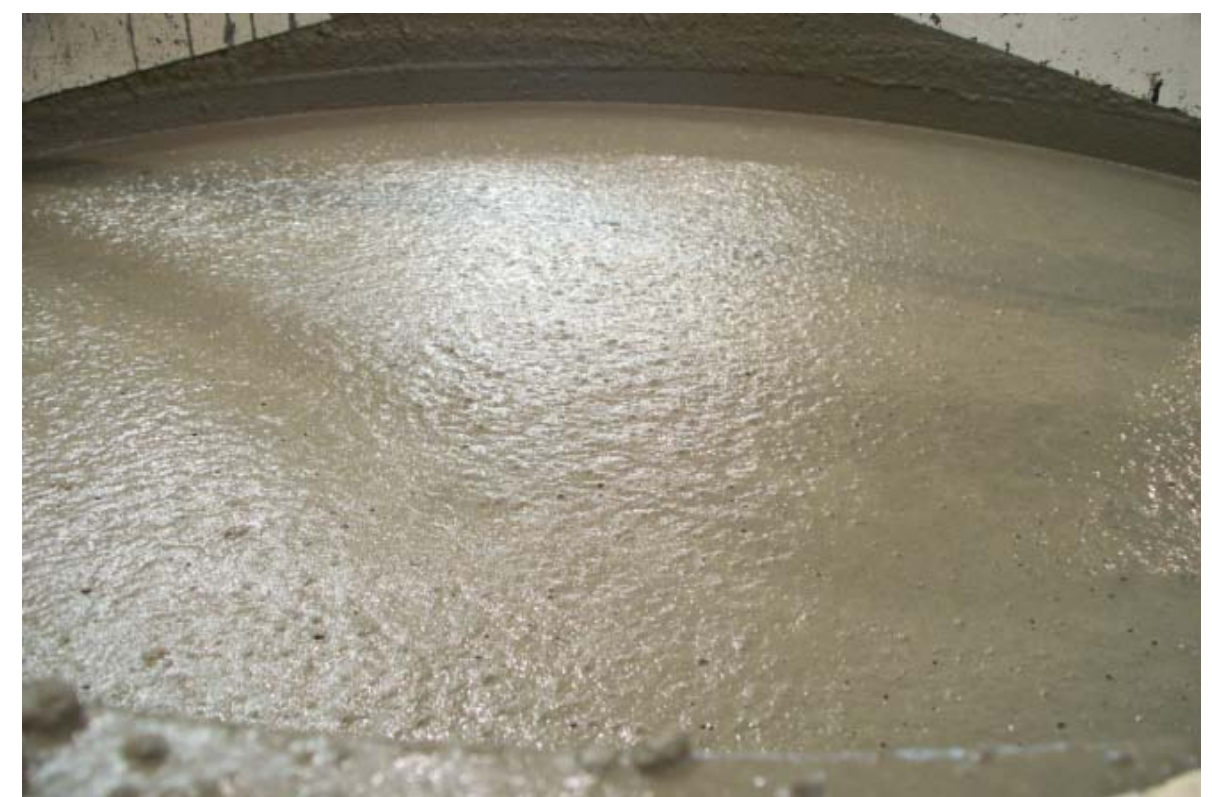

Figure 4.02: Air Bubbles Escaping from a Freshly Batched SCC During a Trial Mix.

\subsection{EXPERIMENTAL PROCESS}

To better understand the migration of air within SCC, a mix design was produced in the laboratory that would have the material requirements as well as the properties associated with producing a foam layer. Upon literature investigation, a company from Taiwan reported seeing a foam layer on the tops of some heavily reinforced piers cast with SCC. They reported that the main reason for this kind of occurrence was that the fine aggregates within the mix might have a fineness modulus that was too high.

The fine aggregate used during this study was natural river sand. An approximately 60 pound sample was sieved to determine the fineness modulus of the sand used. Table 4.01 shows the results from the sieve analysis procedure with the acceptable ASTM limits for percent passing. The highlighted cell shows the calculated fineness modulus from this procedure. The equation for fineness modulus (FM) is given in Equation 2. The grading limits as well as the sieve analysis provided a guide to change the fineness modulus of the natural sand, but remain within the limits. 
Table 4.01: Sieve Analysis of the Natural Sand used during this Study with ASTM Limits.

\begin{tabular}{|c|c|r|r|r|r|r|}
\hline $\begin{array}{c}\text { Sieve } \\
\text { Size }\end{array}$ & Units & $\begin{array}{r}\text { Weight } \\
\text { Retained }\end{array}$ & $\begin{array}{c}\text { Percent } \\
\text { Retained* }\end{array}$ & $\begin{array}{c}\text { Cum. } \\
\text { Percent } \\
\text { Retained }\end{array}$ & \multicolumn{1}{c|}{$\begin{array}{c}\text { Percent } \\
\text { Passing }\end{array}$} & $\begin{array}{c}\text { ASTM Limits } \\
\text { for Percent } \\
\text { Passing }\end{array}$ \\
\hline \# 4 & lb & 0.069 & 0.115 & 0.115 & 99.885 & 100 \\
\hline \# 8 & lb & 7.327 & 12.166 & 12.281 & 87.719 & $95-100$ \\
\hline \# 16 & lb & 11.450 & 19.012 & 31.293 & 68.707 & $80-100$ \\
\hline \# 30 & lb & 17.968 & 29.835 & 61.128 & 38.872 & $50-85$ \\
\hline \# 50 & lb & 17.775 & 29.514 & 90.642 & 9.358 & $25-60$ \\
\hline \# 100 & lb & 5.580 & 9.266 & 99.908 & 0.092 & $5-30$ \\
\hline Pan & lb & 0.055 & 0.092 & 100.000 & 0.000 & $0-10$ \\
\hline Total & lb & 60.226 & & 2.954 & & \\
\hline
\end{tabular}

*Not more than $45 \%$ should be retained between any two consecutive sieves.

$$
F M=\frac{\sum(\text { cumulative percent retained on standard sieves })}{100}
$$

$\mathrm{FM}=$ Fineness Modulus

The sand was altered in such a way to increase the fineness modulus. This was accomplished by withholding material that passed the No. 30, No. 50, and No. 100 in such a way so the ASTM limits were still abided. The fineness modulus of the sand was increased from 2.95 to 3.17 by this process. The sand was then used to produce an SCC mix, denoted as Foam Mix. The mix design and measured fresh properties are given in Tables 4.02 and 4.03, respectively. During the batching of this SCC mix, created to observe air loss or foam generation, the ambient temperature was 79 degrees Fahrenheit and the concrete temperature was the same. 
Table 4.02: One Cubic Yard Mix design for the Observation of Air Migration.

\begin{tabular}{|l|c|r|}
\hline \multicolumn{1}{|c|}{ MATERIAL } & UNIT & FOAM MIX \\
\hline Cement Type 1 & $\mathrm{lb}$ & 600 \\
\hline Slag & $\mathrm{lb}$ & 150 \\
\hline \#8 Crushed Limestone & $\mathrm{lb}$ & 998 \\
\hline \#67 Crushed Limestone & $\mathrm{lb}$ & 428 \\
\hline Natural Sand & $\mathrm{lb}$ & 1369 \\
\hline Water & $\mathrm{lb}$ & 300 \\
\hline w/cm & & 0.4 \\
\hline Air Entrainer & Oz/cwt & 0.05 \\
\hline VMA & Oz/cwt & 2.5 \\
\hline HRWR & Oz/cwt & 6 \\
\hline Retarder & Oz/cwt & 0 \\
\hline
\end{tabular}

Table 4.03: Fresh Properties of the Mix for the Observation of Air Migration.

\begin{tabular}{|l|c|}
\hline \multicolumn{1}{|c|}{ PROPERTY } & FOAM MIX \\
\hline Slump Flow (in) & 25.5 \\
\hline T50 (sec) & - \\
\hline J-ring (in) & - \\
\hline T50 (sec) & - \\
\hline Air Content (\%) & 2.1 \\
\hline Unit Weight (lb/ft ${ }^{3}$ ) & 147.6 \\
\hline
\end{tabular}

The SCC mix was batched in the laboratory and discharged into a five-gallon bucket from the mixer. Three bars were positioned on the top of the bucket in order to agitate the SCC during placement, as shown in Figure 4.03. The agitation of the mix would simulate fresh SCC being cast around reinforcement. This would determine if a foam layer could be reproduced as observed in the RP221 project. The mix was then allowed to remain static to see if air bubbles would come to the surface. The rise of air bubbles to the surface after casting would be indicative a mix instability that is taking place. However, no foam was generated upon the first attempt of producing this mix (Figure 4.04) and only a few air bubbles could be observed rising 
to the surface. The alteration of the fineness modulus of the sand in the batched SCC, during this experiment, did not produce foam.

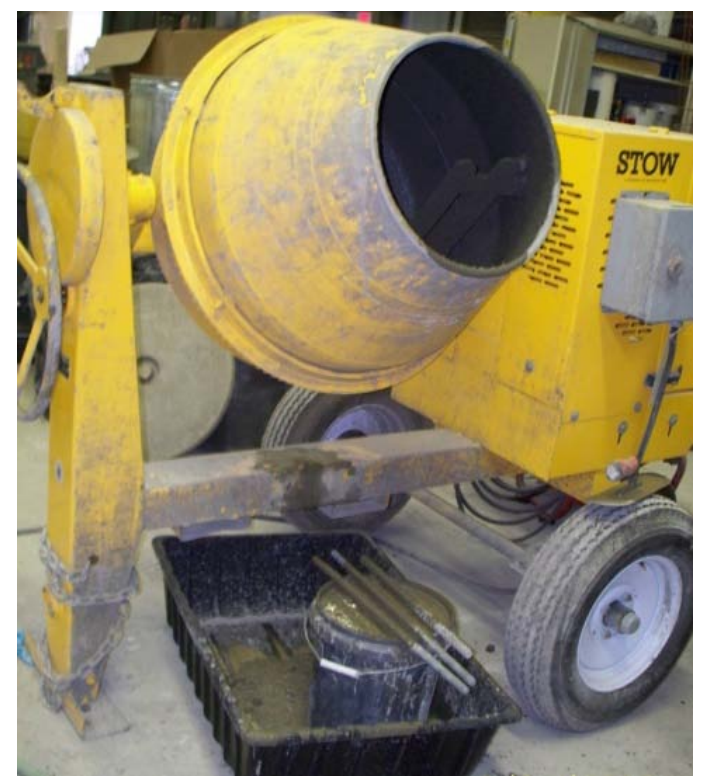

Figure 4.03: Batching of SCC Mix for the Observation of Air Migration.

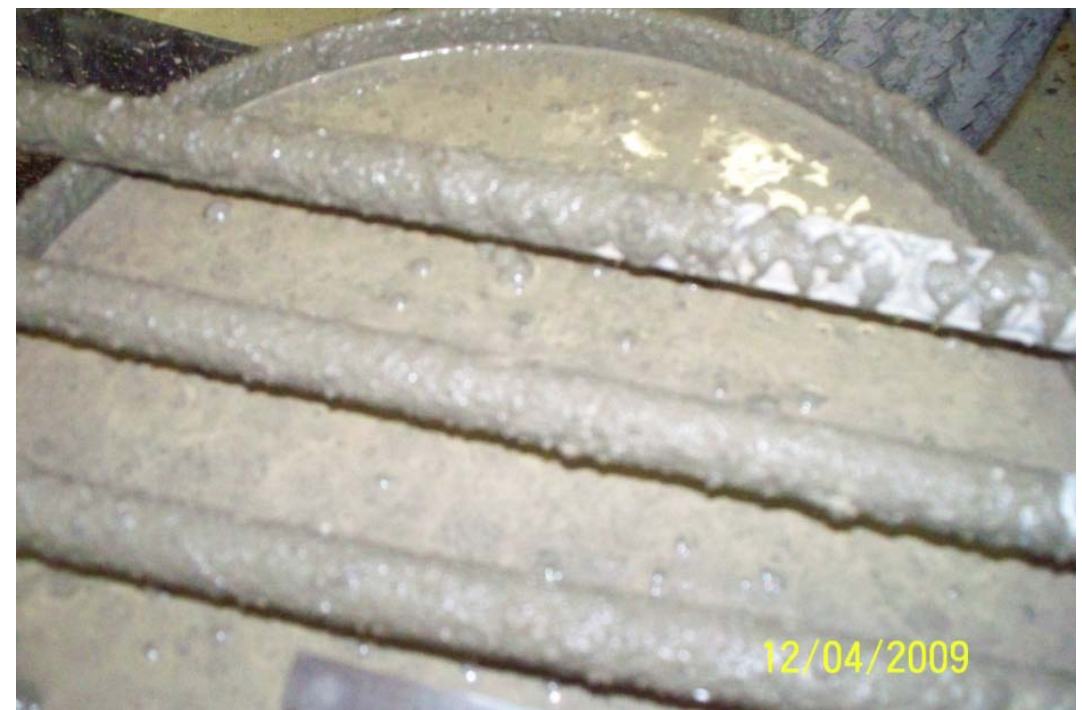

Figure 4.04: Few Air Bubbles Rising to the Surface upon First Batch.

Since the batch was unsuccessful in the generation of foam during casting like was seen in the RP221 project and the observation of air bubbles rising to surface did not take place, it was decided to rebatch the same mix design, but place a larger dosages of HRWR and air entraining 
admixture into the batch. This intentional addition of HRWR and air entrainer was to make the mix less robust than the previous mix by increasing the slump flow and air content. The previous mix had an air content of only $2.1 \%$, so the addition of more air entrainer seemed adequate. Table 4.40 shows how the mix design was altered for the second batch, denoted as Foam Mix 2. The Sika admixture company suggests using a maximum of $12 \mathrm{oz} / \mathrm{cwt}$ of HRWR, which 15 oz/cwt was used during this batch.

Table 4.04: One Cubic Yard Mix design of $2^{\text {nd }}$ Mix for the Observation of Air Migration.

\begin{tabular}{|l|c|r|}
\hline \multicolumn{1}{|c|}{ MATERIAL } & UNIT & FOAM MIX 2 \\
\hline Cement Type 1 & $\mathrm{lb}$ & 600 \\
\hline Slag & $\mathrm{lb}$ & 150 \\
\hline \#8 Crushed Limestone & $\mathrm{lb}$ & 998 \\
\hline \#67 Crushed Limestone & $\mathrm{lb}$ & 428 \\
\hline Natural Sand & $\mathrm{lb}$ & 1369 \\
\hline Water & $\mathrm{lb}$ & 300 \\
\hline w/cm & & 0.4 \\
\hline Air Entrainer & Oz/cwt & 0.3 \\
\hline VMA & Oz/cwt & 2.5 \\
\hline HRWR & Oz/cwt & 15 \\
\hline Retarder & Oz/cwt & 0 \\
\hline
\end{tabular}

Upon discharging the fresh concrete from the mixer, observation of air bubbles rising to the surface were immediately made, Figure 4.05. However, the foam was unable to be replicated as produced during the RP221 study. An interesting discovery was made when the air content was checked and it was the same as the previous batch of $2.1 \%$ The unit weigh was also very similar being $148.3 \mathrm{lb} / \mathrm{ft}^{3}$ for this batch and $147.6 \mathrm{lb} / \mathrm{ft}^{3}$ for the previous batch. The previous batch was at 26 in. in slump flow and this batch was greater than $30 \mathrm{in}$. It is hard to determine the slump flow of a very loose mix because the materials do not continue to spread after a while. 
It then becomes an issue of how much energy was placed into the mix to flow upon raising the slump cone.

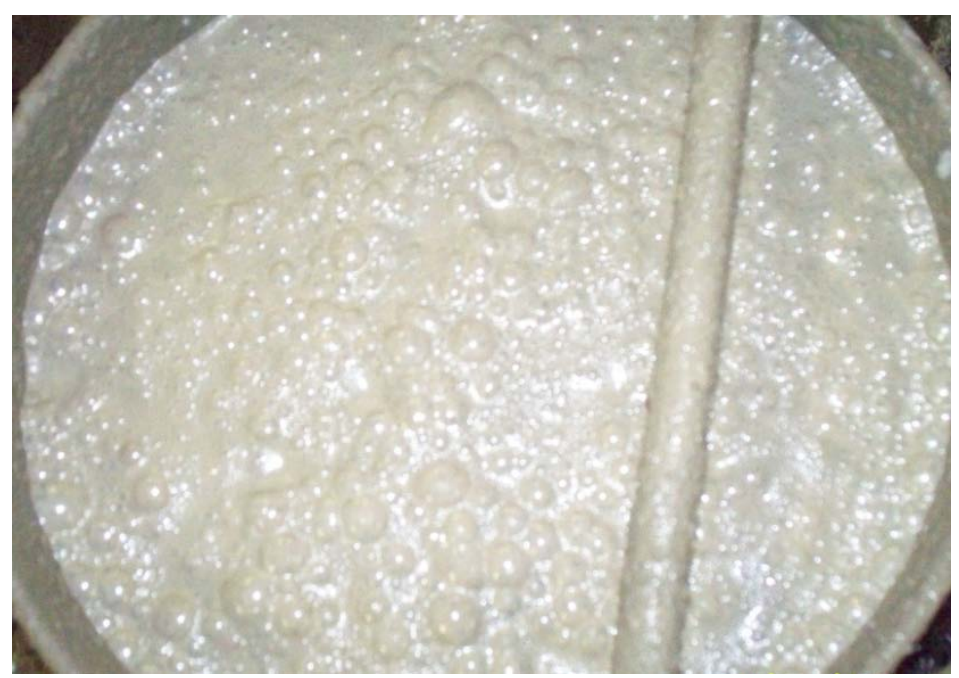

Figure 4.05: Observation of Air Bubbles coming to the Surface of Static Mix.

\subsection{SUMMARY OF FINDINGS}

The migration of air within an SCC mix is a kind of mix instability after placement or when the mix is at rest. However, the generation of air foam during the mixing and actual placing of SCC could be caused by the materials present in the mix or the placement itself. It is important to understand that the air loss of a static fresh SCC mix is probably a sign of a problem in the mix itself. In both cases, the hardened concrete will have a weakened top surface. This layer is prone to scaling, and is able to be scratched off easily. Although oftentimes it would not be feasible to remove the entire pour, at least this top layer must be removed before proceeding, especially if there will be a consecutive pour on top of this one, as in an engineered cold joint. Methods for removing this layer could be by scrapping or grinding it off, but literature from others claim that high pressure water jetting could be used successfully (ZTE, 2006). This is especially a good technique if there are many reinforcing bars protruding out for the next pour and grinding/scrapping is not feasible. 
The experiment performed in this study was able to produce a mix that showed large air bubbles rising to surface of the concrete. These bubbles were not produced by the filling procedure combined with the properties of the mix, as determined as the cause of the air foam in Figure 4.01, and the formwork for that cast element was thin, only a few inches across. However, this experiment did show how an SCC mix can be produced in such a way to show air migration problems. Further investigation will have to be conducted in the future to determine the exact causes of foam on freshly cast concrete surfaces.

The best way to avoid air migration problems is ensuring the robustness of the mix. A robust mix will have very minimal bleed water and development of air that will be prone to migration. An SCC mix that is designed to have a slump flow of 24 inches cannot be loosened up to greater spread diameter by simply adding more HRWR without ensuring that the robustness has not been lost. 


\section{CHAPTER 5 - EFFECTS OF HANDLING ON SMALL BATCH PERFORMANCE}

Before the production of a particular mix design can begin, many agencies including the WVDOT require the mix to be evaluated and tested for acceptance. After mix acceptance, the concrete producer is then allowed to batch the mix for the casting of elements. The development of an SCC mix design can be more cumbersome than that of a traditional mix. Often, the SCC mix under development will have to go under extensive laboratory trials to adjust all of the materials for optimization. Laboratory trials are often in a very small volume, a few cubic feet, for example. These trial batches often need to be reproduced several times in such a manner that the handling and batching of the mix is kept constant such that the changes in material properties are not being overshadowed by effects from the aforementioned.

During the RP221 project and this study, there were many failed attempts at producing SCC. The batching of SCC is more sensitive than that of most TVC mix designs. While not following one procedure correctly could drastically alter the finished product. The following chapter explains all of the environmental or human factors that were witnessed to produce unsatisfactory results.

\subsection{AGGREGATES}

The water content and water demand of an SCC mix needs to be very accurate. From Chapter 1 - The Robustness and Loss of Passing Ability of SCC Mixes, it was concluded that a small change in the water content within the mix could change the expected properties. Aggregates when stockpiled tend to have a non-uniform saturation to them. This means that the moisture content of aggregates in one part of the pile could be several percent different than 
those in other parts. The non-uniform water content of aggregates was also experienced in the laboratory while the aggregates were stored in 55 gallon drums.

Aggregates when stored in 55 gallon drums have a tendency to show non-uniform moisture content. This was seen especially among fine aggregate. Usually, aggregates on the top or around the perimeter of the drum seemed to be drier than that within the core. In order to accurately measure the moisture content of aggregates during laboratory testing, a Speedy moisture meter was used. However, if the small 40 gram fine aggregate sample was removed from the top layer of the storage drum, the moisture reading would be different compared to the average moisture content of the entire drum of aggregates. This would not allow for the correct adjustment factor to the mix water of the batch.

In order to improve the outcome of the adjusted water content, the entire fine aggregate amount for the mix at hand, plus a small extra percentage, would be extracted from the drums, placed into the mixer, and allowed to rotate while other ingredients were weighed out for the batch. After the weighing of the other ingredients, the drum was stopped and a sample was extracted and tested using the Speedy moisture meter. By pre-mixing the fine aggregates, more uniform moisture content was observed, which allowed for better representation of the moisture content of the fine aggregates.

Coarse aggregates, when stored in 55 gallon drums, show the same non-uniform moisture content problem, but seem to dry out quicker under laboratory conditions if allowed to be exposed to the air. The coarse aggregates have an additional problem when stored in drums because they are normally coated with a small amount of powder. This powder is a byproduct of its manufacturing process (crushing) or is naturally occurring. When, retrieving coarse aggregates from the drums for batching and during the transportation of the drums to the 
laboratory, some of the powder settles to the bottom of the drum. The noticeable difference in the fine content at the bottom few inches of the drum can increase the amount of fines in the mix, thereby increasing the water demand and altering the behavior of the mix. To avoid this problem, once the aggregates in the drum were used down to about 6 inches left, no more aggregates were retrieved and a new drum was used.

\subsection{CHEMICAL ADDMIXTURES}

The balance of stability in an SCC mix often rests on the discharging of the chemical admixtures. The tolerances on the amount of chemical admixtures that are put into a laboratory mix needs to be very tight. Not only does the precise amount that goes into a lab mix needs to be known, but a laboratory batch size is sometimes only a few cubic feet in volume. This means that the amount is measured out in milliliters. To measure the admixture quantities, medical syringes were used. The problem that was more importantly noted, however, occurred with improper agitation of the chemical admixtures in their storage container prior to extraction. Some chemical admixtures, especially HRWR and VMA, need to be properly agitated. This ensures that a homogeneous sample of the particular admixture is being represented in the mix. It was found that the best method for agitation was to manually shake the storage buckets vigorously by hand for about 30 seconds. A method that uses the foot to roll the bucket on the

floor, as observed during this study, was deemed unsatisfactory. Admixtures usually have a predetermined shelf life both prior to and after their containers have been opened, and this may also affect their performance. 


\subsection{BATCH SEQUENCE}

The order in which materials are placed with the mixing drum is very important for SCC. When producing SCC in the lab, all materials except for the chemical admixtures were weighed out with a laboratory scale with the capacity of 66 pounds and the accuracy of 0.1 pound. Chemical admixtures were measured using medical syringes and graduated cylinders in the milliliter scale. The fine aggregates were premixed in the mixer to ensure homogeneous moisture content. Representative samples of aggregates were tested for moisture content using a Speedy Moisture Meter and the mix design was adjusted accordingly. The mix water was acquired from the tap in the laboratory and the temperature was kept close to 75 degrees Fahrenheit. The following list shows the batch sequence used during the laboratory testing during this study.

1. The mixer is primed with a mixture of cement and water that is representative of the current mix’s w/cm. The mixer was filled with this mixture, the drum was rotated, and the mixture allowed to coat all of the internal surfaces of the mixer. Remaining fluid was drained.

2. The mixer was then charged with coarse aggregates, fine aggregates, $20 \%$ of the mix water, and air entraining admixture. The mixer was run until the aggregates were homogeneous and uniformly moistened by the water. The mixer was continuously run for about 2 minutes after visual determination of homogeneity.

3. Next the cement/cementitious material and about $60 \%$ of the mix water were charged into the mixer. During charging, the mixer was continuously run and small amounts of water and cement/cementitious material were charged, altering between the two to cut down on dust from the cement/cementitious material.

4. After all of the cement/cementitious material and water from step 3 were charged, the retarding admixture (if used) was dispensed and the mixer was continuously run for 3-5 minutes.

5. Lastly, the VMA and remaining $20 \%$ of the mix water was dispensed into the mixer while continuously running. The remaining amount of the mix water was dumped slowly 
around the lip of mixer (carefully not to spill out of the mixer) to wash material down into the mixer that was not being mixed because it is not within the fluid body. The HRWR was added in stages and the mixer run for another 3-5 minutes.

After the batching of the mix was complete, the mixer was stopped momentarily to acquire samples for testing, but the mixer was set to run slowly between tests. This was the sequence for batching SCC in the laboratory during this study. However, when batching in a truck or central plant mixer the sequence will vary. Many of the chemical admixtures used provide documentation including a suggested sequence of when to add them into the mix. Mainly, the chemical admixtures of HRWR and VMA are normally batched last because of their tendency to lose affect after some time. It was observed in the field that a ready-mix supplier actually withheld the addition of these admixtures until the truck arrived to the site. The admixtures were then batched using household measuring cups by a qualified person (usually a representative from the admixture supplier or their trained producer) on site. When SCC becomes more popular, the admixtures could be premeasured and the responsibility of dispensing them into the truck is the truck drivers', who are trained to add them on site.

\subsection{MIXER CAPACITY}

The capacity of the mixer can often be the attributing factor of the maximum amount of SCC that can be batched at one time. Since SCC is much more fluid, after batching of the chemical admixtures, it has the tendency to slosh around within the mixer and could splash out of the mixer if too much is batched at once. This would not only mean that the amount produced should be less, but could throw off the properties of the mix if full agitation cannot be achieved. Ready-mix suppliers often will haul less SCC in their trucks compared to traditional vibrated concrete to prevent loss and for the safety of the truck traveling (NRMCA, 2004). 


\subsection{TEMPERATURE}

The effect of temperature on the production of SCC was observed in the laboratory. The rate of evaporation in the laboratory, being a low humidity environment, or the effect of temperature on certain admixtures most likely is contributors to this phenomenon. Changes in the fresh properties are among the greatest notable difference as shown in the results from Task 1 (Chapter 2).

\subsection{FRESH PROPERTY TESTING}

The testing of SCC for its fresh properties is noticeably different than that of traditional vibrated concrete. These tests are outlined by ASTM test methods. However, a few observations were noticed during the experiments conducted during this study. For small batches, fresh SCC after being discharged from the mixer should not be redeposited back into the mixer. This is due to the fact that it is impossible to redeposit all of the fine material back into the mixer, as well as the fact that the air content likely changes with the handling. Another key observation that was noticed is that during the barrage of fresh tests performed during this study, the moisture of the surface on which certain tests are performed is important for some mixes. The board predominately used during the slump flow and j-ring tests needs to be dampened before any tests are performed on it. However, more importantly, the wetness of the board needs to be kept minimal and uniform for all tests conducted. If the board is much wetter for one particular test, the residual water can act like a lubricant and skew the test results.

\subsection{SUMMARY OF FINDINGS}

Based on the findings from the literature review as well as the first hand experiences in the laboratory, a set of guidelines has been established for the successful batching of small mixes 
of SCC. When establishing an SCC mix in the laboratory, precautions must be taken in such a manner such that the mix can be reproduced. Environmental factors such as the ambient temperature of the laboratory, temperature of the mixing water, and moisture contents of the coarse and fine aggregates must be taken into consideration carefully. Handling procedures, batch sequencing, and preparation of the test procedures are important as well. The degree of accuracy of the test equipment and the material measurement systems need to be more sensitive due to the fact that only small amounts of concrete can be produced at one time. The duration of mixing needs to be kept constant. Mixing a batch of SCC for an extensive amount of time can allow the hydration process to heighten thus lessening the effect of some of the chemical admixtures that promote the mixes fluidity. However, hydration control admixtures can help this. During Chapter 3 - Vibration of SCC Mixes, the handling procedure from the point of discharge to the filling of the segregation column actually induced segregation into the mix. A consistent method of batching and testing SCC within the laboratory needs to be established in order to measure the true properties of the mix.

It is also important to note certain safety aspects while batching laboratory SCC. The laboratory is often a small confined area. The mixing process stirs up lots of particulate matter that seems to be airborne for long periods of time. Due to SCC containing cement, fly ash, and/or slag particulate mask should always be worn. The mixer and filling of test apparatuses with fluid SCC can splash more easily than TVC, so the wearing of eye protection is required. Also, the wearing of long pants, shirts, and gloves can keep material off of the skin. The wearing of personal protective equipment (PPE) is often required by employers but often not enforced. Personal experiences suggest that even if someone working in the laboratory relinquishes their right to wear these devices, it is still important to drink lots of fluids during laboratory work. 
The increased amounts of physical duress and the moisture absorbing environment, due to cementitious materials present, promote dehydration. 


\section{CHAPTER 6 - VARIABILITY OF SCC AS BATCHED IN A BATCH PLANT}

By taking field trips to ready mix and precast plants, producing or attempting to produce SCC, a better understanding about specific testing and problems that take place in the field was achieved. Since many of the concrete producers are new to the batching of SCC in this region, firsthand knowledge was gained. The following chapter will go into the specific fresh and hardened property tests that these producers use to assess the quality of SCC. SCC, being harder to produce for inexperienced persons than traditional vibrated concrete, is more susceptible to variability.

One of the main goals of this study was to better understand the properties of SCC in order to aid in producing specifications and guidelines for the use of SCC in WVDOT applications. Since SCC is not widely used, most of the pre-cast/ready-mix suppliers visited were actually producing SCC for the first time for production. The expansion of the use of SCC in West Virginia was actually a by-product from this and other research studies occurring simultaneously.

\subsection{READY MIX EXPERIENCES}

The first ready-mix supplier that was visited was J.F. Allen (Alcon) in Morgantown, WV. Regionally, they supply a wide range of masonry supplies and also have a transient ready-mix site. Alcon was interested in beginning to produce SCC. Alcon uses BASF admixtures and was producing an SCC mix design that could be used in caisson construction. A visitation was set up and researchers were able to witness the batching of an SCC mix using a ready-mix truck. This was a good opportunity because not only were representative from the concrete company there, 
but also representatives from the admixture supplier were present and able to answer many questions and give advice about the batching, testing, and delivery of SCC.

The second ready-mix supplier that was interested in the production of SCC in Morgantown, WV was Central Supply Company. Central also supplies many concrete-related products in the region and has a transient mix setup. Central's batch plant uses Euclid admixtures. Since the beginning of this study, Central has developed a successful SCC mix design and has also poured a large job at a ski resort in West Virginia using their SCC mix.

Central Supply acted as a subcontractor for Bilco Construction Company in pouring the caissons for an abutment foundation in Elkins, WV. Central was able to send aggregates from their Elkins batch plant to Morgantown to be used in trial batches produced by WVU researchers. The job also called for the SCC to be poured in a wet shaft condition, so a special placement technique known as a tremie pour had to be utilized. Since Central was fairly new with SCC production, a model caisson was constructed on the WVU campus to demonstrate the effects of the properties of SCC as it was pumped through a concrete pump and placed in a tremie fashion. The first attempt at the model caisson was unsuccessful. The mix design that was proposed called for a HRWR of one particular type, but the incorrect type was added. The mix design, for the caissons, was produced with a joint collaboration of WVU, Central Supply, and Euclid Chemical. WVU researchers produced the mix in the laboratory and used a HRWR of model Eucon 1037 which was the specified model, while Central used model SPC, during the first trial of the model caisson, which had more water reducing capabilities than the type called for. Chemical admixtures even from the same company cannot be used interchangeably. The SCC, produced with the wrong model SPC was visually very unstable, with large segregations and bleeding. The observation of small air bubbles rising to the surface was also observed. 
Normally, an SCC mix can be adjusted by the use of VMA, but if the mix is too far outside the limits it cannot. For this demonstration, the truck had to be rejected.

The next meeting with Central was at their ready-mix plant in Morgantown at the Westover Industrial Park. This field trip to visit their plant was to ensure that the mix would be proportioned correctly, with acceptable fresh properties, and to demonstrate the change in the properties between the pumped and non-pumped SCC. From the literature review of other research agencies, SCC can be pumped and this is often the preferred method of discharge during casting. The demonstration went very well showing that SCC produced by Central could be pumped, and the fresh and hardened properties were acceptable after these actions. Once the demonstration of the pumpability of SCC at Central's plant was successful, Central delivered their SCC mix for testing and casting of the model caisson to the WVU Structures Lab. The mix, upon delivery, was able to pass the fresh properties set forth for acceptance.

After the mix qualification of their SCC mix for the WVDOT, the final meeting with Central was actually at the Stalnaker Run Bridge Project during the casting of the caissons. Since the WVDOT does not currently have an SCC specification, a special provision was written for this project. The amount of concrete that each of the three caissons would require was about 8 cubic yards. This would mean that each of the caissons would take approximately one truckload of concrete, although a fourth truck had to be ordered due to a shortage of concrete to finish the project. Overall, the delivery of the SCC went smoothly with minimum delays.

All of the trucks were accepted by the WVDOT to be used on site. The concrete when delivered to the site did not have the addition of HRWR and VMA added to the truck. This was done on site by a qualified representative of Central Supply. After the addition of the HRWR and the VMA, the fresh properties of the mix were evaluated for acceptance. 
The first truck needed to be adjusted for air content, but was acceptable once this was refined. The concrete for the caissons was pumped and fed into a tremie pipe which filled the wet shaft caissons. The static segregation was also tested, by column technique, on the first truck and found to be zero percent. Table 6.01 shows the measured fresh properties of the SCC mixes delivered to the Stalnaker Run Bridge replacement project. The performance criteria for the fresh properties was required to be the following: air content 4.5 - 7.5\%, slump flow 19 - 23 inches, VSI less than 1.5, $\mathrm{T}_{50}$ time 2 to 7 seconds, and the J-ring difference from the slump flow less than 1.5 inches. The properties of all of the trucks passed the acceptance criteria and did not show a large variation. It seemed that by this point in SCC production, the concrete producer had become very comfortable in the batching of their mix design and began to understand how the chemical admixtures affected the mix. Truck 3 and 4 had relaxed fresh property testing.

Table 6.01: Fresh Properties of the Trucks during the Caisson Casting at Stalnaker Run.

\begin{tabular}{|c|c|c|c|c|}
\hline & Truck 1 & Truck 2 & Truck 3 & Truck 4 \\
\hline Slump-Flow (in) & 19.5 & 19 & - & - \\
\hline J-Ring Value (in) & 1.25 & 0 & - & - \\
\hline T50 (sec) & 2.2 & 4.55 & - & - \\
\hline Air (\%) & 6.8 & 7 & 5.5 & 6.5 \\
\hline Unit Wt (lb/ft3) & 141.00 & 140.92 & 143.88 & - \\
\hline Concrete Temp (F) & 86 & 85.5 & 79 & 85 \\
\hline
\end{tabular}

\subsection{PRECAST EXPERIENCES}

The first precast plant, Sidley Precast in Youngwood, PA, was visited in order to see how SCC was used in a precast setting. This plant uses a large 12 cubic yard central mixer that is fully automated. The hopper system contains eight compartments that could hold different 
aggregate materials. This producer uses Type III cement and often uses slag in its mixes. Upon visitation, slag was not utilized in the batch produced since its price at the time was higher than cement. Sidley normally fabricates double T girders for parking garages, solid and hollow core slabs, and stadium seating/staircases. The transport of the SCC from the central mixer to the casting beds was accomplished using common front discharge concrete trucks.

At Sidley, onsite quality-control personnel measured the fresh properties of the mix. The mix, on the day of visitation, had a slump flow of 25.5 inches, a temperature of 78 degrees Fahrenheit, an air content of 3.4\%, and a unit weight of $139.2 \mathrm{lb} / \mathrm{cu} \mathrm{ft}$. A few observations were noted during this trip; first was that the SCC mix seemed to lose its workability relatively quickly. Within one-half hour after batching the slump flow reduced from 25.5 inches to about 12 inches. However, this loss of slump flow came well after the very quick discharge of the concrete into the slab form. Also, it was common practice of this precast plant to vibrate the SCC. This was mainly due to the fact that many of the elements cast at this plant, especially double tees, have very dense reinforcement.

The second precast plant that was visited was Eastern Vault in Princeton, WV. Eastern Vault was chosen by Bilco Construction Company to produce the precast pretensioned box girders for the Stalnaker Run Bridge to be built in Elkins, WV. Eastern Vault had never produce SCC before the beginning of this study. WVU researchers were coordinating with the WVDOT during the SCC mix qualification for the beams. Eastern Vault has a central pan-type concrete mixer that has some limitations. The mixer is fed by silos, one for Type III cement, one for natural silica sand, and one for crushed limestone \#57 coarse aggregate. Since the project specification limited the maximum aggregate size for the mix in that all aggregates were to pass a 3/4” sieve, they had to replace their stockpile of \#57 aggregates with \#67 for this project. 
WVU researchers coordinated with Eastern Vault to produce a successful SCC mix design for qualification. Eastern Vault was able to purchase or fabricate many of the testing apparatuses needed for the fresh tests. The researchers visited their plant after they had switched to a \#67 coarse aggregate and became familiar with producing their SCC mix. For this batching day, the precaster would demonstrate that they could produce their SCC mix design and pass the following fresh property acceptance criteria.

Upon visitation, the fresh properties were recorded on a day they were attempting to produce their SCC mix to pass a particular set of performance criteria. Since the mixes produced, Table 6.02, were going to be used for a WVDOT mix qualification, the performance criteria were held in tight tolerance. However, the quality control in most precast plants is withheld to very high standards. The air content had to fall within $4.5-5.5 \%$, the slump flow between 23 - 24 inches, $T_{50}$ between 2 to 7 seconds, VSI less than 1, J-ring difference between slump flow less than 1 inch, and the static segregation column had to be below $12 \%$. Batches 1 through 5 were not able to satisfy the air content requirements. Finally, the last batch displayed properties of an acceptable SCC mix.

Table 6.02: Fresh Properties of SCC Produced at a Precast Plant During Trial Batches.

\begin{tabular}{|c|c|c|c|c|c|c|}
\hline Time & $\mathbf{2 : 3 8}$ & $\mathbf{3 : 0 8}$ & $\mathbf{3 : 4 0}$ & $\mathbf{4 : 0 0}$ & $\mathbf{4 : 2 0}$ & $\mathbf{4 : 5 5}$ \\
\hline Slump-Flow [in] & 25 & 17.75 & 21 & 24 & 24.75 & 23.25 \\
\hline T50 [sec] & - & - & - & - & - & 2.15 \\
\hline J-Ring [in] & - & - & - & 2.5 & - & - \\
\hline T50 [sec] & - & - & - & - & - & - \\
\hline Air Content [\%] & 4 & 4 & 6.6 & 6.4 & 6.4 & 5.5 \\
\hline Unit Weight [pcf] & 141.4 & 143.4 & 137.2 & 138.4 & 138.6 & 139.8 \\
\hline Ambient Temp [F] & 82.4 & 80.8 & 81.7 & 82.9 & 82.9 & 83.2 \\
\hline Concrete Temp [F] & 79.8 & 82.7 & 83.5 & 83.4 & 84 & 83.5 \\
\hline
\end{tabular}




\subsection{SUMMARY OF FINDINGS}

The batching of an SCC mix is certainly more detailed than the batching of most TVC mixes. After the concrete producer learns how the fresh properties of their new mix design are controlled by materials and chemical admixtures, they are then able to increase the quality of the mix. When making an SCC mix, it is often good to practice batching, since the making of SCC is more dependent on outside factors. Sufficient practice batches should come well before the production of SCC for element casting.

It was evident from some of the producers visited and the many others that were read about or talked to, that some producers enjoy doing things the way they have always been done and are not apt to change. They do not like to adopt new technologies, take risks that could potentially ease production and reduce labor. For these companies, the old way of making concrete may be the best. They will not have to abide by new specifications, learn how to perform test methods associated with SCC, and potentially save money.

However, there are many more concrete producers that see SCC as a way to solve many construction and placement issues in the field. SCC when implemented in a precast plant can easily reduce the compaction efforts needed and therefore reduce the labor force needed on the casting bed or inside of formwork during the pour. These men could be doing other operations such as preparing for the next pour or demolding a previously cast element. The contractor that cast the caissons at the Stalnaker Run Bridge praised SCC after the pour. This is because a caisson, being a drilled shaft into the earth and commonly heavily reinforced, can be very difficult to consolidate. Sidley Precast casts about $90 \%$ of their products using SCC. The benefit was obvious for this precast producer to use SCC.

The implementation of SCC in the state of West Virginia for the use on DOT jobs should happen relatively soon. However, the success of this product in the field will have to be the 
collaboration between the contractor and the concrete producer. In the precast plant, it will be up to the particular company because they will be the ones who will have to purchase the equipment to be able to produce an SCC mix. Some precasters have inadequate or outdated equipment that may cost too much to upgrade. For the ready-mix companies they may be able to produce SCC fairly easily, but it will have to be requested by the contractor. So in turn, if the concrete supplier is confident in their ability to produce SCC, but the contractor is not aware of the product then SCC may still go unused.

The production of SCC by concrete companies was observed to be very feasible. One of the ready-mix plants produced an SCC mix to a customer because they had a job that vibration was not feasible. SCC could also be supplied to customers for caisson construction because casting of this type of member is often very difficult to vibrate. The suppliers of SCC, during this study, learned about the product through self-investigation, but often obtained help from their admixture supplier. Of the companies visited, three different admixture suppliers were represented. 


\section{CHAPTER 7 - EFFECTS OF SCC IN FORMWORK}

The effect of lateral pressure of SCC in its plastic state on formwork compared to that of traditional vibrated concrete is currently of great interest among SCC researchers. SCC, being more fluid than traditional vibrated concrete (TVC), has the potential of exerting more pressure on vertical or inclined formwork surfaces than that of its predecessor TVC. Maximum theoretical lateral formwork pressure can be denoted by the fundamental equation for hydrostatic pressure of liquids.

$$
p=\rho * g * h
$$

$\mathrm{p}=$ the resulting pressure $(\mathrm{psi})$

$\rho=$ mass density of the fluid $\left(\mathrm{lb} / \mathrm{in}^{3}\right)$

$\mathrm{g}=$ gravitational constant $\left(\mathrm{in} / \mathrm{sec}^{2}\right)$

$\mathrm{h}=$ head height above point of pressure (in)

However, it is widely accepted that the lateral formwork pressure exerted by a TVC would be significantly less than full hydrostatic taking into consideration the height of placement. This is primarily due to the fact that this type of concrete does not act as a true Newtonian fluid. The longer concrete sets in a particular form, the longer the hydration process is able to occur and therefore will support itself, no longer possessing the ability to exert more horizontal force on formwork surfaces.

Traditionally vibrated concrete needs to be consolidated properly into its respectable formwork. Internal wand type vibrators are common amongst the concrete industry and are used 
for consolidation. The vibration of concrete often possesses a threat to the structural integrity of formwork components. Vibration causes concrete to become fluid and able to flow into congested or small areas of the formwork where normal slump concrete would not normally flow otherwise. However, the action of vibration and the extra fluidity of the concrete place a high lateral pressure on formwork. It has been noted that for a 4" slump concrete the lateral pressure exerted through the vibration process could easily be between 50 to $80 \%$ of the theoretical hydrostatic pressure (Khayat \& Mitchell, 2009).

The thixotropic nature, flowability, and casting rate are all parameters in the amount of lateral formwork pressure exerted during the casting of SCC. It is expected that the formwork pressure of SCC, even with the absence of vibration for compaction, will be higher than that of traditional vibrated concrete. Direct comparison of the formwork pressures of SCC and traditional concrete can be accomplished because the theoretical maximum hydrostatic pressure for two identical elements cast with SCC and TVC are almost the same. This is simply because the assumed hydrostatic pressure is only dependent on the height of the formed element and the unit weight of the liquid. The unit weight of SCC and TVC are usually close to one another.

Currently, many research studies have been trying to determine the exact differences between the lateral formwork pressure rise and decay of SCC and TVC, so that guidelines and predictive models can be created in order to inform users of SCC the proper way to construct and support formwork during construction. Other formwork considerations for the use of SCC may also include the better sealing of form joints in order to reduce or eliminate fluid paste from exiting forms during casting. 


\subsection{LITERATURE REVIEW}

Many research studies have been devising ways in order to test the relationship between SCC and TVC through both laboratory and field testing of formwork pressure. This is mainly due to the fact that few guidelines and specification have been adopted. Provisions of the current ACI Manual of Concrete Practice do not address SCC formwork, but recommend that there should be experimental data to back any method of designing formwork for SCC. If no experimental data exists, then formwork design should be developed assuming full hydrostatic pressure (ACBM, 2007). The Eurocode also specifies that full hydrostatic pressure be accounted for. However, German standards for formwork (DIN 18218) have been recently been updated to include SCC. Their equations are dependent on the unit weigh of the fresh concrete, setting time, and the rate of concrete placement (Concrete International, 2010).

There are many factors of SCC that attribute to the formwork pressure, such as the stiffening behavior of SCC, casting rate, height of formwork, temperature, and disturbances or vibration. However, there is no standard test method to easily evaluate the exerted formwork pressure of an SCC.

The laboratory testing of SCC commonly uses circular PVC sections that can be fabricated in such a way to resemble mock columns. The heights of these columns normally are between 3 and 12 feet in height and 8 inches in diameter is the popular size (Khayat et al., 2007). Researchers have also tried to build pressure vessels to simulate the casting of a tall element (Concrete International, 2010). A popular way to measure the lateral pressure on the formwork is through the use of flush mount diaphragm pressure transducers. Flush mount diaphragm pressure gauges with a mechanical dial reading show promise to be used in the field to monitor pressures during construction (ACBM, 2007). 


\subsection{EXPERIMENTAL PROCESS}

Experimentation was carried out to determine if the height of the placement, casting rate, and fresh properties of SCC versus the elapsed time has any effect on the measured formwork pressure of test columns. For this experiment, two test columns, one short and one tall, were erected and hosted ports for flush mount diaphragm pressure transducers to be placed for the recording of pressure measurements. The columns were constructed out of 8 inch diameter SDR35 piping; they were split longitudinally for easier de-molding of the concrete after casting, allowing the column to be reused. Large steel hose clamps were used to hold the two halves together during experimentation and a cap fitting was placed on the bottom of the column. To ensure that no paste was lost during casting, the two halves of the column were caulked together. The piping was lubricated with standard motor oil to provide for a form release agent in order for the columns to be easily de-molded after the tests. Figure 7.01 shows a schematic of both the tall and short pressure column setups.

The short column that was fabricated had a head height above the sensor of 47 in. while, the tall column was made by placing two short columns together using a union. When erected, the tall pressure column housed two pressure sensors, designated as the top sensor, which has a head height above the sensor of 47 in, and the bottom sensor, which had a head height above the sensor of 105 in. The pressure transducers, with an accuracy of $\pm 0.5 \mathrm{psi}$, had an output of 50 $\mathrm{mV} / \mathrm{psi}$ plus a $500 \mathrm{mV}$ offset voltage and a sensing range of 0 - 100 psi. The diameter of the sensing head of the pressure transducer was 0.75 inch. A picture of the transducer used is shown in Figure 7.02a. Figure 7.02b shows a typical setup of a short pressure column prior to casting. 

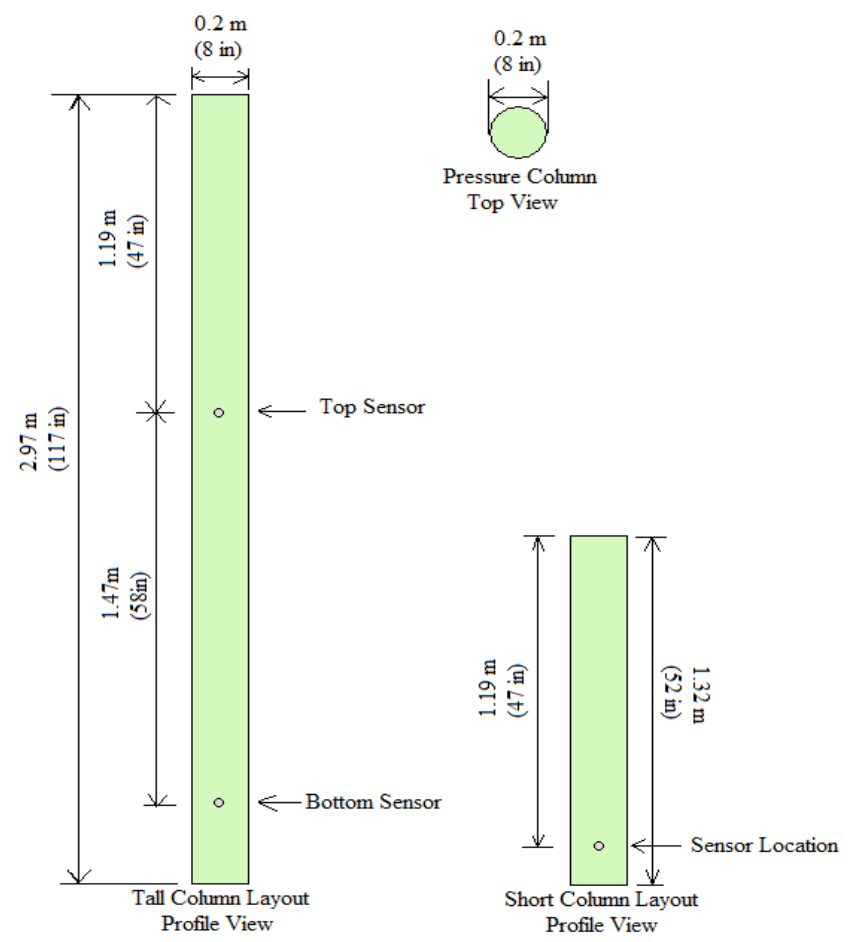

Figure 7.01: Schematic of the Short and Tall Pressure Column Setups.

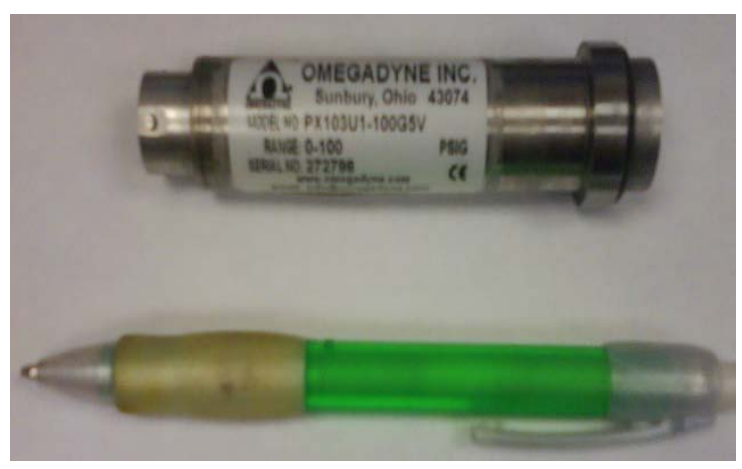

(a)

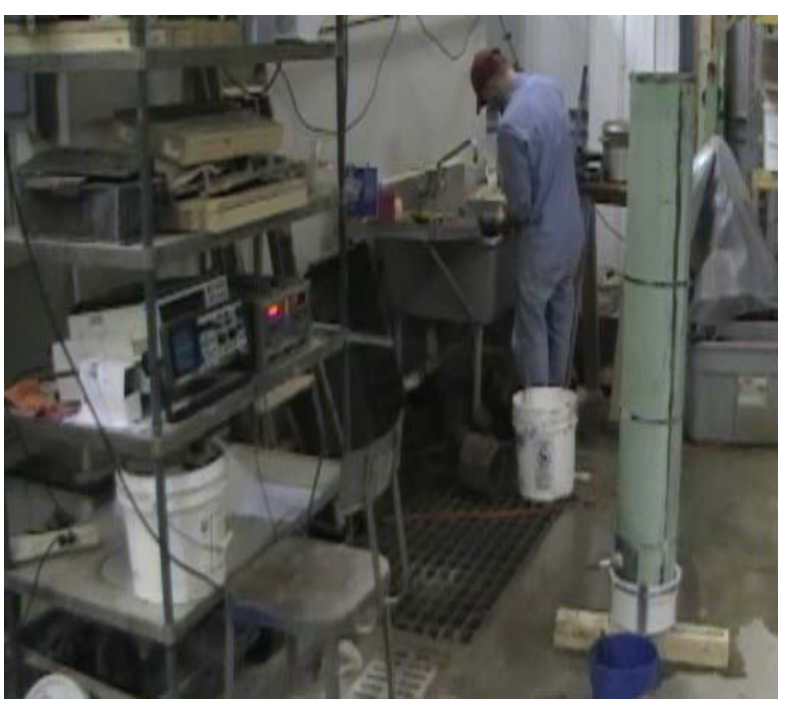

(b)

Figure 7.02: (a) Diaphragm Pressure Transducer. (b) Typical Short Pressure Column Setup.

During the experimentation using the short pressure columns, either SCC or TVC was produced, as applicable, and placed into the columns at different filling rates. Prior to filling the columns, the fresh properties of the mixes were measured. Among filling the columns, a power 
supply provided the proper input voltage of 24 to 32 volts DC (normally set to $28 \mathrm{~V}$ ) to power the sensors and a data acquisition system recorded the voltage outputs of the sensors to be converted into the pressure reading. The data acquisition system would continually record the output sensor voltages until the lateral pressure of the columns stopped.

\subsection{SHORT PRESSURE COLUMNS}

In total, four pressure columns were tested using SCC and two were tested using TVC. To test the experimental setup, the short column with pressure transducer was filled with water for a calibration check. The TVC used was a WVDOT class B-modified mix. The goal of this part of the experimentation was to compare the maximum lateral pressure between SCC and TVC in a short cast element.

\subsubsection{SHORT PRESSURE COLUMN CALIBRATION}

Prior to the testing of the short columns, a calibration method was used. To ensure that the column setup and the pressure transducer were working correctly, the column was filled with water and the pressure from the sensor was recorded. The results from the short column water test are shown in Figure 7.03 below. 


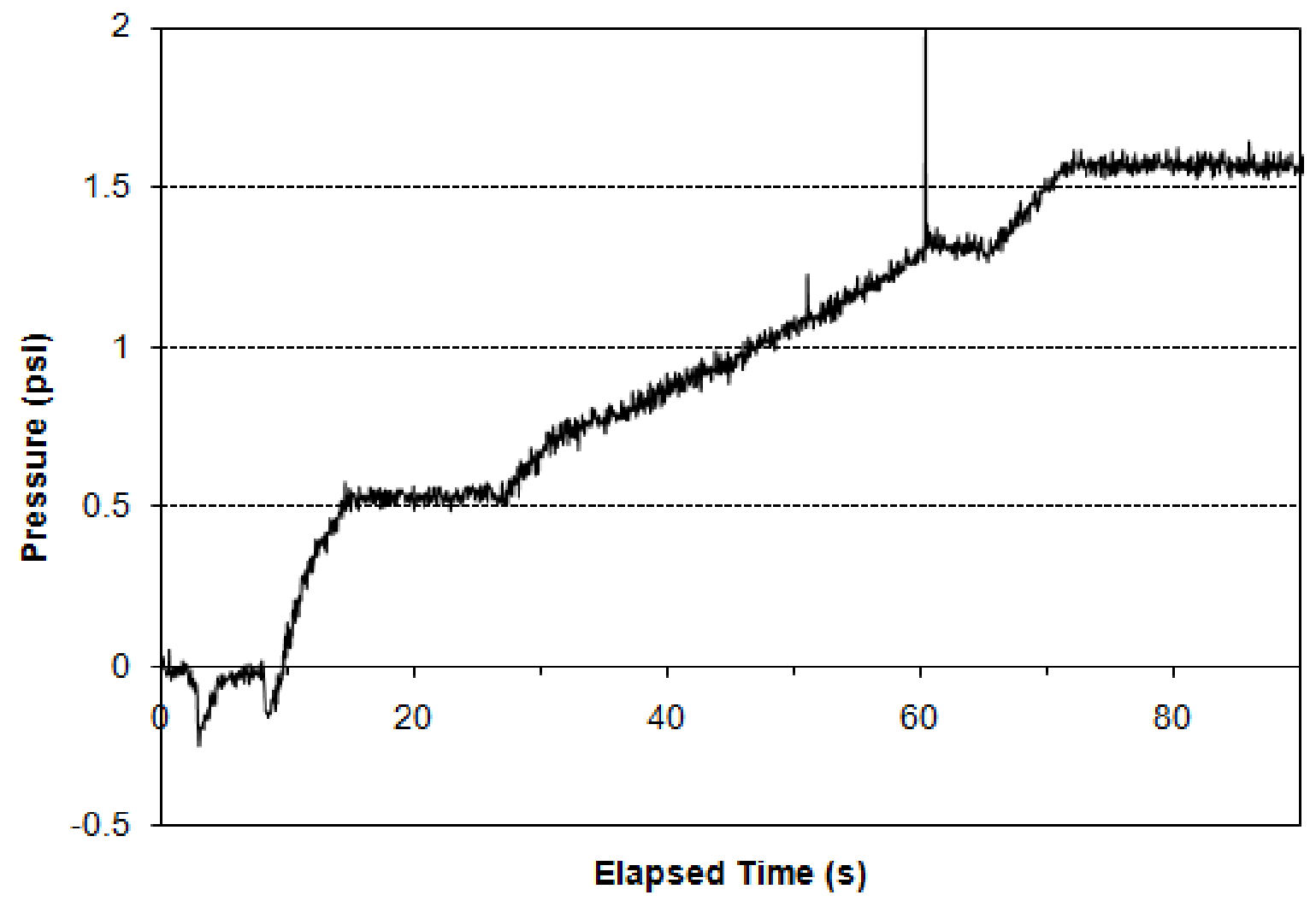

Figure 7.03: Testing of the Short Pressure Column with Water.

It can be seen from the figure that the maximum pressure recorded during the short column water test was about 1.6 psi. By calculating the pressure, using the above formula, the calculated pressure would be 1.69 psi. This is using the head height of 47 inches for the short pressure column and the STP unit weight of water of $62.4 \mathrm{lb} / \mathrm{ft}^{3}$. This shows that the short pressure column can give an accurate estimation of the lateral pressure exerted by a fluid.

\subsubsection{SCC SHORT COLUMN 1}

An SCC mixture with the material quantities shown in Table 7.01 was batched and cast in the short column. Before filling the column with fresh SCC the fresh properties of the mix were measured and are displayed in Table 7.02. To transfer the concrete from the mixer drum to the 
formwork column, five-gallon buckets were filled and placed into the column. The total filling time for this column was about 3 minutes, which translates to a casting rate of $87 \mathrm{ft} / \mathrm{hr}$. The ambient temperature of the laboratory during this casting was estimated to be 70 degrees Fahrenheit.

Table 7.01: One Cubic Yard Mix Design for SCC Short Column 1.

\begin{tabular}{|l|c|r|}
\hline \multicolumn{1}{|c|}{ MATERIAL } & UNIT & SCC SHORT 1 \\
\hline Cement Type 1 & $\mathrm{lb}$ & 550 \\
\hline Fly Ash & $\mathrm{lb}$ & 236 \\
\hline \#8 Crushed Limestone & $\mathrm{lb}$ & 742 \\
\hline \#67 Crushed Limestone & $\mathrm{lb}$ & 685 \\
\hline Natural Sand & $\mathrm{lb}$ & 1294 \\
\hline Water & $\mathrm{lb}$ & 282 \\
\hline w/cm & & 0.36 \\
\hline Air Entrainer - MB AE 90 & Oz/cwt & 1.3 \\
\hline VMA - UW 450 & Oz/cwt & 3 \\
\hline HRWR - Glenium 3030 NS & Oz/cwt & 10.7 \\
\hline Retarder - Delvo Stabilizer & Oz/cwt & 2 \\
\hline
\end{tabular}

Table 7.02: Fresh Properties of SCC Short Column 1.

\begin{tabular}{|l|c|}
\hline \multicolumn{1}{|c|}{ PROPERTY } & SCC SHORT 1 \\
\hline Slump Flow (in) & 25.0 \\
\hline T50 (sec) & 1.78 \\
\hline J-ring (in) & - \\
\hline T50 (sec) & - \\
\hline Air Content (\%) & 2.6 \\
\hline Unit Weight (lb/ft $\mathbf{3}^{3}$ ) & 149.2 \\
\hline Ambient Air Temperature $\left.\mathbf{(}^{\mathbf{0}} \mathbf{F}\right)$ & 70 \\
\hline
\end{tabular}

The maximum recorded pressure was $3.8 \mathrm{psi}$ and the theoretical hydrostatic pressure was calculated to be 4.06 psi. So, this short column reached $93.6 \%$ of full hydrostatic pressure. The pressure recordings for the first hour are shown in Figure 7.04. 


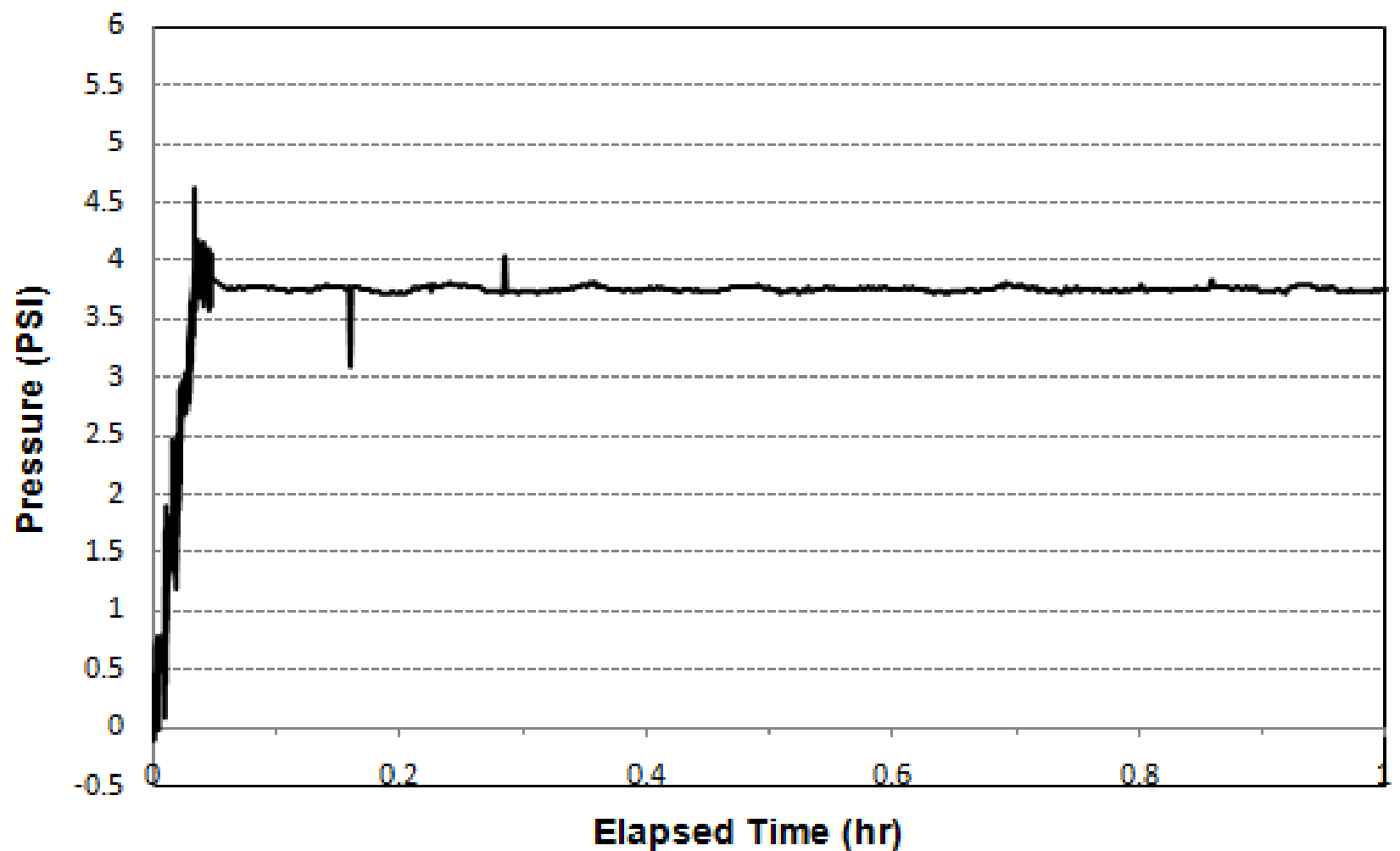

Figure 7.04: First Hour Pressure Recordings for SCC Short 1.

\subsubsection{SCC SHORT COLUMN 2}

The main difference between SCC Short Column 1 and SCC Short Column 2 was that the slump flow for SCC Short Column 2 was 29 inches compared to 25 inches for SCC Short Column 1. The mix design for this short column is given in Table 7.03 and the measured fresh properties are given in Table 7.04. The ambient temperature for the lab during this casting was 65 degrees Fahrenheit and the temperature of the concrete after batching was 70 degrees Fahrenheit. 
Table 7.03: One Cubic Yard Mix Design for SCC Short Column 2.

\begin{tabular}{|l|c|r|}
\hline \multicolumn{1}{|c|}{ MATERIAL } & UNIT & SCC SHORT 2 \\
\hline Cement Type 1 & lb & 550 \\
\hline Fly Ash & lb & 236 \\
\hline \#8 Crushed Limestone & lb & 742 \\
\hline \#67 Crushed Limestone & lb & 685 \\
\hline Natural Sand & lb & 1294 \\
\hline Water & lb & 282 \\
\hline w/cm & & 0.36 \\
\hline Air Entrainer - MB AE 90 & Oz/cwt & 1.3 \\
\hline VMA - UW 450 & Oz/cwt & 3 \\
\hline HRWR - Glenium 3030 NS & Oz/cwt & 10.7 \\
\hline Retarder - Delvo Stabilizer & Oz/cwt & 2 \\
\hline
\end{tabular}

Table 7.04: Fresh Properties of SCC Short Column 2.

\begin{tabular}{|l|c|}
\hline \multicolumn{1}{|c|}{ PROPERTY } & SCC SHORT 2 \\
\hline Slump Flow (in) & 29.0 \\
\hline T50 (sec) & 2.7 \\
\hline J-ring (in) & - \\
\hline T50 (sec) & - \\
\hline Air Content (\%) & 1.0 \\
\hline Unit Weight (lb/ft ${ }^{\mathbf{3}}$ ) & 146.6 \\
\hline Ambient Air Temperature ( ${ }^{\mathbf{0}} \mathbf{~ F )}$ & 65 \\
\hline Concrete Temperature ( ${ }^{\mathbf{0}} \mathbf{~ F )}$ & 70 \\
\hline
\end{tabular}

The pressures recorded during casting and after casting are displayed in two figures. The first, Figure 7.05, shows the first hour of pressure recordings. Figure 7.06 shows the total 21 hours of pressure recording. The casting of the column took approximately 9 minutes, translating to a casting rate of $29 \mathrm{ft} / \mathrm{hr}$. The maximum pressure recorded after casting was $4.0 \mathrm{psi}$ and the calculated maximum hydrostatic pressure was 3.99 psi. This column reached full hydrostatic pressure (100\%). 


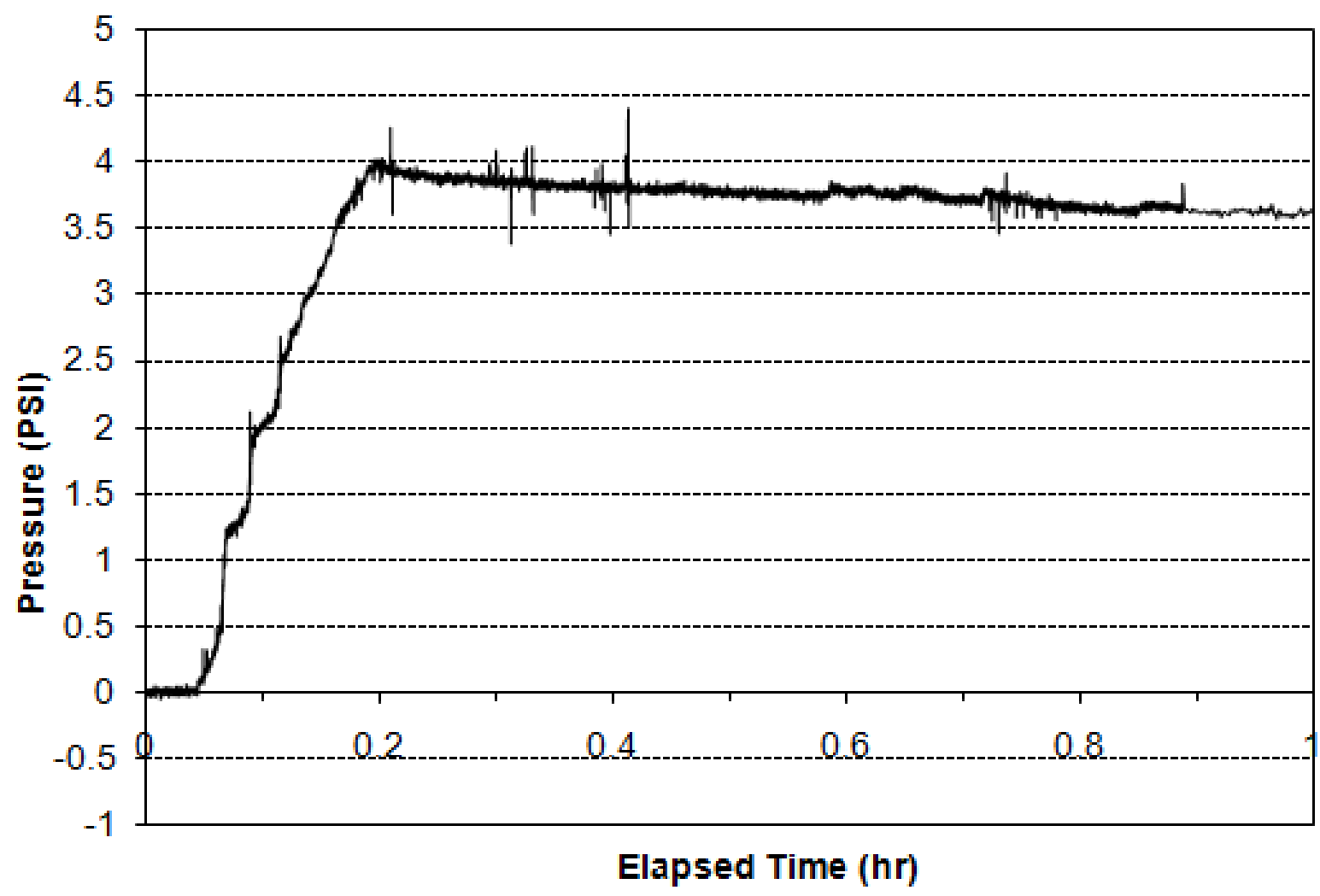

Figure 7.05: First Hour Pressure Recordings for SCC Short 2.

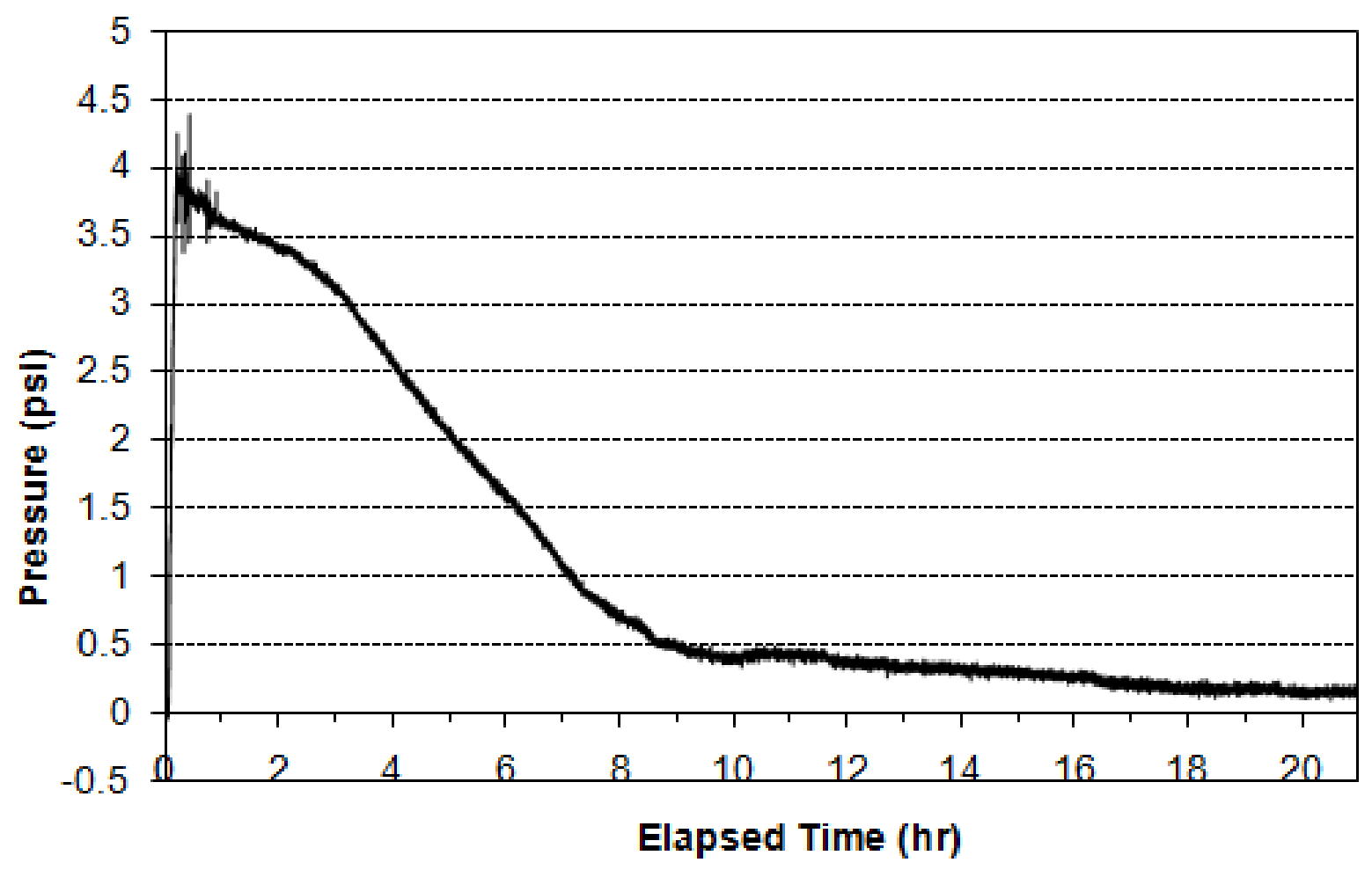

Figure 7.06: Recorded Pressures for SCC Short 2. 


\subsubsection{SCC SHORT COLUMN 3}

SCC Short Column 3 showed a slump flow of 25 inches. The mix design and the measured fresh properties are shown in Table 7.05 and Table 7.06, respectively. The ambient temperature for the lab was 78 degrees Fahrenheit and the concrete temperature at the time of casting was 81 degrees Fahrenheit.

Table 7.05: One Cubic Yard Mix Design for SCC Short Column 3.

\begin{tabular}{|l|c|r|}
\hline \multicolumn{1}{|c|}{ MATERIAL } & UNIT & SCC SHORT 3 \\
\hline Cement Type 1 & $\mathrm{lb}$ & 550 \\
\hline Fly Ash & $\mathrm{lb}$ & 236 \\
\hline \#8 Crushed Limestone & $\mathrm{lb}$ & 742 \\
\hline \#67 Crushed Limestone & $\mathrm{lb}$ & 685 \\
\hline Natural Sand & $\mathrm{lb}$ & 1294 \\
\hline Water & $\mathrm{lb}$ & 283 \\
\hline w/cm & & 0.36 \\
\hline Air Entrainer - MB AE 90 & $\mathrm{Oz} / \mathrm{cwt}$ & 1.3 \\
\hline VMA - UW 450 & $\mathrm{Oz} / \mathrm{cwt}$ & 4.0 \\
\hline HRWR - Glenium 3030 NS & $\mathrm{Oz} / \mathrm{cwt}$ & 10.7 \\
\hline Retarder - Delvo Stabilizer & $\mathrm{Oz} / \mathrm{cwt}$ & 2.0 \\
\hline
\end{tabular}

Table 7.06: Fresh Properties of SCC Short Column 3.

\begin{tabular}{|l|c|}
\hline \multicolumn{1}{|c|}{ PROPERTY } & SCC SHORT 3 \\
\hline Slump Flow (in) & 25.0 \\
\hline T50 (sec) & - \\
\hline J-ring (in) & - \\
\hline T50 (sec) & - \\
\hline Air Content (\%) & 1.9 \\
\hline Unit Weight (lb/ft ${ }^{3}$ ) & 147.4 \\
\hline Ambient Air Temperature ( $\left.{ }^{\mathbf{0}} \mathbf{F}\right)$ & 78 \\
\hline Concrete Temperature $\mathbf{(}^{\mathbf{0}} \mathbf{~ F )}$ & 81 \\
\hline
\end{tabular}

The time to fill this pressure column was recorded to be 23 minutes. This relates to casting rate of $11 \mathrm{ft} / \mathrm{hr}$. The maximum recorded pressure after casting was $3.5 \mathrm{psi}$. With the 
theoretical full hydrostatic pressure being $4.0 \mathrm{psi}$, the pressure of this column reached $87.5 \%$ hydrostatic. The first hour of pressure recording is shown in Figure 7.07 and the total pressure recording is shown in Figure 7.08. Something interesting occurred between hours 10 and 11 (Figure 7.08), where the pressure curve actually dropped suddenly to negative and then continued with a recorded negative pressure. It is speculated that this is the time in which the concrete has hardened to the point where it actually detaches itself from the pressure head. The absence of air could cause the negative reading as air returns to this location to read zero psi pressure.

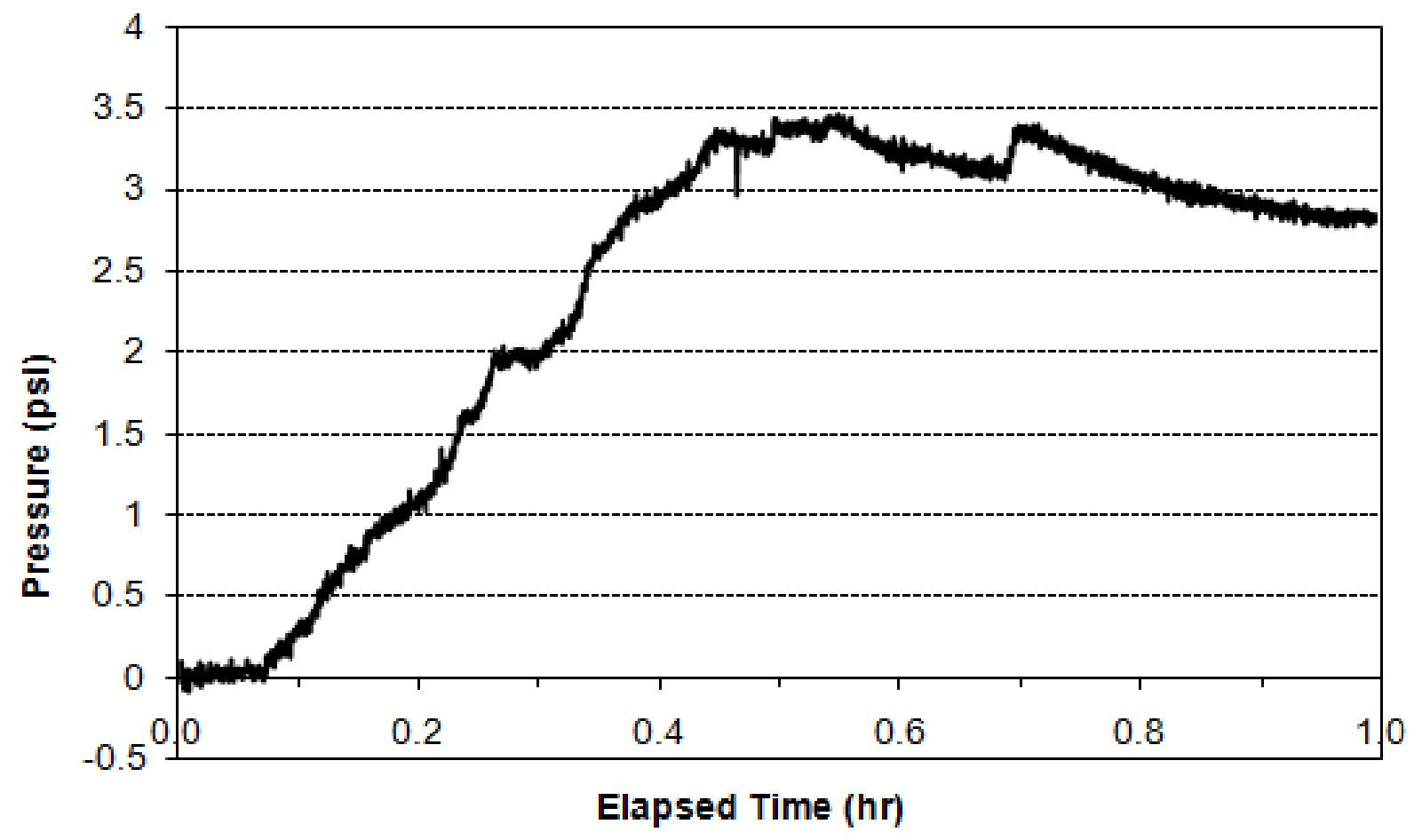

Figure 7.07: First hour Pressure Recordings for SCC Short 3. 


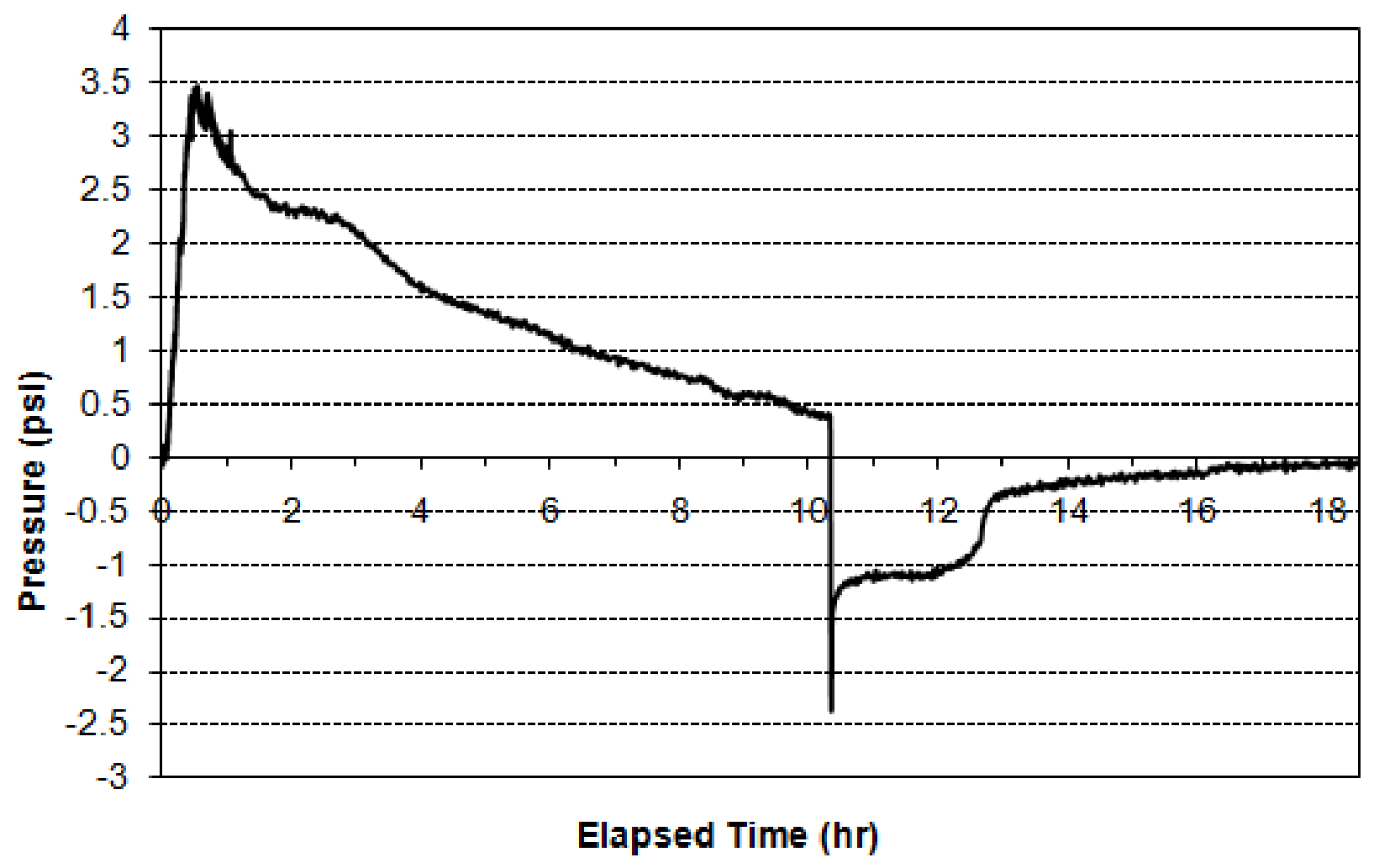

Figure 7.08: Recorded Pressures for SCC Short 3.

\subsubsection{SCC SHORT COLUMN 4}

SCC Short Column 4 was a different mix design than the previous three columns. The slump flow was only measured to be 18 inches. The mix design and measured fresh properties are shown in Tables 7.07 and Table 7.08, respectively. The ambient temperature of the laboratory was 81 degrees Fahrenheit and the concrete temperature at the time of casting was 76 degrees Fahrenheit. 
Table 7.07: One Cubic Yard Mix Design for SCC Short Column 4.

\begin{tabular}{|l|c|r|}
\hline \multicolumn{1}{|c|}{ MATERIAL } & UNIT & SCC SHORT 4 \\
\hline Cement Type 1 & $\mathrm{lb}$ & 600 \\
\hline Slag & $\mathrm{lb}$ & 150 \\
\hline \#8 Crushed Limestone & $\mathrm{lb}$ & 553 \\
\hline \#67 Crushed Limestone & $\mathrm{lb}$ & 830 \\
\hline Natural Sand & $\mathrm{lb}$ & 1384 \\
\hline Water & $\mathrm{lb}$ & 300 \\
\hline w/cm & & 0.4 \\
\hline Air Entrainer AEA-15 & Oz/cwt & 0.15 \\
\hline VMA - 300 SCC & Oz/cwt & 2.5 \\
\hline HRWR -V2100 & Oz/cwt & 6.0 \\
\hline Retarder - Plastiment & Oz/cwt & 2.5 \\
\hline
\end{tabular}

Table 7.08: Fresh Properties of SCC Short Column 4.

\begin{tabular}{|l|c|}
\hline \multicolumn{1}{|c|}{ PROPERTY } & SCC SHORT 4 \\
\hline Slump Flow (in) & 18.0 \\
\hline T50 (sec) & - \\
\hline J-ring (in) & - \\
\hline T50 (sec) & - \\
\hline Air Content (\%) & 7.8 \\
\hline Unit Weight (lb/ft ${ }^{3}$ ) & 139.6 \\
\hline Ambient Air Temperature ( $\left.{ }^{\mathbf{0}} \mathbf{F}\right)$ & 81 \\
\hline Concrete Temperature $\left.\mathbf{(}^{\mathbf{0}} \mathbf{F}\right)$ & 76 \\
\hline
\end{tabular}

The time to cast this column was recorded to be 35 minutes. This corresponds to a casting rate of $7 \mathrm{ft} / \mathrm{hr}$. The maximum recorded pressure for this column was 3.9 psi. However, according to the mixes measured unit weigh the theoretical hydrostatic pressure was calculated to be 3.8 psi. So, the achieved pressure in this column was $103 \%$ hydrostatic. Since a value of $100 \%$ hydrostatic seems more reasonable for this type of casting, the accuracy of the pressure gage could account for the value above $100 \%$. The recording for the first hour of pressure measurements is shown in Figure 7.09 and the total pressure recordings are shown in Figure 7.10. The same occurrence of sudden pressure drop is observed in this column as well at around 
hour 10. This time the pressure did not drop as far negative and did not climb back towards zero psi. However, when detaching the sensor, during hour 23, the pressure is recorded as zero psi.

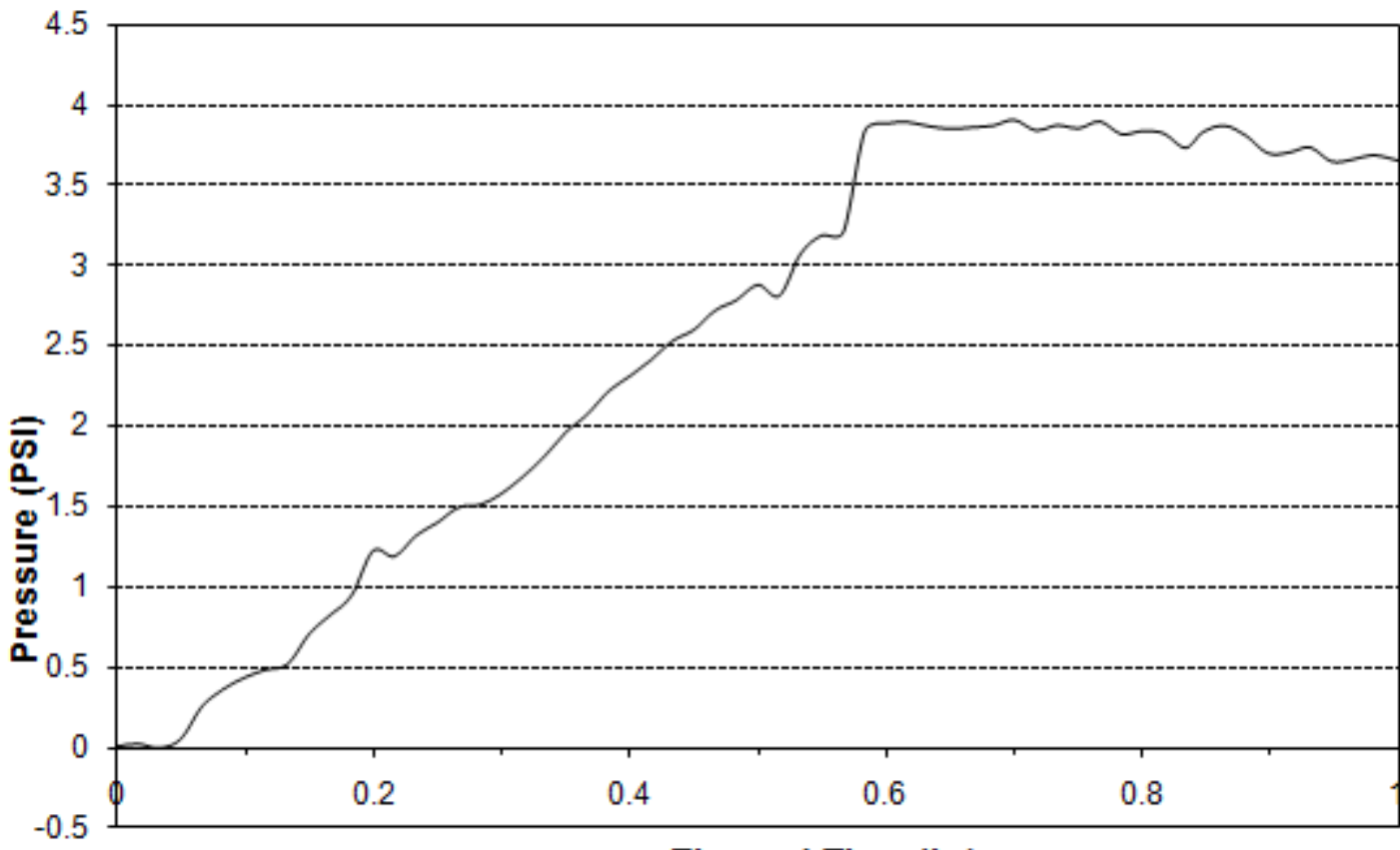

Elapsed Time (hr)

Figure 7.09: First Hour Pressure Recordings for SCC Short 4.

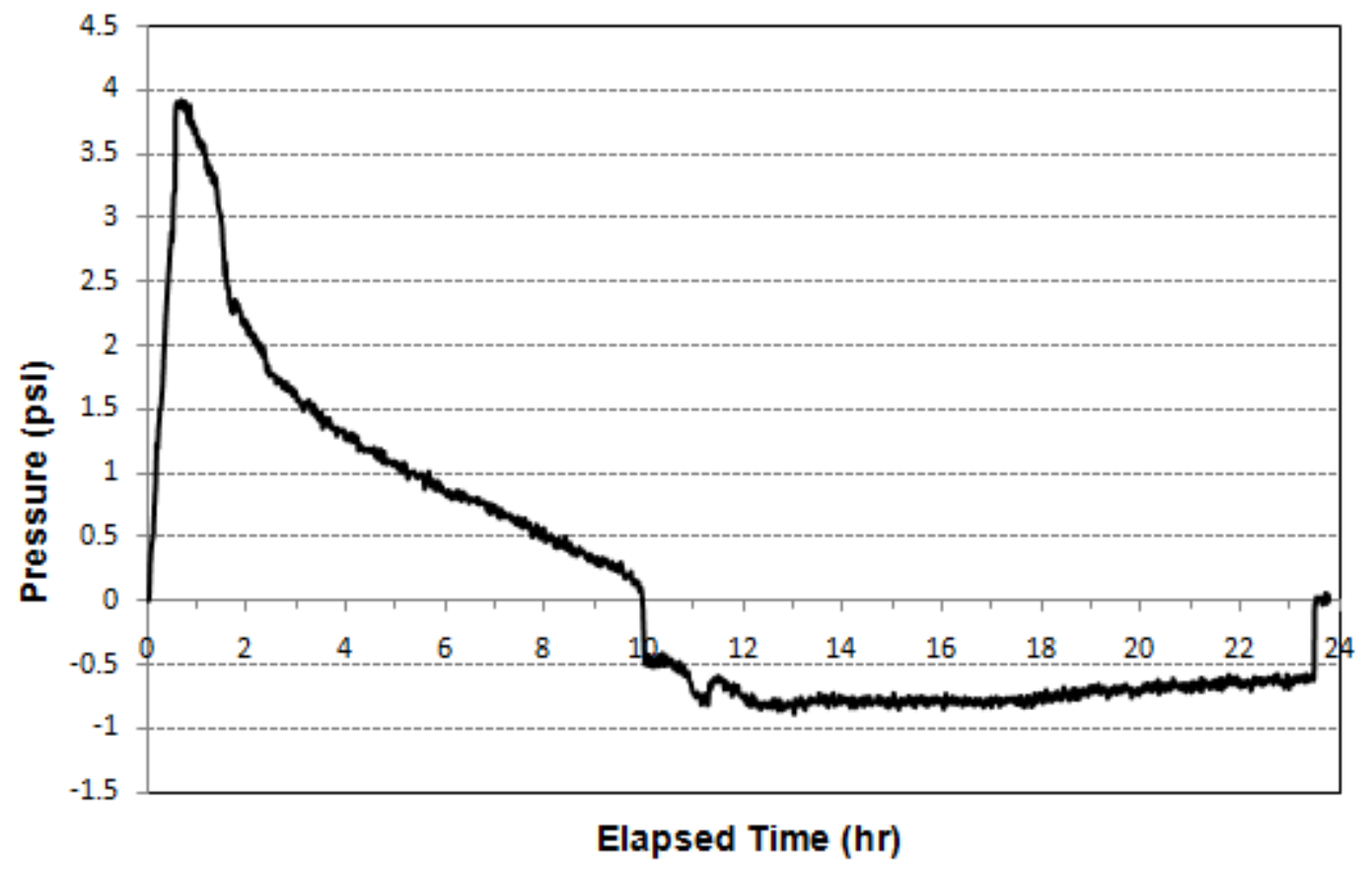

Figure 7.10: Recorded Pressures for SCC Short 4. 
The hydration temperature of this column was also recorded. The mix design used for the casting of this column contained $20 \%$ of the cementitious material slag and the mix also contained a dosage of retarding admixture. Figure 7.11 shows the temperatures recorded from the inside of the column. The sensor was located near the middle of the height. It can be seen from the figure that the slag and retarding admixture had slowed the final setting (steep temperature increase) until after about 6 hours. After about 6 hours the slope of the hydration curve becomes very steep.

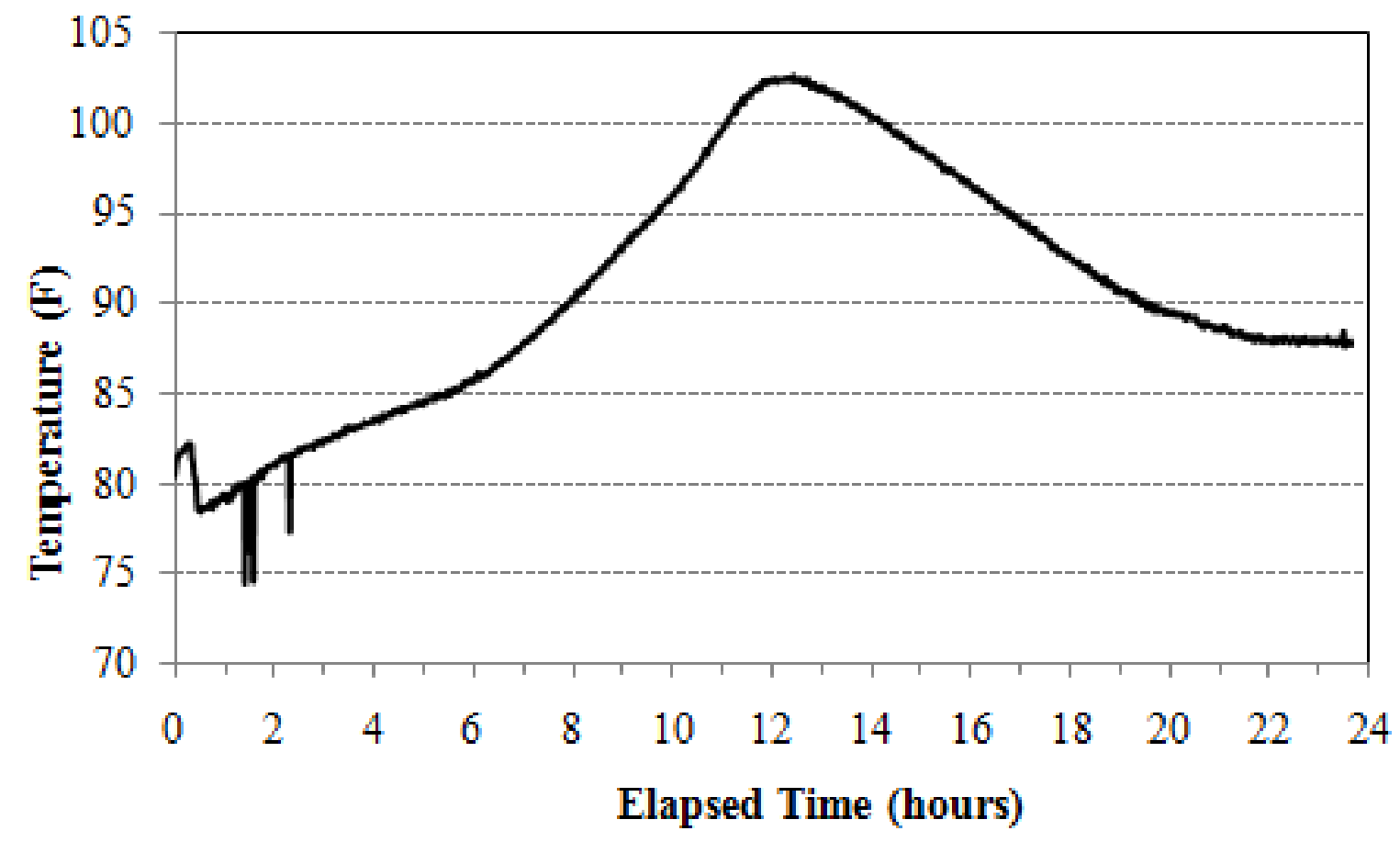

Figure 7.11: Temperatures Recorded During SCC Short Column 4.

\subsubsection{TVC SHORT COLUMN 1}

The short columns cast with traditionally vibrated concrete (TVC) featured a WVDOT Class B-Modified mix. This mix was batched, in the laboratory, with the material quantities in Table 7.09. Although, elements cast with this type of concrete would normally be vibrated to 
achieve proper compaction in the field, it was decide to not vibrate the TVC columns tested to observe the pressure rise and decay from the placement of the concrete itself. The ambient temperature of the laboratory during this test was 74 degrees Fahrenheit and the concrete temperature upon mixing was 63 degrees Fahrenheit. Before the casting of the column, the fresh properties were tested; the results are shown in Table 7.10.

Table 7.09: One Cubic Yard Mix Design for TVC Short Column 1.

\begin{tabular}{|l|c|r|}
\hline \multicolumn{1}{|c|}{ MATERIAL } & UNIT & TVC SHORT 1 \\
\hline Cement Type 1 & $\mathrm{lb}$ & 658 \\
\hline \#67 Crushed Limestone & $\mathrm{lb}$ & 1775 \\
\hline Natural Sand & $\mathrm{lb}$ & 1133 \\
\hline Water & $\mathrm{lb}$ & 270 \\
\hline w/cm & & 0.41 \\
\hline Air Entrainer & Oz/cwt & 1.5 \\
\hline Pozzolith 200N & Oz/cwt & 4 \\
\hline
\end{tabular}

Table 7.10: Fresh Properties of TVC Short Column 1.

\begin{tabular}{|c|c|}
\hline PROPERTY & TVC SHORT 1 \\
\hline Slump (in) & 2.25 \\
\hline Air Content (\%) & 7.0 \\
\hline Unit Weight $\left(\mathbf{l b} / \mathbf{f t}^{3}\right)$ & 144.0 \\
\hline Yield $\left(\mathrm{ft}^{3} / \mathrm{yd}^{3}\right)$ & 26.6 \\
\hline Ambient Air Temperature $\left({ }^{0} \mathrm{~F}\right)$ & 74 \\
\hline Concrete Temperature $\left({ }^{0} \mathrm{~F}\right)$ & 63 \\
\hline
\end{tabular}

The time to cast this short column was very quick, approximately 5 minutes. The column was filled by discharging the fresh concrete from the mixer into a five-gallon bucket. The bucket was then dumped into the column. Figure 7.12 shows the filling as well as the first hour of pressure recording. The flat areas during the filling process are the times in between the dumping of the buckets into the column. The casting time of 5 minutes to fill the entire height of the 
column would translate into a casting rate of 52 feet per hour. The maximum recorded pressure after the completion of the casting was 3.7 psi. The pressure however continued to rise up until 2 hours after casting which was strange. The theoretical hydrostatic pressure calculated for this column was 3.92 psi. This would translate to the column reaching $94.4 \%$ of hydrostatic pressure. Figure 7.13 shows the pressure vs. time up until 12 hours.

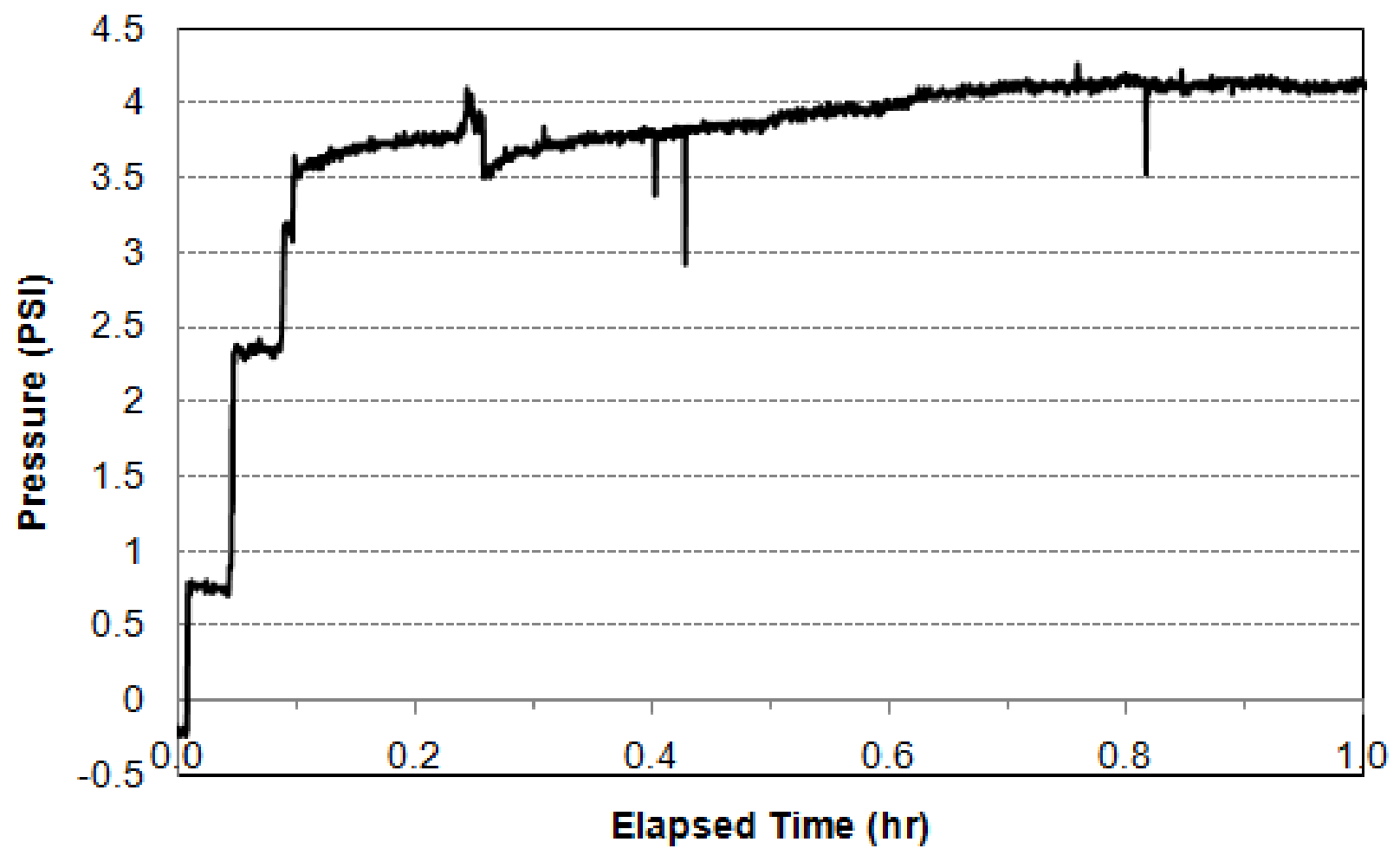

Figure 7.12: First Hour Pressure Recordings for TVC Short 1. 


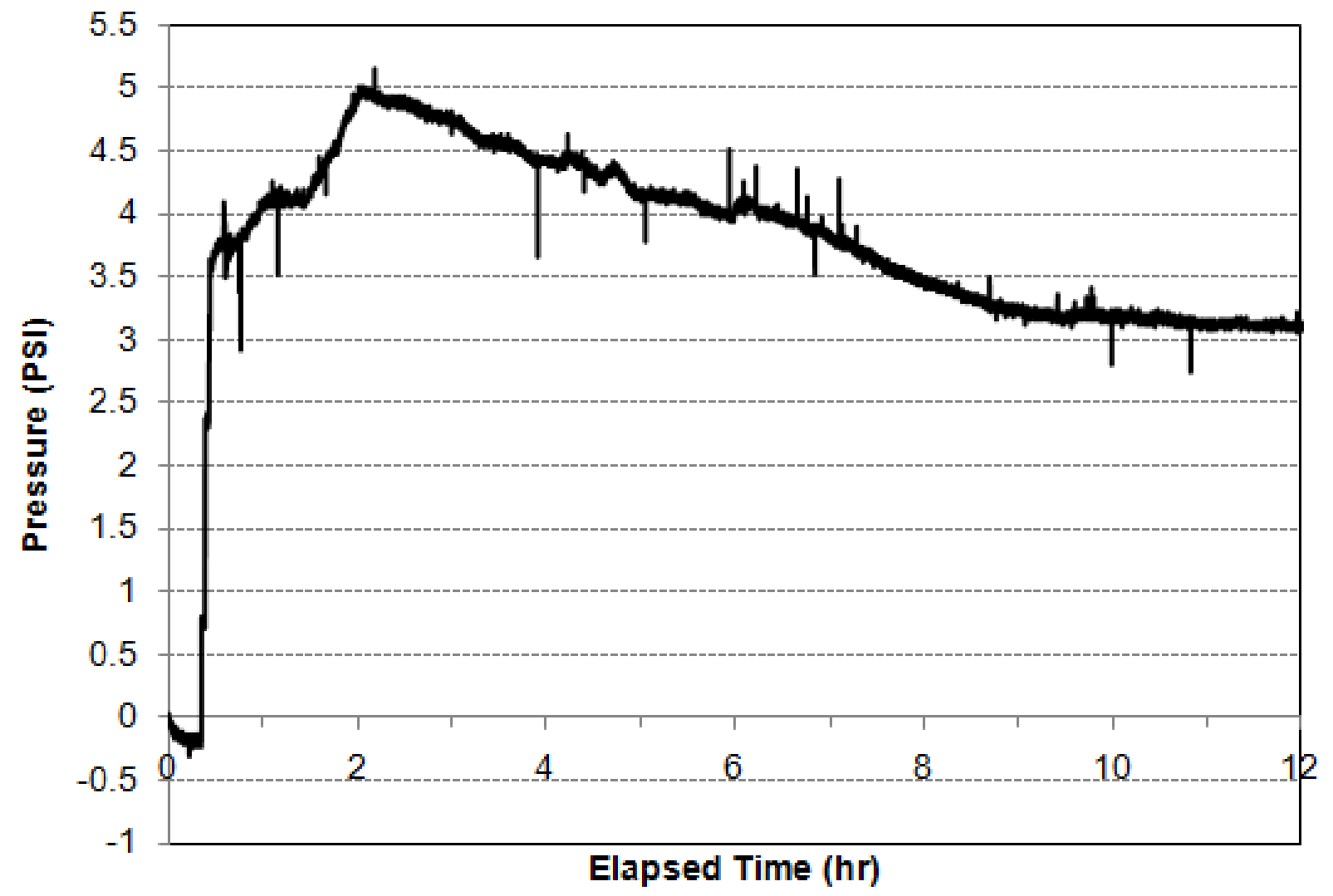

Figure 7.13: Recorded Pressures for TVC Short 1.

\subsubsection{TVC SHORT COLUMN 2}

TVC short column 2 featured a WVDOT Class B-Modified mix. This mix was delivered to the laboratory for testing by Central Supply, with the material quantities listed in Table 7.11. Although, elements cast with this type of concrete would normally be vibrated to achieve proper compaction in the field, it was decide to not vibrate the TVC columns tested to observe the pressure rise and decay from the placement of the concrete itself. Only rodding and tapping was done in order to aide in compaction, but minimize dynamic effects. Before the casting of the column, the fresh properties were tested; the results are shown in Table 7.12. 
Table 7.11: One Cubic Yard Mix Design for TVC Short Column 2.

\begin{tabular}{|l|c|r|}
\hline \multicolumn{1}{|c|}{ MATERIAL } & UNIT & TVC SHORT 2 \\
\hline Cement Type 1 & $\mathrm{lb}$ & 564 \\
\hline Fly Ash - Class F & $\mathrm{lb}$ & 70 \\
\hline \#67 Crushed Limestone & $\mathrm{lb}$ & 1743 \\
\hline Natural Silica Sand & $\mathrm{lb}$ & 1220 \\
\hline Water & $\mathrm{lb}$ & 250 \\
\hline w/cm & & 0.39 \\
\hline Air Entrainer & Oz/cwt & 2 \\
\hline Water Reducer - Eucon WR & Oz/cwt & 6 \\
\hline
\end{tabular}

Table 7.12: Fresh Properties of TVC Short Column 2.

\begin{tabular}{|l|c|}
\hline \multicolumn{1}{|c|}{ PROPERTY } & TVC SHORT 2 \\
\hline Slump (in) & 6.5 \\
\hline Air Content (\%) & 6.5 \\
\hline Unit Weight (lb/ft $\mathbf{~}^{\mathbf{3}}$ ) & 143.1 \\
\hline Yield $\left(\mathbf{f t}^{\mathbf{3}} \mathbf{\text { /yd }} \mathbf{~}^{\mathbf{3}}\right.$ ) & 26.9 \\
\hline
\end{tabular}

The casting of this pressure column was accomplished in 7 minutes. This corresponds to a casting rate of $37 \mathrm{ft} / \mathrm{hr}$. The maximum recorded pressure after casting was 4.1 psi. The calculated theoretical full hydrostatic pressure was 3.89 psi. So, this column reached $105.4 \%$ of full hydrostatic pressure. The first hour pressure recording can be seen in Figure 7.14. The spikes in the pressure during the filling and the sudden increase in pressure around 0.4 hours were most likely due to the rodding process. 


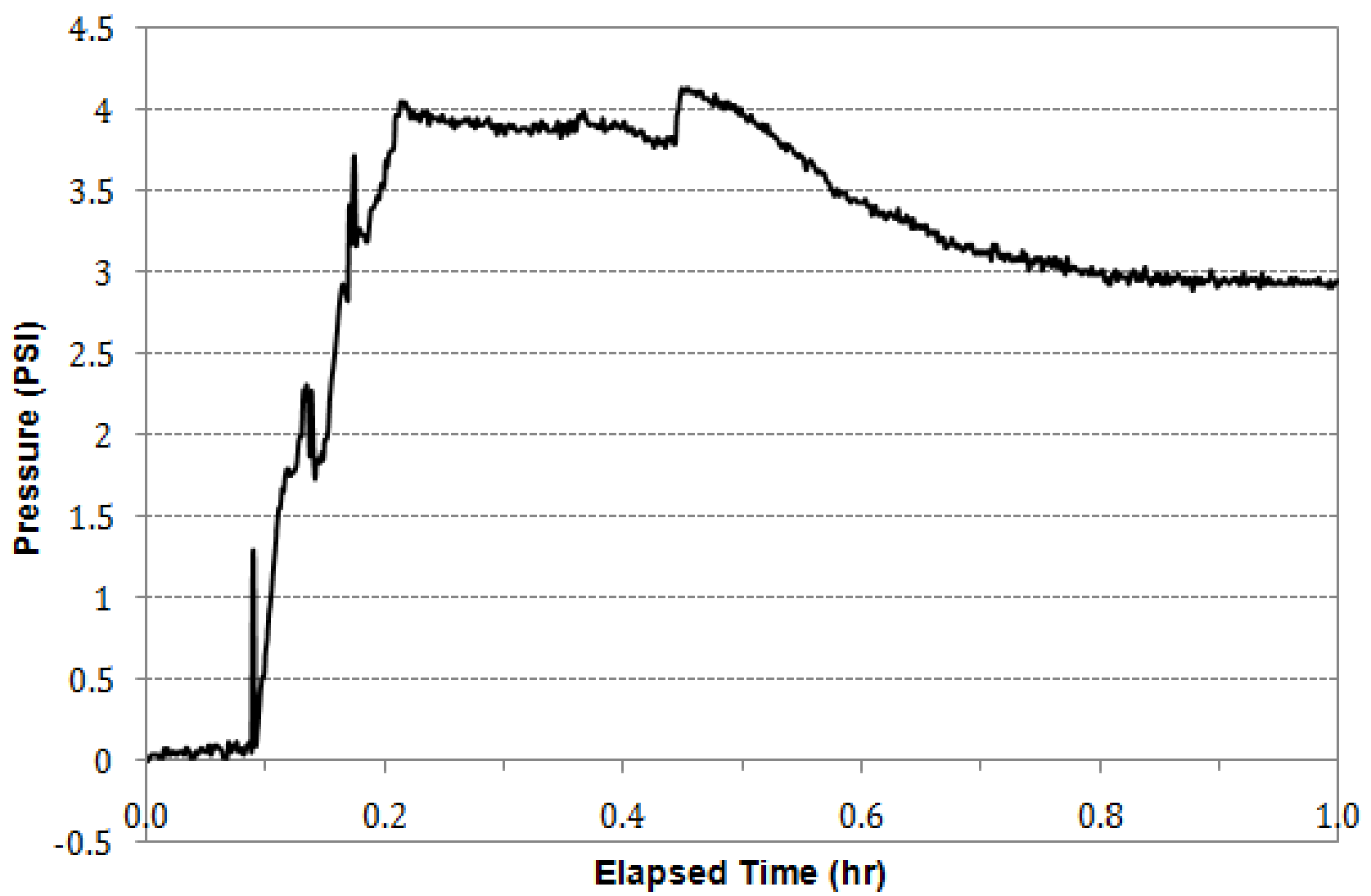

Figure 7.14: First Hour Pressure Recordings for TVC Short 2.

\subsection{TALL PRESSURE COLUMNS}

The tall pressure columns, as discussed in the introduction of this chapter, were fabricated out of two short pressure columns. The two short pressure columns were held together using a union. The bottom of the column was affixed with a cap. The tall pressure columns housed two pressure transducers. The top pressure transducer with a head height of 47 inches same as the short pressure column and the bottom pressure transducer with a head height of 105 inches.

\subsubsection{TALL PRESSURE COLUMN CALIBRATION}

The tall pressure column was calibrated in the same fashion as the short pressure column. The column was erected, fitted with the two pressure transducers used, and filled with water. 
The maximum recorded pressure for the top and bottom sensor was compared to the theoretical hydrostatic pressure of water at the specific heights. The top sensor recorded a pressure of 1.7 psi which showed a direct correlation with the calculated value of 1.7 psi. The bottom sensor recorded a maximum pressure of $4.0 \mathrm{psi}$ and the calculated value of $3.8 \mathrm{psi}$ was a little off but still acceptable. Figure 7.15 shows the pressures recorded during this water calibration test.

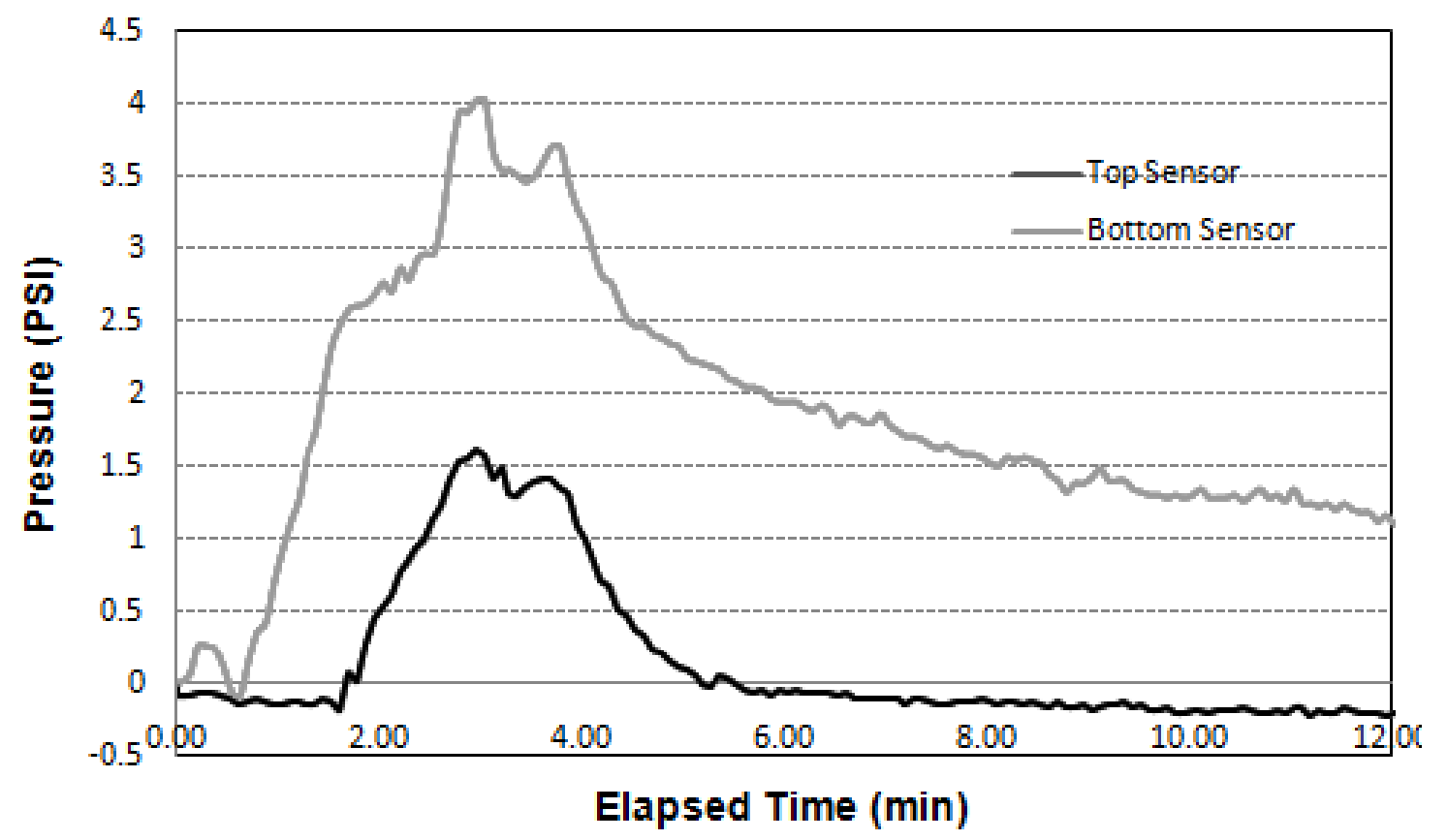

Figure 7.15: Tall Column Water Calibration.

\subsubsection{SCC TALL COLUMN}

The tall column with SCC was cast in the WVU Concrete Lab. Due to height restrictions of this laboratory, the overhead crane could not be utilized to aid in the filling of the columns. Instead, the column had to be filled by carrying five gallon buckets filled with SCC up a ladder. The mix design and fresh properties of the self-consolidating concrete can be seen in Tables 7.13 and 7.14, respectively. The ambient temperature of the laboratory during this day of casting was 81 degrees Fahrenheit and the concrete temperature at placement was 78 degrees Fahrenheit. 
Table 7.13: One Cubic Yard Mix Design for SCC Tall Column.

\begin{tabular}{|l|c|r|}
\hline \multicolumn{1}{|c|}{ MATERIAL } & UNIT & SCC TALL \\
\hline Cement Type 1 & lb & 550 \\
\hline Class F Fly ash & lb & 236 \\
\hline \#8 Crushed Limestone & lb & 742 \\
\hline \#67 Crushed Limestone & lb & 685 \\
\hline Natural Sand & lb & 1294 \\
\hline Water & lb & 283 \\
\hline w/cm & & 0.36 \\
\hline Air Entrainer - MB AE90 & Oz/cwt & 1.3 \\
\hline VMA - UW 450 & Oz/cwt & 4 \\
\hline HRWR - Glenium 3030 NS & Oz/cwt & 10.7 \\
\hline Retarder - Delvo Stabilizer & Oz/cwt & 2 \\
\hline
\end{tabular}

Table 7.14: Fresh Properties of SCC Tall Column.

\begin{tabular}{|l|c|}
\hline \multicolumn{1}{|c|}{ PROPERTY } & SCC TALL \\
\hline Slump Flow (in) & 23.5 \\
\hline T50 (sec) & 5.7 \\
\hline J-ring (in) & - \\
\hline T50 (sec) & - \\
\hline Air Content (\%) & 2.5 \\
\hline Unit Weight (lb/ft ${ }^{\mathbf{3}}$ ) & 147.2 \\
\hline Ambient Air Temperature $\mathbf{(}^{\mathbf{0}} \mathbf{~ F )}$ & 81 \\
\hline Concrete Temperature $\mathbf{(}^{\mathbf{0}} \mathbf{\text { F) }}$ & 78 \\
\hline
\end{tabular}

The SCC tall column took 27 minutes to cast. This translates to a casting rate of 19.4 $\mathrm{ft} / \mathrm{hr}$. The maximum recorded pressure of the bottom sensor was $7.1 \mathrm{psi}$ and the theoretical calculated hydrostatic pressure for this location was 9.0 psi. The means that the maximum lateral pressure on at the bottom location of the formwork reached $79.9 \%$ of hydrostatic pressure. The top sensor reached a maximum recorded pressure of 3.8 psi after casting. The theoretical calculated hydrostatic pressure for this location was determined to be 4.0 psi. This would mean that the top section reached $95 \%$ of its hydrostatic capacity. The pressure recordings for the first 
hour are shown in Figure 7.16. The pressure recordings for the entire experiment are shown in Figure 7.17.

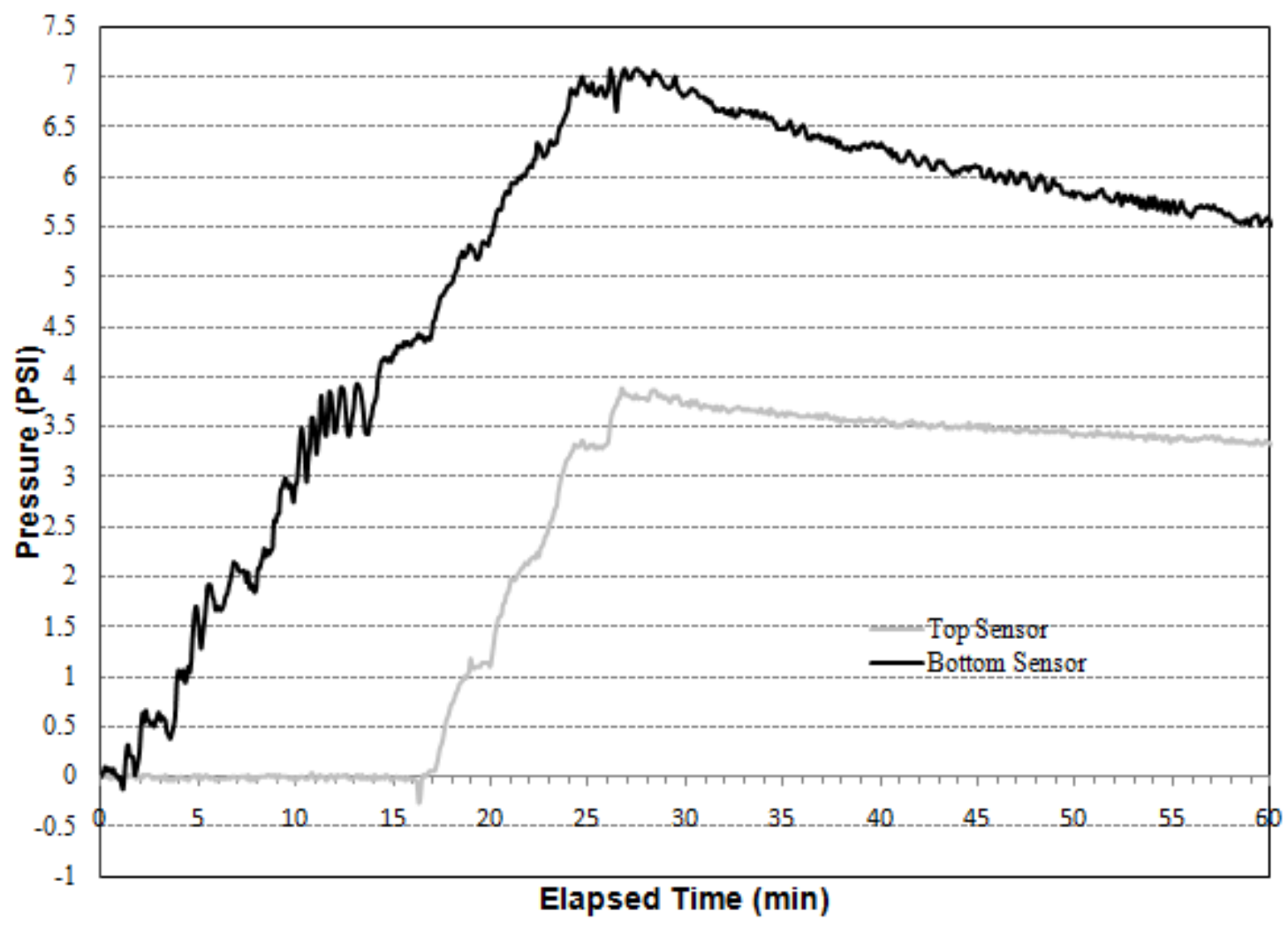

Figure 7.16: First Hour Pressure Recordings for SCC Tall. 


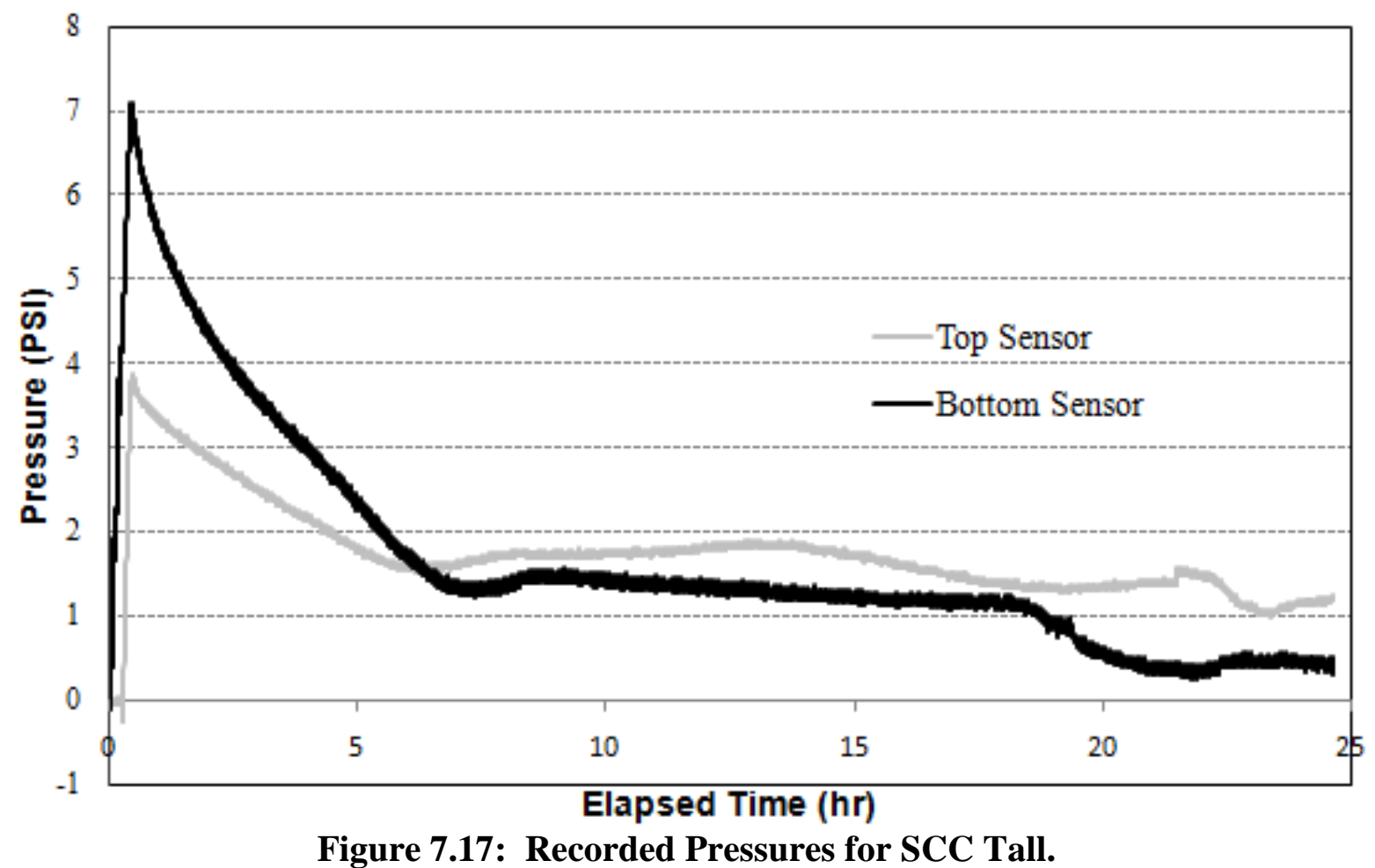

The hydration temperature of this column was also recorded. The mix design used for the casting of this column contained $30 \%$ of the cementitious material was Class F fly ash and the mix also contained retarding admixture. Figure 7.18 shows the temperatures recorded from the inside of the column. The sensor was located near the middle of the height. It can be seen from the figure that the fly ash and retarding admixture delayed the final setting (steep temperature increase) until after about 7 hours. 


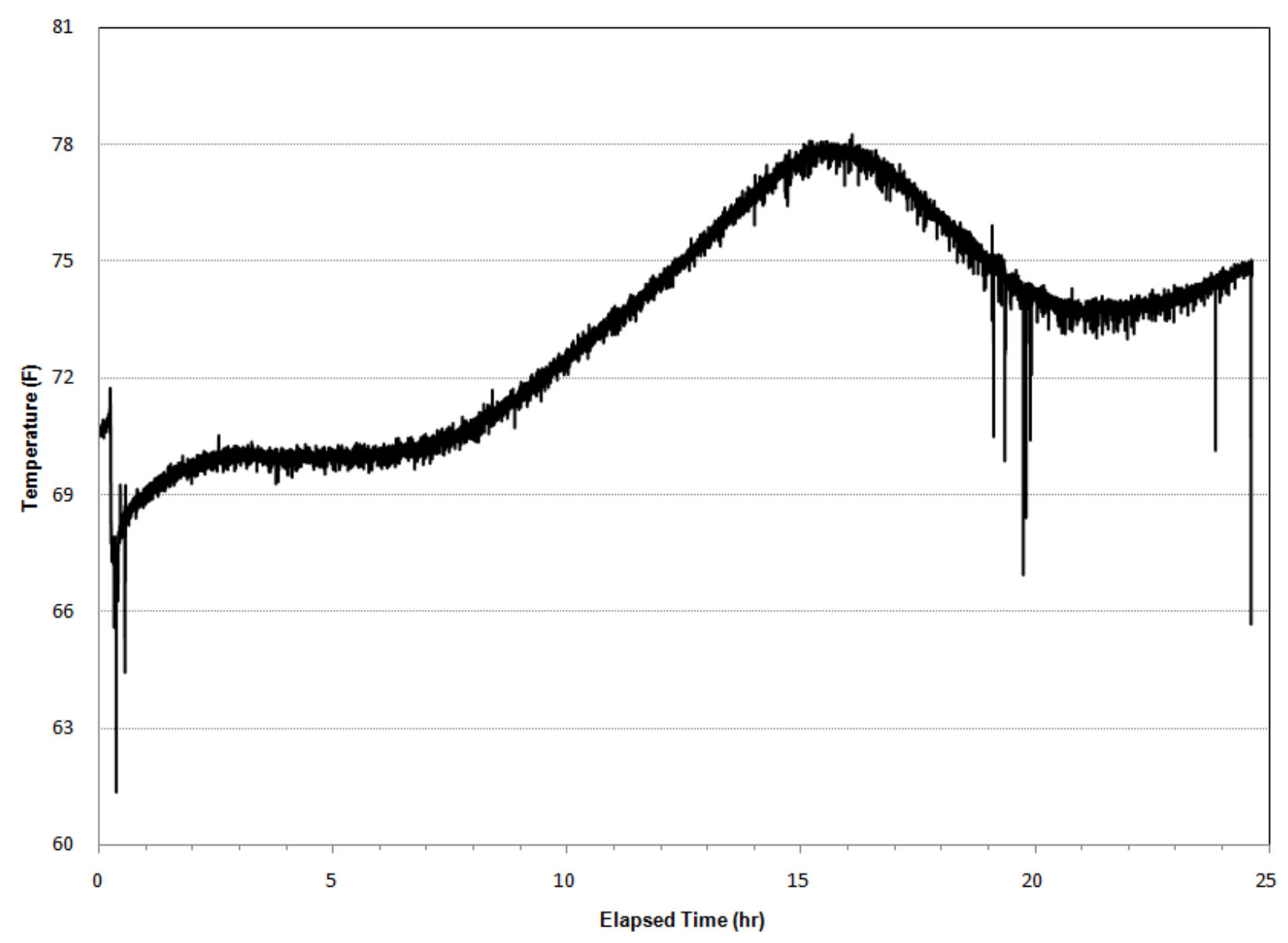

Figure 7.18: Temperatures Recorded During SCC Tall Column.

\subsubsection{TVC TALL COLUMN}

The TVC Tall Column was cast at the same time as the TVC Short column 2, so it has the same mix design and fresh properties as shown in Table 7.11 and Table 7.12, respectively. The concrete for the casting of this mix was WVDOT Class B-modified and was delivered by the Central Supply Company. The tall column set up for this column was identical to the tall column cast with SCC. The temperature of the concrete and laboratory was estimated to be 75 degrees Fahrenheit.

This tall column took 22 minutes to cast, which translates to a casting rate of $23.9 \mathrm{ft} / \mathrm{hr}$. The maximum recorded pressure of the bottom sensor was 4.3 psi and the theoretical hydrostatic 
pressure was calculated to be $8.7 \mathrm{psi}$. This means that the lateral formwork pressure in the bottom of the column reached $49.4 \%$. The maximum recorded pressure for the top sensor was $3.2 \mathrm{psi}$ and the theoretical hydrostatic pressure was calculated to be $3.9 \mathrm{psi}$. So, the top sensor reached $82.1 \%$ hydrostatic. The pressure recordings for the first hour of this experiment are shown in Figure 7.19 and the total time of pressure recording is shown in Figure 7.20. The bottom pressure sensor, in Figure 7.19, fluctuated a lot during the pressure decay. It was also strange to see that the pressure stated to decay on the bottom sensor before the column was completely filled. The pressure suddenly jumped up to the same position as the top sensor near time 0.4 hour. At this time, the column was tapped on to try to alleviate an entrapped air voids. One of those voids could have been interfering with the bottom sensor.

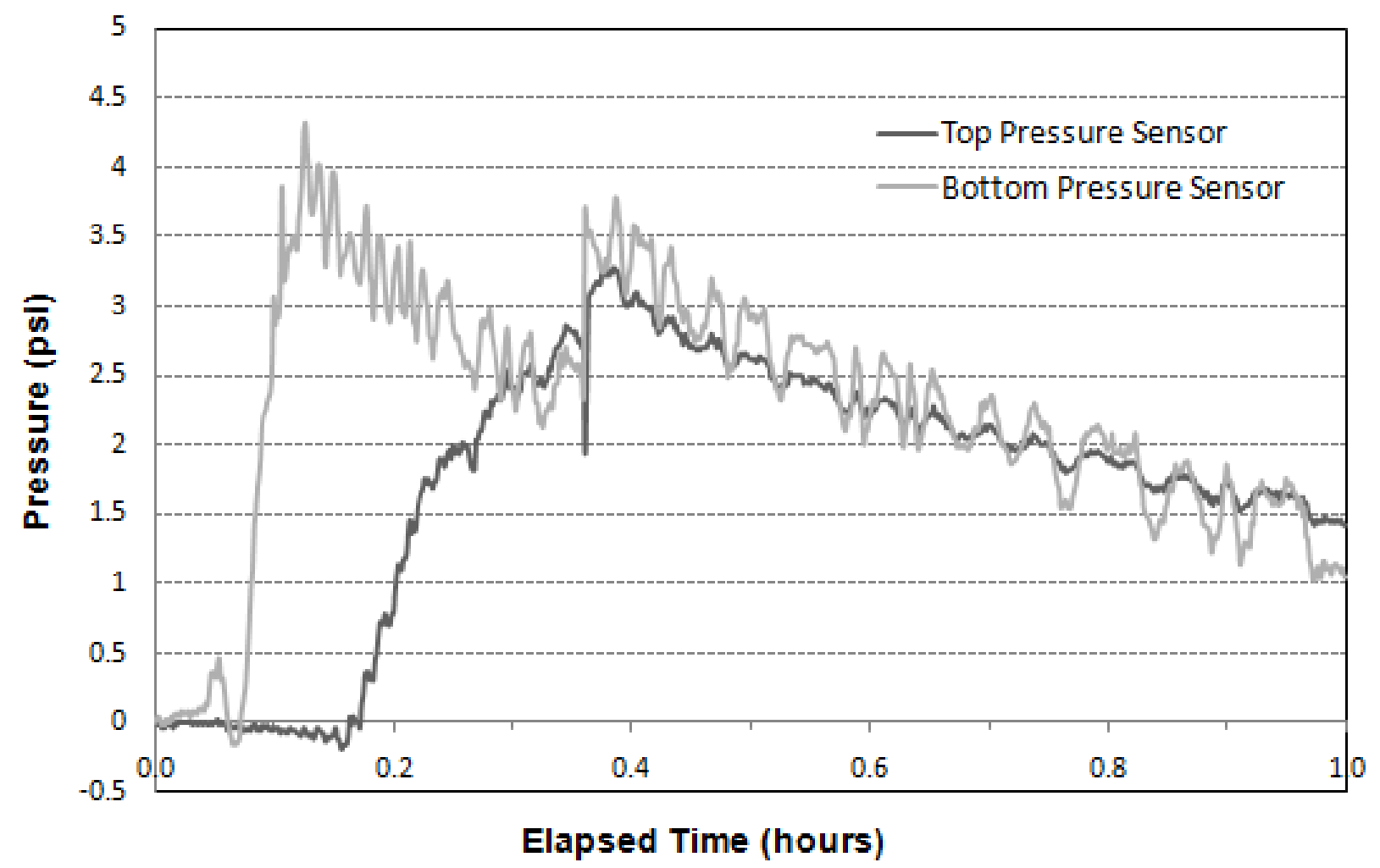

Figure 7.19: First Hour Pressure Recordings for SCC Tall. 


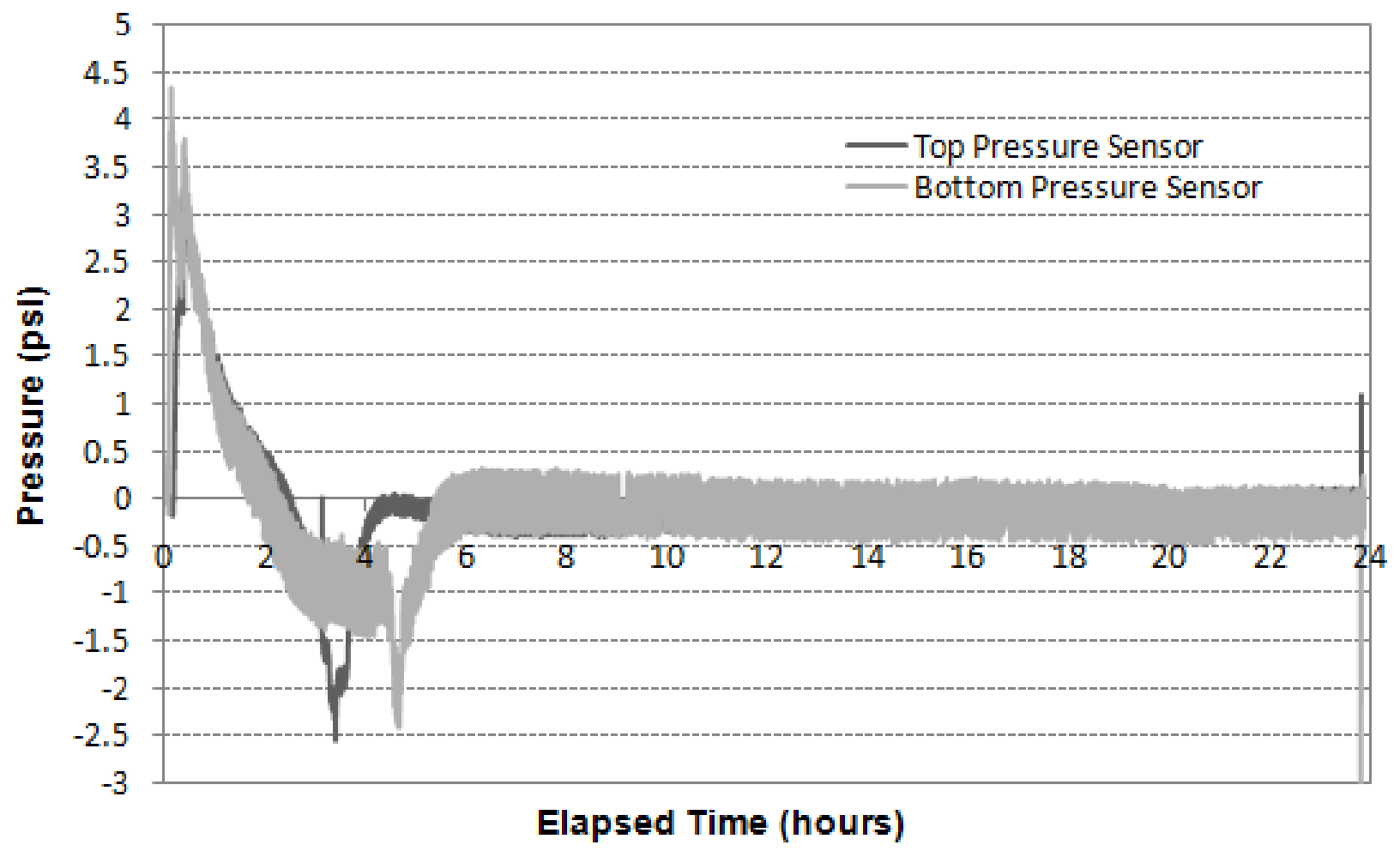

Figure 7.20: Recorded Pressures for TVC Tall.

\subsection{SUMMARY OF FINDINGS}

Short and tall pressure columns were cast with traditional mixes and SCC mixes. The method of using 8 inch diameter SDR35 PVC pipes for column formwork with attached flush mount diaphragm pressure transducers was very successful. All of the short columns tested, SCC and TVC, showed above $80 \%$ hydrostatic pressure with many of them at full hydrostatic pressure. The casting rate and slump/slump flow was changed between the columns cast, but the temperature was kept relatively constant. A comparison of all of the short columns tested during this study is shown in Table 7.15. The results of the short pressure columns were consistent with results from other researchers that conducted similar short columns of 1 meter height (Khayat and Mitchell, 2009). 
Table 7.15: Comparison of all of the Short Columns Tested.

\begin{tabular}{|l|c|c|c|c|c|c|}
\hline & $\begin{array}{c}\text { SCC } \\
\text { (1) }\end{array}$ & $\begin{array}{c}\text { SCC } \\
\text { (2) }\end{array}$ & $\begin{array}{c}\text { SCC } \\
\text { (3) }\end{array}$ & $\begin{array}{c}\text { SCC } \\
(\mathbf{4})\end{array}$ & $\begin{array}{c}\text { TVC } \\
(\mathbf{1})\end{array}$ & $\begin{array}{c}\text { TVC } \\
\text { (2) }\end{array}$ \\
\hline Slump Flow / Slump, (in) & 25 & 29 & 25 & 18 & 2.25 & 6.5 \\
\hline Fill Time, (min) & 3 & 9 & 23 & 35 & 5 & 7 \\
\hline Fill Rate, m/hr (ft/hr) & 87 & 29 & 11 & 7 & 52 & 37 \\
\hline Max Recorded Pressure, (psi) & 3.8 & 4.0 & 3.5 & 3.9 & 3.7 & 4.1 \\
\hline Full Hydrostatic Pressure, (psi) & 4.06 & 3.99 & 4.00 & 3.80 & 3.92 & 3.89 \\
\hline Percent Hydrostatic (\%) & $\mathbf{9 3 . 6}$ & $\mathbf{1 0 0}$ & $\mathbf{8 7 . 5}$ & $\mathbf{1 0 3}$ & $\mathbf{9 4 . 4}$ & $\mathbf{1 0 5 . 4}$ \\
\hline
\end{tabular}

The tall pressure columns which housed two pressure sensors were cast with an SCC mix and a WVDOT Class B-modified mix. Neither the TVC nor the SCC column cast exhibited full hydrostatic pressure. The bottom sensor (105 inch head height) on the SCC column did reach near $80 \%$ hydrostatic pressure, while the TVC mix only reached near $50 \%$ hydrostatic pressure. The top sensors (47 inch head height), having the same head height as the short columns, reached $82 \%$ for the TVC and 95\% for the SCC mix.

Table 7.16: Comparison of the SCC and TVC Tall Columns Tested.

\begin{tabular}{|l|c|c|}
\hline & SCC & TVC \\
\hline Slump Flow / Slump, (in) & 23.5 & 6.5 \\
\hline Fill Time, (min) & 27 & 22 \\
\hline Fill Rate, (ft/hr) & 19.4 & 23.9 \\
\hline Max Recorded Pressure, (psi) Top Sensor & 3.8 & 3.2 \\
\hline Full Hydrostatic Pressure, (psi) Top Sensor & 4.0 & 3.9 \\
\hline Percent Hydrostatic Top Sensor & $\mathbf{9 5}$ & $\mathbf{8 2 . 1}$ \\
\hline Max Recorded Pressure, (psi) Bottom Sensor & 7.1 & 4.3 \\
\hline Full Hydrostatic Pressure, (psi) Bottom Sensor & 9.0 & 8.7 \\
\hline Percent Hydrostatic Bottom Sensor & $\mathbf{7 9 . 9}$ & $\mathbf{4 9 . 4}$ \\
\hline
\end{tabular}

The formwork used for heavy and highway construction is normally designed for using ACI 347 equations or equivalent. However, the strength of formwork on average is commercially manufactured to resist $1000 \mathrm{lb} / \mathrm{ft}^{2}$ for normal applications and $1500 \mathrm{lb} / \mathrm{ft}^{2}$ for heavy duty applications, but can vary from these values. When building timber forms, out of 
dimensional lumber by a contractor, they must resist $600 \mathrm{lb} / \mathrm{ft}^{2}$ the minimum pressure restricted by ACI. Using $1000 \mathrm{lb} / \mathrm{ft}^{2}$ formwork, corresponding to $6.94 \mathrm{psi}$, considering full hydrostatic pressure for a normal weight concrete $\left(145 \mathrm{lb} / \mathrm{ft}^{3}\right)$, and neglecting the effects of temperature on the lateral pressure the tallest formed element that can be cast would be 7 feet. However, the lateral pressure of formwork depends on many aspects other than only the unit weight of the liquid material and the height of the element. The pressure rise of the concrete within the formwork will not reach hydrostatic pressure when cast in a tall element, but was clearly evident within a short element.

ACI 347R currently has three equations that govern formwork design for columns. The definition of a column being any element that's greatest plan dimension does not exceed $6.5 \mathrm{ft}$ (Hurd, 2007). The minimum equation provides the minimum pressure that a column form must resist, shown in Equation (4). No formwork can be made to resist less than this pressure. The maximum pressure allowed in formwork is governed by the maximum of two equations. The first is the equation for full hydrostatic pressure, given in Equation (3) and the second is shown in Equation (5), which is dependent on a few parameters. However, only Equation (3) is valid when using SCC. The data collected from the columns tested during this study were placed into these equations and it was found that for the short column, Equation (4) would govern for formwork design, with the minimum pressure the form needing to resist being $4.2 \mathrm{psi}$ (600 psf). As for the tall columns, cast with either TVC or SCC, they would be governed by the full hydrostatic pressure for formwork design. Equation (5) is dependent on casting rate and temperature only, (not height) meaning that the casting rate for future experiments would need to be much slower for this equation to become governing. 


$$
P_{\min }=600 * C_{w}
$$

$\mathrm{P}_{\min }=$ minimum allowable formwork pressure for design $\left(\mathrm{lb} / \mathrm{ft}^{2}\right)$

$\mathrm{C}_{\mathrm{w}}=$ unit weigh coefficient $=1.0$ with unit weigh $\left(140 \mathrm{lb} / \mathrm{ft}^{3}-150 \mathrm{lb} / \mathrm{ft}^{3}\right)$

$$
P_{\max }=C_{w} * C_{c}[150+9000(R / T)]
$$

$\mathrm{P}_{\max }=$ maximum allowable formwork resistance for design if less than full hydrostatic $\left(\mathrm{lb} / \mathrm{ft}^{2}\right)$

$\mathrm{C}_{\mathrm{w}}=$ unit weigh coefficient $=1.0$ with unit weigh $\left(140 \mathrm{lb} / \mathrm{ft}^{3}-150 \mathrm{lb} / \mathrm{ft}^{3}\right)$

$\mathrm{C}_{\mathrm{c}}=$ chemistry coefficient (given in Table 7.15)

$\mathrm{R}=$ rate of placement $(\mathrm{ft} / \mathrm{hr})$

$\mathrm{T}=$ temperature of the placed concrete $\left({ }^{\circ} \mathrm{F}\right)$

Table 7.17: Chemistry Coefficients for Equation 5 (Hurd, 2007).

\begin{tabular}{|l|c|}
\hline \multicolumn{1}{|c|}{ Cement type or blend } & $C_{c}$ \\
\hline Types I, II, and III cements without retarders* & 1.0 \\
\hline Types I, II, and III cements with a retarder & 1.2 \\
\hline $\begin{array}{l}\text { Other types or blends containing less than 70\% } \\
\text { slag or 40\% fly ash without retarders* }\end{array}$ & 1.2 \\
\hline $\begin{array}{l}\text { Other types or blends containing less than 70\% } \\
\text { slag or 40\% fly ash with a retarder* }\end{array}$ & 1.4 \\
\hline $\begin{array}{l}\text { Blends containing more than 70\% slag or 40\% } \\
\text { fly ash }\end{array}$ & 1.4 \\
\hline
\end{tabular}

* Retarders include any admixture, such as a retarder, retarding water-reducer, retarding mid-range water-reducing admixture, or high-range water-reducing admixture, that delays setting of concrete 
The equations for the hydrostatic, ACI, and DIN were calculated and compared to the recorded pressures during the tall column experimentation. All three of the equation sources, when using the parameters from the column casting experiments, come out to be limited by hydrostatic pressure. This means that if formwork is being constructed to be under the same conditions as the tall column experiments, it would have to be built to withstand full hydrostatic pressure. However, from the tall column experiments the recorded pressures from the sensors were lower than hydrostatic. The pressure vs. height curves for the tall SCC and tall TVC columns are shown in Figures 7.21 and 7.22, respectively.

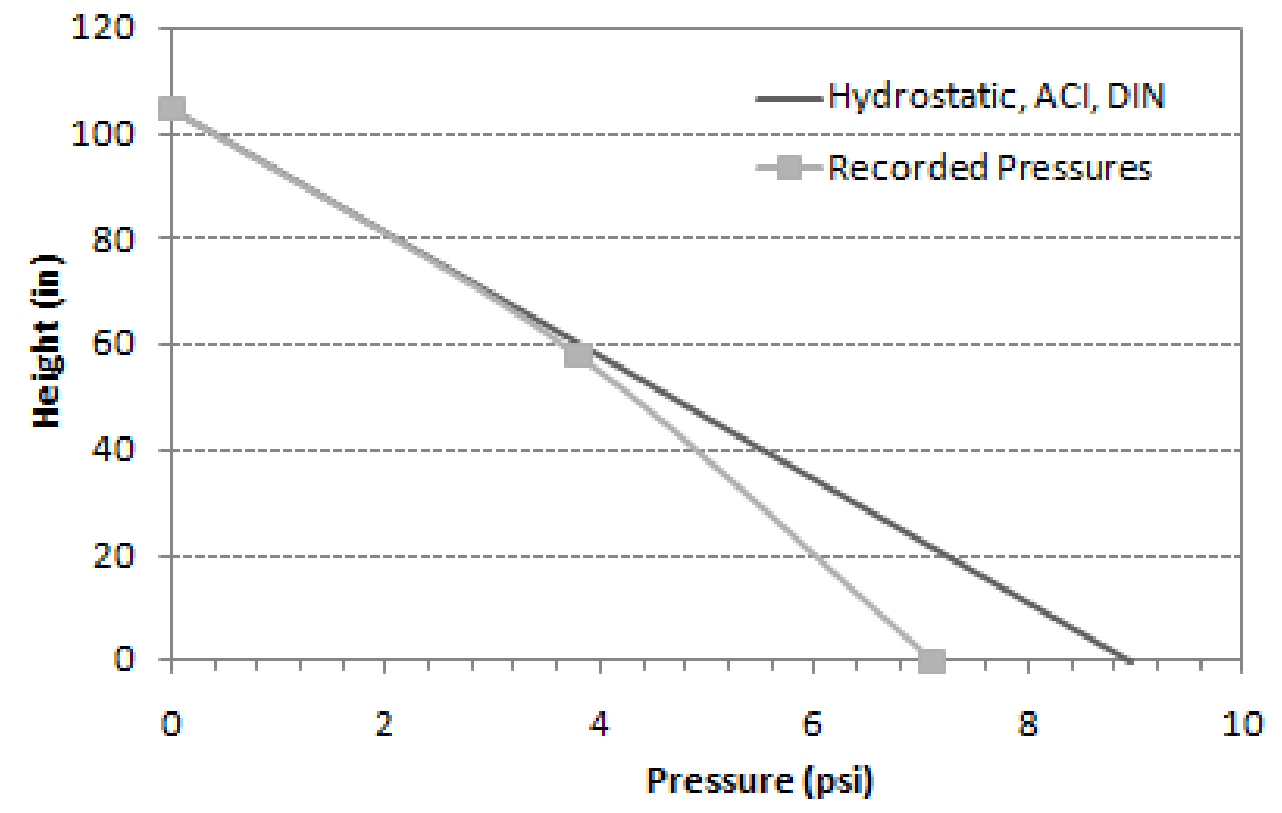

Figure 7.21: Comparison of Tall SCC Column Recorded Pressures and Modeling Equations. 


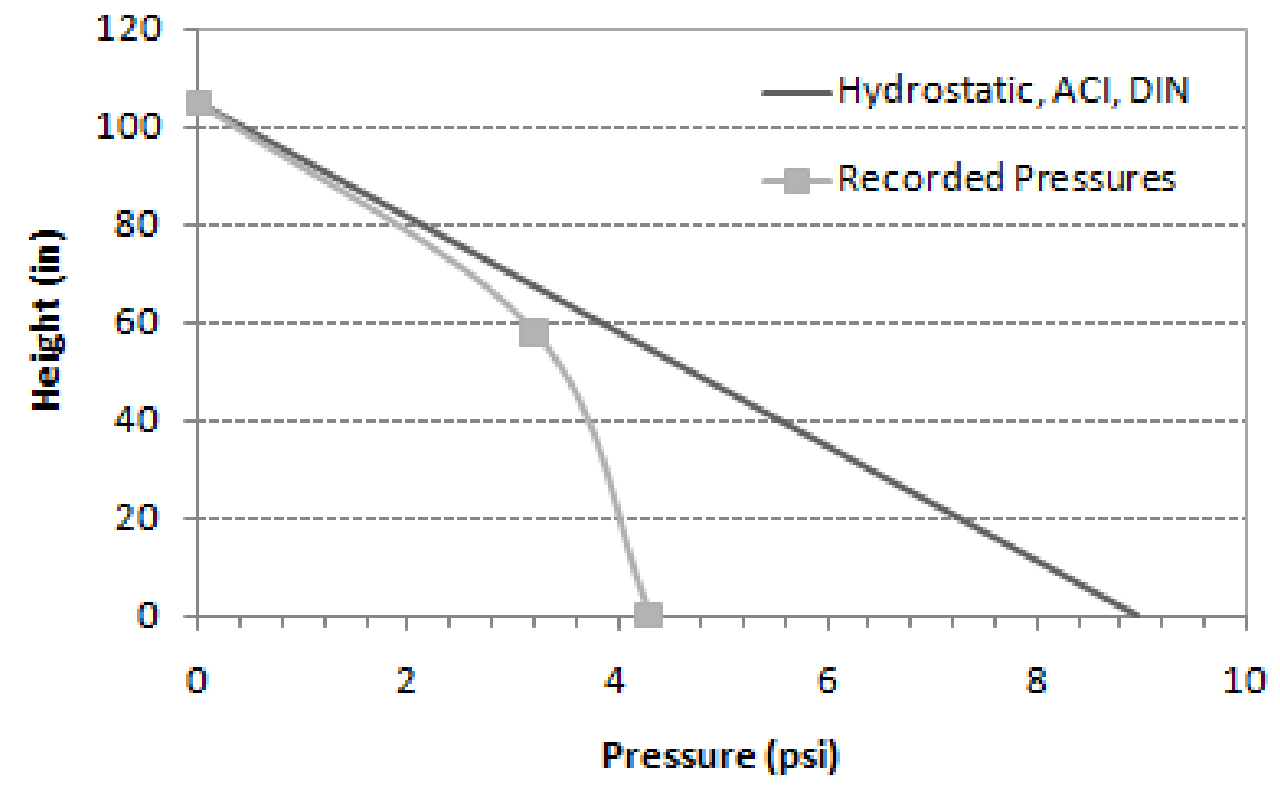

Figure 7.22: Comparison of Tall SCC Column Recorded Pressures and Modeling Equations.

When casting elements in the field using SCC, it is most critical to keep the casting rate low. This allows the concrete in the bottom of the formwork to generate shear resistance due to viscosity in SCC and not continue to exert pressure on the lateral surfaces of the formwork. To date, there are no guidelines, in the United States, for the formwork design when using SCC; hence full hydrostatic pressure must be used (ACI 347R, 2004). Continual research in this topic is needed in order to reach a future guideline or specification. 


\section{CHAPTER 8 - CONCLUSIONS AND RECCOMENDATIONS}

This study looked at many of the construction related topics of self-consolidating concrete (SCC). These topics are important to successfully develop a specification for the WVDOT. The making of a successful SCC does not only pertain to the materials contained within the mix, but how the mix is batched and handled all the way into the formwork. Outside factors such as stockpile moisture content, the sequence in which materials are charged into the mix, the ambient temperature, and the formwork itself are all important factors for a successful production and placement of SCC.

The robustness and loss of passing ability can be detrimentally affected if the amounts of water and HRWR within the mix are deviated from the theoretical mix design. A robust SCC mix should be able to tolerate the deviation of water within the mix by about five percent. After this threshold, the mix can quickly show signs of instability in the forms of segregation and excessive bleed water. Adding too much polycarboxylate based high range water reducer (HRWR) can induce large air bubbles within the mix.

Vibrating an SCC mix for compaction is often not necessary due to the SCC's ability to flow and fill the formwork without additional energy. However, construction delays may make vibration inevitable to alleviate cold joints. This study proved that the vibration of a robust SCC mix is possible. The vibration of an SCC mix that may contain small instabilities or slight static segregation may exhibit large amounts of segregation after vibration. The permission to vibrate an SCC mix must come from an experienced inspector. The vibration should then be carried out in a short duration method or through the use of a small pencil vibrator. If a producer would like to vibrate their SCC mix, then they must demonstrate that the mix will not segregate under the 
vibration. Alternative methods to vibrating to alleviate cold joints can include rodding the concrete or tapping of the formwork if the element is small enough.

During this study, it was observed that there were many details that could cause an SCC mix to be tainted by outside factors. The aggregates stored in drums can show non-uniform moisture content. The admixtures need to be agitated and dispensed with extreme accuracy. The wetness of the target board in which the fresh properties were conducted can influence the results. Most importantly, the temperature of the laboratory and the handling procedure of transporting the fresh SCC sample to its respective test area could induce segregation.

The maximum size of the batch compared to the size of the mixer is important to consider because of SCC's ability to slosh around. The batch sequence and also the time in which to dose the HRWR and viscosity modifying admixture (VMA) also become important because of their short life span. The use of hydration control admixtures can play an important role by extending the slump flow retention time.

Several trips were made to ready-mix and precast companies producing SCC. One of the precast companies visited uses SCC almost exclusively. A few local ready-mix companies were also visited during this study. One ready-mix producer has successfully batched SCC for a job for a private contractor as well as for a contractor working for a WVDOT project. Which was the first time SCC was utilized on a WVDOT project.

ACI 347R oversees the specifications for formwork and states that SCC does not fit the models for current formwork equations, so full hydrostatic pressure must be assumed. In laboratory tests, it was determined that full hydrostatic pressure can be observed in short cast concrete columns. These columns had a head height above the sensor of 47 inches. When the 
height, above the sensor, was increased to 105 inches neither the TVC nor the SCC mix reached hydrostatic pressure. It was determined that the traditional concrete was about 50\% hydrostatic, about 30\% less than the SCC. The formwork calculations for traditional concrete can be altered in a way to include SCC mixes.

This study looked at six different areas of the implementation of SCC in the field. Investigations in the areas of robustness, loss of passing ability, vibration resistance, air migration, small-scale production, repeatability of batching, and formwork pressure. With the combined efforts of the RP221 and RP221B projects, a specification will be written to implement SCC into WVDOT projects. The specification will include material limitations, test methods, batch requirements, and address some construction issues such as vibration, formwork pressure, and handling.

For future studies, it is suggested that more experimentation should be conducted in order to make SCC an easier, faster, and cost effective solution for producers and contractors. The mix design and material constituents have to be studied extensively. There are many manufactures and types of admixtures that maybe compatible with making SCC. Concrete producers if given an SCC mix design can follow it, but they will need to be told in what tolerance the materials need to be in and what quality control testing devices need to be used. If the mixing and quality control of a new mix is not easy, fast, and cost effective then a producer would most likely shy away from making it. The formwork for SCC needs to have specific equations with variables that consider several different types of SCC mixes together. SCC can also be placed into formwork by alternative methods, such as pumping the concrete into the bottom of the formwork through a special valve. However, this technique is in need of study. 


\section{REFERENCES}

American Concrete Institute. Guide to Formwork for Concrete. , ACI 347R-04. 32 pages January 2004.

ASTM Standard C138, 2009, "Standard Test Method for Density (Unit Weight), Yield, and Air Content (Gravimetric) of Concrete," ASTM International, West Conshohocken, PA, www.astm.org.

ASTM Standard C231, 2009, "Standard Test Method for Air-Content of Freshly Mixed Concrete by Pressure Method," ASTM International, West Conshohocken, PA, www.astm.org.

ASTM Standard C1610, 2009, "Standard Test Method for Static Segregation of SelfConsolidating Concrete Using Column Technique," ASTM International, West Conshohocken, PA, www.astm.org.

ASTM Standard C1611, 2009, "Standard Test Method for Slump Flow of Self-Consolidating Concrete," ASTM International, West Conshohocken, PA, www.astm.org.

ASTM Standard C1621, 2009, "Standard Test Method for Passing Ability of SelfConsolidating Concrete by J-Ring," ASTM International, West Conshohocken, PA, www.astm.org.

ASTM Standard C1712, 2009, "Standard Test Method for Rapid Assessment of Static Segregation Resistance of Self-Consolidating Concrete Using Penetration Test," ASTM International, West Conshohocken, PA, www.astm.org.

BIBM, CEMBUREA, ERMCO, EFCA, AND EFNARC. The European Guidelines for SelfCompacting Concrete. European Project Group. 2005.

Bui, V. K., Montgomery, D., Hinczak, I., \& Turner, K. "Rapid Testing Method for Segregation Resistance of Self-Compacting Concrete". Cement and Concrete Research, 32, pp.1489-1496, 2002.

Chen, Roger HL, Baranowski, Kyle B., Sweet, Joseph G. "Exploration of Placement Techniques on The Properties of Self-Consolidating Concrete." (Paper presented at fib 2010, Washington, DC May 29 - June 2, 2010).

Chen, Roger HL, Sweet, Joseph G., and Baranowski, Kyle B., "Testing of Self-Consolidating Concrete for Drilled Shafts in a Rural Bridge Replacement in West Virginia." (Paper presented at fib 2010, Washington, DC May 29 - June 2, 2010).

Concrete International. "DIN Standard on Formwork Pressures Updated”. Pp.27-29. June 2010. 
Horta, A. Evaluation of Self-Consolidating Concrete for Bridge Structure Applications. Georgia Institute of Technology. Master’s Thesis. 2005.

Hurd, M. K. "Lateral Pressures for Formwork Design”. Concrete International. pp. 31-33. June 2007.

Khayat, K. H., and Mitchell, D. Self-Consolidating Concrete for Precast, Prestressed Concrete Bridge Elements. Report 628. Washington, DC: National Cooperative Highway Research Program. 2009.

Khayat, K. H., Bonen, D., Shah, S., and Taylor, P. "SCC Formwork Pressure”. The National Ready-Mix Concrete Research Foundation and The Strategic Development Council, American Concrete Institute. 2007.

Koehler, Eric P. and Fowler, David W. "Aggregates in Self-Consolidating Concrete”. ICAR Project 108. March 2007.

Mid-Atlantic States Prestressed Committee for Economic Fabrication QA/QC Sub-Committee. Specification Guidelines for Precast/Prestressed Concrete Bridge Products. 2003.

Mindess, Sidney, Young, J. Francis, and Darwin, David. Concrete $2^{\text {nd }}$ Edition. Pearson Education, Inc., New Jersey, 2003.

National Ready Mix Concrete Association, "Cip 37 - Self-Consolidating Concrete (SCC)". www.nrmca.org, 2004.

Safawi, M. I., Iwaki, I. and Miura, T. "The Segregation Tendency in the Vibration of High Fluidity Concrete”. Cement and Concrete Research, pp. 219-226. 2003.

Slag Cement Association, "Slag Cement and Fly Ash”. Slag Cement in Concrete, No. 11. 2002.

Szwabowski, Janusz and Lanzniewska-Piekarcyz, "Air Entrainment Problem in SelfCompacting Concrete”. Journal of Civil Engineering and Management. Poland, 2009.

Sweet, Joseph and Chen, Roger HL. Feasibility and Implementation of Self-Consolidating Concrete. RP \#221, Sponsored by West Virginia Department of Transportation, West Virginia University, 2008.

The Center for Advance Cement Based Materials. Self-Consolidating Concrete. White Paper, Chicago. 2007.

ZTE. Self-Compacting Concrete Construction Supervision of Technical Guidelines (written in Chinese). Technology Books. 2006. 


\section{APPENDIX 1 - DISSUSIONS}

The discussion section is meant to answer questions raised during this study. Six questions were raised that are directly related to the WVDOT's interests in adopting SCC into their current specifications. The questions and their respective answers are given.

\section{Which tests (slump flow, j-ring, column segregation, etc.) to perform at what frequencies (in mix design development and in the field) and what ranges of results are acceptable?}

There are several tests currently adopted by United States standards such as AASHTO and ASTM that directly relate to the assessment of SCC. However, there are many more tests that are used in other parts of the world and have not been adopted as standardized tests in the United States. When establishing an SCC mix design in the laboratory or implementing it in the field it is also important to note that there are multiple ways to produce a satisfactory mix. SCC mixes are often classified into slump flow categories depending on the element and reinforcement configuration. There is no one SCC mix that can be used in all applications.

The slump flow test is more than only looking at the diameter of the fresh patty. The time in which the concrete flows 20 inches or 50 centimeters is known as the T50 time. The quality assessment of the fresh patty after the diameter measurement is also important, known as the Visual Stability Index (VSI). The J-ring test also goes hand-in-hand with these tests and the only difference is the bar apparatus being present. These tests are essential and should be used in mix design development as well as in the field. During mix design development, the slump flow, T50, and VSI and the J-ring should be kept in tight tolerance. These tests should also be performed on a mix several times during a predetermined amount of time after batching, such as 90 minutes to ensure that the acceptable properties are not quickly lost after a short waiting time. This measurement is known as slump retention and loss of passing ability. In the field these tests 
can be performed rapidly, so every batch of concrete can feasibly be tested. To shorten the duration of testing in the field, use two target boards can alleviate the need to rinse the boards between the testing for slump flow and J-ring.

The column segregation test is extremely necessary during the mix development phase because it adequately measures the static segregation resistance of the mix. However, this test is cumbersome and takes time to perform, so the application of this test in the field is not practical. Recently, a test method has been standardized by ASTM. ASTM C 1712, the rapid assessment of the segregation resistance of a normal-weight self-consolidating concrete, uses an apparatus to quick find the acceptance of an SCC. This test is quick and can be performed in the field before the slump flow or J-ring test. There are also tests performed in other parts of the world that are not observed as standardized test in the United States. A few tests for example are the V-funnel, which measured the viscosity quickly and can be used in the field, and the L-box, which characterizes the mixes flowability and passing ability quickly by performing one test.

The testing of SCC for air content, unit weight, yield, and compressive strength are identical to that of traditional vibrated concrete. The filling of the testing apparatuses and cylinder specimens are done without rodding or by layers.

\section{Materials limitations - what types, what amounts, and what combinations should be permitted?}

SCC is made with the same main ingredients that TVC is composed of, cement, sand, stone, and water. However the proportions of these materials differ. For flowability, an SCC mixture needs to contain more fines. This was accomplished by adding more cementitious materials to the mix, increasing the fine aggregate to total aggregate content and decreasing the size of 
traditionally used coarse aggregate. The amount of cement needed can be replaced by a supplementary cementitious material such as slag, fly ash or micro silica, but can also be accompanied by an inert fine material such as limestone powder. By increasing the fines with a supplementary cementitious material the permeability can be decreased and the shrinkage can be reduced. The maximum size of coarse aggregate should be limited to $3 / 4$ inch or $\# 67$. Often the \#67 coarse aggregate is blended with a smaller coarse aggregate such as \#8 or \#9 to make a finer gradation in the mix. The w/cm of the mix should be kept low for SCC and in no circumstance should adding water to the mix, beyond specified, be permitted to achieve flowability. After the calculated water is introduced into the batch, only the chemical admixtures should be adjusted to meet acceptability. Since there are many different chemical admixtures on the market for use in making SCC, the quantities of a certain admixture and their maximum quantities need to be provided by the supplier. Certain admixtures do not work with others, so the checking for chemical compatibility is a must. Also, polycarboxylate based HRWR can induce air into the mix. However, the induced air can be unstable and non-uniform, so the mix must contain an air entraining admixture to alleviate associated problems. The specifications for the application for SCC will need to contain limitations in lieu of the current concrete specifications for material constituents.

\section{Time constraints on SCC mixes and any special batching or mixing requirements?}

The batch sequence, order in which materials are charged into the mixer, often play a vital role in the successful production of SCC. The chemical admixtures HRWR and VMA are often charged last due to their time dependent loss of effect. Many admixture suppliers note batch sequences and requirements. Hydration control admixtures, set retarders, can be used in order to achieve extra time for batching. The batch produced within a particular mixer should not be too 
small because of the amount of fine particles that can be adhered to mixer surfaces. Since SCC is more fluid than TVC, a batch should not be produced that would be large enough to slosh out of the mixer during mixing or transport.

The time constraints that exist for TVC can be easily adopted for SCC as well. However, it is much more sensitive to loss of workability. SCC should be tested for both slump flow retention and loss of passing ability to determine how long the mix is able to be placed. The temperature effects on the fluidity will also have to be monitored, and this should be caught during mix qualification or quality control testing.

\section{Variability and repeatability in SCC mixes (variability would play a large part in the required testing frequencies) due to the sensitivity of SCC and due to the use of different materials}

During the production of SCC, the source of materials and the types and sources of the chemical admixtures will have to be kept constant. Any changes in materials or chemical admixtures will mean that the mix will have to be requalified. The variability in the mix will mostly come from the moisture content of the aggregates, which must be kept in tight tolerance. As for the ambient temperature, the variations could be combated with a slight change in the admixture dosages. Until a producer can batch SCC to a high degree of confidence, the test frequencies will have to be high, testing every truck or batch.

The batching of SCC in the laboratory as well as most of the observations in the field suggest that an SCC batch can be repeated with only minimal variations in measured properties. However, because a slight variation in materials, water content on aggregates, can vary the properties of the fresh concrete immensely, and tests of fresh properties will have to be performed to check for any variations. These can be accomplished quickly in a field setting. 


\section{Concerns with air content and the air void spacing system (we often see a layer of foam form at the top of an SCC placement).}

The foam layer that forms on the top of an SCC placement can be indicative to segregation that is occurring within the mix. The large aggregates are settling to the bottom of the mix as the air bubbles are raising to the surface. These bubbles are often small and resemble those produced by air entrainment. To worsen the matter, excessive bleed water will accompany the air migration to form weakened surface layers. This layer will be scaly and easily scratched. High pressure water jetting, grinding, or sand blasting will have to be used to remove this layer before subsequent pours. This phenomenon can also occur at the formwork interface to produce little voids resembling bug holes. The only way to produce a smooth surface finish and eliminating foam layer is to ensure the production of a robust SCC mix.

Polycarboxylate based HRWR can also produce large air bubbles within the mix. This was most likely the case of the large air bubbles formed during the RP221 project. These bubbles will most likely be created and dissipated during the batching process, but in the case of a very fluid mix with a large dosage of HRWR they can be seen escaping during the filling

process. If these large bubbles become trapped they will act as entrapped air voids. So, the addition of an air entrainment admixture breaks these bubbles up during mixing. It is always important to have proper levels of air entrainment and only enough HRWR to provide for the correct levels of workability.

\section{Any field placement limitations?}

As of now, there are no equations for the design of formwork using SCC in the United States. The assumption of full hydrostatic pressure has to be assumed. If there is a way to safely monitor the pressure of the casting of SCC within formwork then it is okay to go above this 
criterion. Some countries, such a Germany, currently have a specification for the use of SCC in formwork. The equation is based on filling rate, setting time, and unit weight of the fresh concrete. ACI and RILEM speculate that they will also have specifications for SCC in formwork, but not until 2012 (Concrete International, 2010). SCC has shown ability to be pumped and because of its additional fluidity can be easier on the pump mechanism. SCC was originally designed for underwater placement and it does a substantial job when it is placed by tremie. SCC is great in location where vibrators are not easily accessible or in area of thin sections and highly congested reinforcement.

Future research will identify alternative placement techniques. An alternative placement technique by pumping SCC into the bottom of the formwork shows great promise. This techniques has already been implemented in the field, but has not gained popularity. Experimental investigation is needed to determine the applicable casting rates as well as properties of the mix required.

7. Ready-mix concrete often has to be hauled great distances to jobsites within the state. Is there a way to put SCC “to sleep” stopping hydration?

SCC without the additions of the HRWR and VMA admixtures has the characteristics of a low-slump traditional concrete mix, displaying a slump of less than a few inches. This is the way that most ready-mix producers choose to ship the concrete to the site where qualified personnel will dispense the correct amount of HRWR and VMA to the mixture. The truck is usually batched with only about $80 \%$ of its capacity because of the fluid nature of SCC. The drum of the truck is rotated at mixing speed until the mix becomes homogeneous. Waiting until the site also alleviates issues with the HRWR and VMA losing their effect. If added at the plant it takes time away from the casting crew. 
A mix that is being transported a long distance can be put to sleep in the same fashion that companies do with traditional mixes. The only difference being that the HRWR and VMA will have to be added on site. The addition of admixtures into a concrete mix always needs to be checked for chemical compatibility. In the design of any concrete mix design, a trial batching of the mix needs to be accomplished to determine if any influences of fresh or hardened properties would occur.

8. It seems that the RP221 and RP221B projects used crushed limestone exclusively as the coarse aggregate. Some producers may be able to get other types of aggregate (river gravel) more easily and cost effective, is there any difference in use different types of aggregates?

The RP221B project looked mainly at construction issues, placement techniques, and robustness and loss of passing ability of SCC. Although, there are differences in using different types of aggregates such as strength, freeze-thaw resistance, thermal expansion coefficients, etc. This study only looked primary at the size and absorption of coarse aggregates and how they affected the mechanical properties. Since, producers have the option to choose river gravels as coarse aggregates it was investigated.

Samples of \#57 and \#8 river gravel were obtained from a local source in Morgantown, WV. The sizes of crushed limestone used for this study were \#67 and \#8, but \#67 in river gravel was not locally obtainable. In the making of SCC, it is common to limit the maximum size of aggregate to 3/4”. The main difference observed besides the size and shape was the absorption. The absorption of the river gravels was much higher than that of crushed limestone. The absorption of the river gravel with the \#57 was at $2.3 \%$ and the $\# 8$ at $2.1 \%$. The crushed limestone used during this study was \#67 at $0.7 \%$ and the \#8 at $0.6 \%$. The difference in the absorption values plays an important role in the adjustment of the mix design before mixing. 
A mix was made in the laboratory using river gravels and was identical to that of Mix 4 of this study. The mix design for the river gravel mix is shown in Table A.01. The moisture contents of the fine aggregates were measured and the mix was adjusted to include the absorption values of the river gravels. When the mix was made it displayed a 22 inch slump flow, a j-ring value of 3.5 inches, and an air content of 5.8\%. The fresh properties of the river gravel mix are summarized in Table A.02. The absorption of the river gravels if not adjusted for can be a few percent higher in difference than that of crushed limestone. If the aggregates are not at or above the SSD condition, then water would have to be added to the mix. It is not sure if the aggregates will absorb all of the water to be at SSD condition. It has been observed that some concrete producers will spray water on their stockpiles to keep them above SSD condition.

The mechanical properties of an SCC mix made with crushed limestone compared to that of the same mix design made with river gravel are very similar. Literature reports that the HRWR demand, viscosity, and J-ring blocking are not substantially changed between the two types of aggregates. The J-ring shows the biggest difference with the river gravel actually performing better. This was not the case during this study, most likely because \#57 river gravel was used. The literature also states no large compressive strength change between using crushed limestone and river gravel (Koehler and Fowler, 2007). 
Table A.01: Mix Design of the Batch Tested with River Gravel.

\begin{tabular}{|l|c|r|}
\hline \multicolumn{1}{|c|}{ MATERIAL } & UNIT & RIVER GRAVEL \\
\hline Cement Type 1 & $\mathrm{lb}$ & 600 \\
\hline Slag & $\mathrm{lb}$ & 150 \\
\hline \#8 River Gravel & $\mathrm{lb}$ & 553 \\
\hline \#57 River Gravel & $\mathrm{lb}$ & 830 \\
\hline Natural Sand & $\mathrm{lb}$ & 1384 \\
\hline Water & $\mathrm{lb}$ & 300 \\
\hline w/cm & & 0.4 \\
\hline Air Entrainer & Oz/cwt & 0.15 \\
\hline VMA & Oz/cwt & 2.5 \\
\hline HRWR & Oz/cwt & 6 \\
\hline Retarder & Oz/cwt & 2.5 \\
\hline
\end{tabular}

Table A.02: Fresh Properties of the Batch with River Gravel Compared to Mix 4.

\begin{tabular}{|l|c|c|}
\hline \multicolumn{1}{|c|}{ PROPERTY } & MIX 4 & $\begin{array}{c}\text { RIVER } \\
\text { GRAVEL }\end{array}$ \\
\hline Slump Flow (in) & 23.5 & 22 \\
\hline T50 (sec) & 1.4 & 2.08 \\
\hline J-ring Difference(in) & 0 & 3.5 \\
\hline T50 (sec) & 1.9 & - \\
\hline Air Content (\%) & 2.5 & 5.8 \\
\hline Unit Weight (lb/ft ${ }^{3}$ ) & 146.0 & 137.9 \\
\hline Ambient Air Temperature ( $\left.\mathbf{~}^{\mathbf{0}} \mathbf{F}\right)$ & 79 & 70 \\
\hline Mix Water Temperature $\mathbf{(}^{\mathbf{0}} \mathbf{~ F )}$ & 79 & 71 \\
\hline
\end{tabular}




\section{VITA}

The author, Kyle Blaine Baranowski, was born in Fredrick, Maryland on March 17, 1986. He spent his childhood in Hardy County, West Virginia and enjoyed living on a farm. Attending East Hardy Schools, he received his high school diploma in June 2004. During this time, he was active in the Boy Scouts of America (Troop 81), local 4-H club (Rock Oak Live Wires), and played baseball for 13 years.

In fall 2004, the author enrolled in West Virginia University where he studied Civil Engineering. Obtaining a Bachelors of Science in May 2008, he went on to pursue a Master of Science in Civil Engineering from West Virginia University. As a graduate student, he worked on West Virginia Department of Transportation funded research projects. In addition to this paper, the author has coauthored on one other final research report and a conference paper. The author plans on working for the West Virginia Department of Transportation, where he has a current job offer. 